\title{
IMPROVED STEAMFLOOD ANALYTICAL MODEL
}

\author{
A Thesis \\ by \\ SUANDY CHANDRA
}

\begin{abstract}
Submitted to the Office of Graduate Studies of Texas A\&M University

in partial fulfillment of the requirements for the degree of

MASTER OF SCIENCE
\end{abstract}

August 2005

Major Subject: Petroleum Engineering 
IMPROVED STEAMFLOOD ANALYTICAL MODEL

\author{
A Thesis \\ by \\ SUANDY CHANDRA \\ Submitted to the Office of Graduate Studies of \\ Texas A\&M University \\ in partial fulfillment of the requirements for the degree of \\ MASTER OF SCIENCE
}

\begin{abstract}
Approved by :
Co-Chairs of Committee, Daulat D. Mamora

Robert A. Wattenbarger

Committee Member, Luc T. Ikelle

Head of Department,

Stephen A. Holditch
\end{abstract}

August 2005

Major Subject: Petroleum Engineering 


\author{
ABSTRACT \\ Improved Steamflood Analytical Model. \\ (August 2005) \\ Suandy Chandra, B.S., Institut Teknologi Bandung \\ Co-Chairs of Advisory Committee: Dr. Daulat D. Mamora \\ Dr. Robert A. Wattenbarger
}

The Jeff Jones steamflood model incorporates oil displacement by steam as described by Myhill and Stegemeier, and a three-component capture factor based on empirical correlations. The main drawback of the model however is the unsatisfactory prediction of the oil production peak: usually significantly lower than the actual. Our study focuses on improving this aspect of the Jeff Jones model.

In our study, we simulated the production performance of a 5-spot steamflood pattern unit and compared the results against those based on the Jeff Jones model. Three reservoir types were simulated using 3-D Cartesian black oil models: Hamaca $\left(9^{\circ} \mathrm{API}\right)$, San Ardo (12 $\mathrm{API})$ and that based on the SPE fourth comparative solution project ( $\left.14^{\circ} \mathrm{API}\right)$. In the first two field cases, a $45 \times 23 \times 8$ model was used that represented $1 / 8$ of a 10 -acre 5-spot pattern unit, using typical rock and reservoir fluid properties. In the SPE project case, three models were used: $23 \times 12 \times 12(2.5 \mathrm{ac}), 31 \times 16 \times 12(5 \mathrm{ac})$ and $45 \times 23 \times 8$ (10 ac), that represented $1 / 8$ of a 5 -spot pattern unit.

To obtain a satisfactory match between simulation and Jeff Jones analytical model results of the start and height of the production peak, the following refinements to the Jeff Jones model were necessary. First, the dimensionless steam zone size $A_{c D}$ was modified to account for decrease in oil viscosity during steamflood and its dependence on the 
steam injection rate. Second, the dimensionless volume of displaced oil produced $V_{o D}$ was modified from its square-root format to an exponential form.

The modified model gave very satisfactory results for production performance up to 20 years of simulated steamflood, compared to the original Jeff Jones model. Engineers will find the modified model an improved and useful tool for prediction of steamflood production performance. 


\section{DEDICATION}

This thesis is dedicated to my family in Indonesia, especially to my mother, Sia Soei

Hwa, for her endless love. 


\section{ACKNOWLEDGEMENTS}

I am deeply grateful to my advisor, Dr. Daulat D. Mamora, who has provided encouragement and constructive comments and suggestions since the beginning of this research. I am much honored to be his student.

I would like to convey my sincere thanks to the distinguished professors, Dr Robert A. Wattenbarger for serving as co-chair of my committee and Dr. Luc. T. Ikelle, for serving as valuable committee member.

I would like to acknowledge BP MIGAS and Chevron Texaco Exploration and Production Technology Company for funding my study.

Special thanks go to all the faculty members and staff in the Petroleum Engineering Department at Texas A\&M University for their support and help. 


\section{TABLE OF CONTENTS}

Page

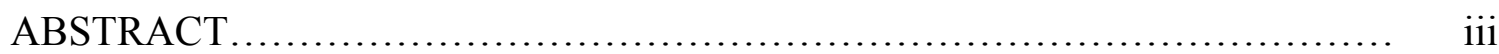

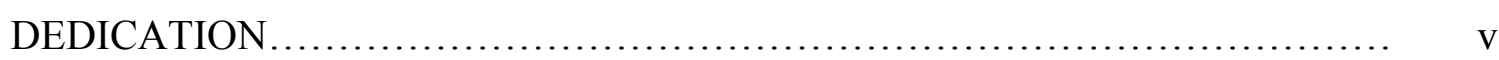

ACKNOWLEDGEMENTS .............................................. vi

TABLE OF CONTENTS ................................................ vii

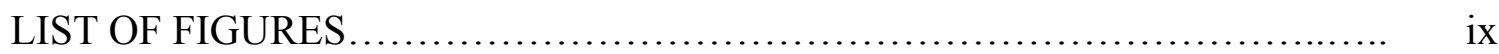

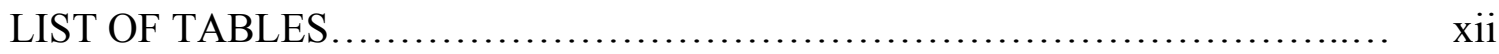

\section{CHAPTER}

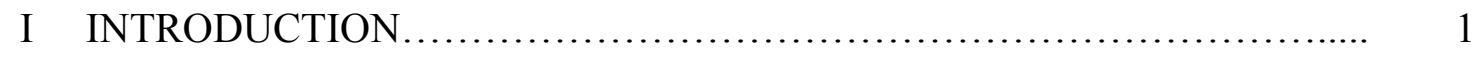

1.1 Objective of the Study.................................. 2

1.2 Methodology.......................................... 3

1.3 Chapter Organization................................. 3

II THEORETICAL BACKGROUND................................... 5

2.1 Steamflooding Mechanism ............................... 5

2.2 Prediction of Steamflood Performance.......................... 8

2.3 Literature Review...................................... 11

2.4 Jeff Jones' Method....................................... 13

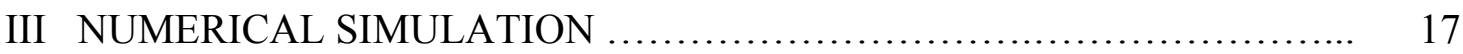

3.1 Symmetrical Element $\ldots \ldots \ldots \ldots \ldots \ldots \ldots \ldots \ldots \ldots \ldots \ldots \ldots \ldots, 18$

3.2 Grid Orientation Effect .................................. 19

3.3 Block Geometry Modifier............................... 22

3.4 SPE Comparative Case Simulation Model................... 24

3.5 San Ardo Simulation Model............................ 30

3.6 Hamaca Simulation Model.................................. 33

IV NEW STEAMFLOOD MODEL..................................... 37

4.1 New Model Calculation Steps............................. 42

4.1.1 Displacement Calculation........................... 43

4.1.2 Production Calculations............................. 45

4.2 Oil Production Rate Performance............................ 45 
4.3 Cumulative Oil Steam Ratio................................. 54

V SUMMARY AND CONCLUSIONS .................................. 61

5.1 Summary.................................................. 61

5.2 Conclusions.............................................. 62

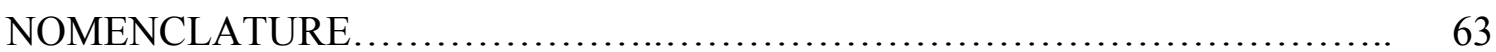

REFERENCES ................................................................. 67

APPENDIX A JEFF JONES OIL DISPLACEMENT CALCULATION............. 70

APPENDIX B SIMULATION INPUT FOR FOURTH SPE COMPARATIVE CASE, AREA $=2.5$ ACRE, STEAM INJECTION RATE $=400$ STB/D.................................................. 72

APPENDIX C SIMULATION INPUT DATA FOR SAN ARDO CASE, AREA $=10$ ACRE, STEAM INJECTION RATE $=1600$ STB/D.......... 81

APPENDIX D SIMULATION INPUT DATA FOR HAMACA CASE, AREA = 10 ACRE, STEAM INJECTION RATE = 1600 STB/D .......... 90

APPENDIX E VBA PROGRAM OF NEW MODEL .......................... 99

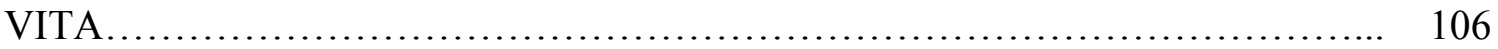




\section{LIST OF FIGURES}

Page

Fig. 2.1 Steamflood typical temperature and saturation profile................ 6

Fig. 2.2 Temperature profile of Marx-Langenheim model..................... 11

Fig. 2.3 Three production stages of Jeff Jones' model........................ 14

Fig. 3.1 1/8 element of inverted 5-spot pattern model: (a) plan view; (b) 3D view.............................................................

Fig. 3.2 Five spot pattern grids: (a) diagonal grid; (b) parallel grid.............. 20

Fig. 3.3 Five and nine-point, finite-difference formulation................... 21

Fig. 3.4 Five-point vs nine-point formulation on oil production rate in 1/8 fivespot....................................................... 22

Fig. 3.5 Active and inactive cells in a 1/8 five-spot pattern model.............. 23

Fig. 3.6 Simulation grid for area of $2.5 \mathrm{ac}$, SPE comparative case model........ 25

Fig. 3.7 Simulation grid for area of 5.0 ac, SPE comparative case model........ 26

Fig. 3.8 Simulation grid for area of $10 \mathrm{ac}$, SPE comparative case model......... 26

Fig. 3.9 Relative permeability curve (water/oil system) for SPE comparative case........................................................ 29

Fig. 3.10 Relative permeability curve (gas/oil system) for SPE comparative case. 29

Fig. 3.11 Water-oil relative permeability curves with temperature dependence, San Ardo Model.................................................. 32

Fig. 3.12 Gas-oil relative permeability curves with temperature dependence, San Ardo model..................................................... 33

Fig. 3.13 Water-oil relative permeability, Hamaca model...................... 36

Fig. 3.14 Gas-oil relative permeability, Hamaca model........................ 36

Fig. 4.1 New model: three different stages of oil production under steam 37 drive. 
Fig. $4.2 \quad \alpha$ vs injection rate relationship................................... 39

Fig. $4.3 \quad \beta$ vs $N_{c}$ relationship......................................... 42

Fig. 4.4 Oil production rate (SPE comparative model, area $=2.5 \mathrm{ac}$, injection

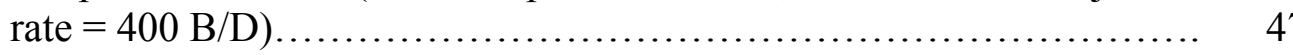

Fig. 4.5 Oil production rate (SPE comparative model, area $=2.5 \mathrm{ac}$, injection rate $=600 \mathrm{~B} / \mathrm{D})$

Fig. 4.6 Oil production rate (SPE comparative model, area $=2.5$ ac, injection rate $=800 \mathrm{~B} / \mathrm{D})$.

Fig. 4.7 Oil production rate (SPE comparative model, area $=5.0$ ac, injection rate $=600 \mathrm{~B} / \mathrm{D})$.

Fig. 4.8 Oil production rate (SPE comparative model, area $=5.0$ ac, injection rate $=800 \mathrm{~B} / \mathrm{D})$.

Fig. 4.9 Oil production rate (SPE comparative model, area $=5.0$ ac, injection rate $=1000 \mathrm{~B} / \mathrm{D})$.

Fig. 4.10 Oil production rate (SPE comparative model, area $=5.0$ ac, injection rate $=1200 \mathrm{~B} / \mathrm{D})$

Fig. 4.11 Oil production rate (SPE comparative model, area $=10 \mathrm{ac}$, injection rate $=1000 \mathrm{~B} / \mathrm{D})$.

Fig. 4.12 Oil production rate (SPE comparative model, area $=10 \mathrm{ac}$, injection rate $=1200 \mathrm{~B} / \mathrm{D})$.

Fig. 4.13 Oil production rate (SPE comparative model, area $=10 \mathrm{ac}$, injection rate $=1400 \mathrm{~B} / \mathrm{D})$

Fig. 4.14 Oil production rate (SPE comparative model, area $=10 \mathrm{ac}$, injection rate $=1600 \mathrm{~B} / \mathrm{D})$.

Fig. 4.15 Oil production rate (San Ardo model, area $=10 \mathrm{ac}$, injection rate $=$ $1600 \mathrm{~B} / \mathrm{D})$.

Fig. 4.16 Oil production rate (Hamaca model, area $=10 \mathrm{ac}$, injection rate $=1600$ $\mathrm{B} / \mathrm{D})$

Fig. 4.17 Cumulative oil steam ratio (SPE comparative model, area $=2.5 \mathrm{ac}$, injection rate $=400 \mathrm{~B} / \mathrm{D}$ ) 
Fig. 4.18 Cumulative oil steam ratio (SPE comparative model, area $=2.5 \mathrm{ac}$,

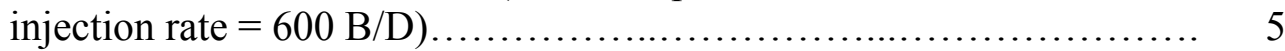

Fig. 4.19 Cumulative oil steam ratio (SPE comparative model, area $=2.5 \mathrm{ac}$, injection rate $=800 \mathrm{~B} / \mathrm{D})$

Fig. 4.20 Cumulative oil steam ratio (SPE comparative model, area $=5.0 \mathrm{ac}$, injection rate $=600 \mathrm{~B} / \mathrm{D})$

Fig. 4.21 Cumulative oil steam ratio (SPE comparative model, area $=5.0 \mathrm{ac}$, injection rate $=800 \mathrm{~B} / \mathrm{D})$

Fig. 4.22 Cumulative oil steam ratio (SPE comparative model, area $=5.0 \mathrm{ac}$, injection rate $=1000 \mathrm{~B} / \mathrm{D})$.

Fig. 4.23 Cumulative oil steam ratio (SPE comparative model, area $=5.0 \mathrm{ac}$, injection rate $=1200 \mathrm{~B} / \mathrm{D})$.

Fig. 4.24 Cumulative oil steam ratio (SPE comparative model, area $=10 \mathrm{ac}$, injection rate $=1000 \mathrm{~B} / \mathrm{D})$

Fig. 4.25 Cumulative oil steam ratio (SPE comparative model, area $=10 \mathrm{ac}$, injection rate $=1200 \mathrm{~B} / \mathrm{D})$

Fig. 4.26 Cumulative oil steam ratio (SPE comparative model, area $=10 \mathrm{ac}$, injection rate $=1400 \mathrm{~B} / \mathrm{D})$.

Fig. 4.27 Cumulative oil steam ratio (SPE comparative model, area $=10 \mathrm{ac}$, injection rate $=1600 \mathrm{~B} / \mathrm{D})$.

Fig. 4.28 Cumulative oil steam ratio (San Ardo model, area $=10$ ac, injection rate $=1600 \mathrm{~B} / \mathrm{D})$

Fig. 4.29 Cumulative oil steam ratio (Hamaca model, area $=10$ ac, injection rate $=1600 \mathrm{~B} / \mathrm{D})$. 


\section{LIST OF TABLES}

Page

Table 2.1 Typical Data Required by Thermal Reservoir Simulators.......... 9

Table 3.1 Modification Parameters for Edges and Corner-Grids.............. 24

Table 3.2 Initial Reservoir Properties................................. 25

Table 3.3 Cell Dimensions for SPE Comparative Case Model............... 27

Table 3.4 Temperature-Viscosity Relationship for SPE Comparative Case.... 27

Table 3.5 Initial Reservoir Properties for San Ardo Model.................. 30

Table 3.6 Oil Component Properties for San Ardo Model.................... 31

Table 3.7 Temperature-Viscosity Relationship for San Ardo Oil................ 32

Table 3.8 Initial Reservoir Properties for Hamaca Model.................... 34

Table 3.9 Temperature-Viscosity Relationship for Hamaca Oil.............. 35

Table 4.1 Formula for Capture Factor Components: New Model and Jones Model............................................................ 


\section{CHAPTER I}

\section{INTRODUCTION}

Steamflooding is a major EOR process applied to heavy oil reservoirs. Steamflooding uses separate injection and production wells to improve both the rate of production and the amount of oil that will ultimately be produced. Injected steam heats the formation around the wellbore and eventually forms a steam zone that grows with continuous steam injection. Steam reduces the oil viscosity and saturation in the steam zone to a low value, pushing the mobile oil (i.e. difference between the initial and residual oil saturations) out of the steam zone. As the steam zone grows, more oil is moved from the steam zone to the unheated zone ahead of the steam front. Then the oil accumulates to form an oil bank. The condensed hot water also moves across the steam front, heating and displacing the accumulated oil. The heated oil with reduced viscosity moves towards the producing well and is produced usually by artificial lifting.

A steam flood project typically proceeds through four phases of development: (1) reservoir screening; (2) pilot tests; (3) fieldwide implementation; and (4) reservoir management. Performance prediction is essential to provide information for proper execution of each of these development phases. Three different mathematical models (statistical, numerical, and analytical models) are commonly used to predict steam flood performance.

This thesis follows the style of Society of Petroleum Engineers Journal. 
Statistical models are commonly based on the historical data of steamflood performance from other reservoirs which have similar oil and rock properties. This is the reason why statistical models do not give a unique result for one particular reservoir. Numerical models usually require extensive information about the reservoir and lengthy calculations using computers. They may be extremely comprehensive and better serve as tools for research or advanced reservoir analysis. Meanwhile, analytical models may be much more economical at the expense of the accuracy and flexibility and serve as tools for engineering screening of possible reservoir candidates for field testing.

For many years, attempts ${ }^{1-7}$ have been made to provide analytical models for steamflood production performance prediction. One of the most widely-used analytical

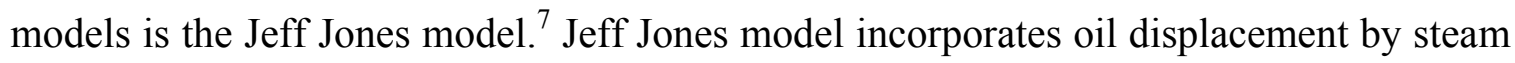
as described by Myhill and Stagemeier, ${ }^{5}$ and a three-component capture factor based on empirical correlations. The main drawback of the model however is the unsatisfactory prediction of the oil production peak: usually significantly lower than the actual. Our study focused on improving this aspect of the Jeff Jones model.

\subsection{Objective of the Study}

The main drawback of the Jeff Jones model is the unsatisfactory prediction of the oil production peak: usually significantly lower than the actual. The main objective of this study is therefore to improve this aspect of the Jeff Jones model. The results of the modified model will be tested against results based on numerical simulation to verify its accuracy and validity. A more accurate steamflood model will provide engineers with an improved and useful tool for prediction of steamflood production performance. 


\subsection{Methodology}

A series of simulation runs were conducted to simulate the production performance of a 5-spot steamflood pattern unit. The simulation results were then compared against that based on the Jeff Jones model. CMG STARS Thermal Simulator was used for this purpose. Three different reservoir types and fluid properties were simulated using 3-D Cartesian black oil models: Hamaca $\left(9^{\circ} \mathrm{API}\right)$, San Ardo $\left(12^{\circ} \mathrm{API}\right)$ and that based on the SPE fourth comparative solution project ${ }^{8}\left(14^{\circ} \mathrm{API}\right)$. In the first two field cases (Hamaca and San Ardo), a $45 \times 23 \times 8$ model was used that represented $1 / 8$ of a 10 -acre 5 -spot pattern unit, using typical rock and reservoir fluid properties. In the SPE project case, three models were used: $23 \times 12 \times 12(2.5 \mathrm{ac}), 31 \times 16 \times 12(5 \mathrm{ac})$ and $45 \times 23 \times 8(10 \mathrm{ac})$, that represented $1 / 8$ of a 5 -spot pattern unit.

To obtain a satisfactory match between simulation and the Jeff Jones analytical model results of the start and height of the production peak, the following refinements to the Jeff Jones model were necessary. First, the dimensionless steam zone size $A_{c D}$ was modified to account for decrease in oil viscosity during steamflood and its dependence on the steam injection rate. Second, the dimensionless volume of displaced oil produced $V_{o D}$ was modified from its square-root format to an exponential form.

\subsection{Chapter Organization}

This thesis is organized into five chapters. Chapter I (Introduction) provides methodology used and the objective of the study. Chapter II provides description of the steamflooding process mechanism, description of methodologies used in steamflooding production performance prediction and literature review of available analytical methods for 
steamflooding performance prediction. Chapter III discusses important concepts generally used in thermal simulation modeling. Simulation models used in this thesis will be explained in detail in Chapter III. Chapter IV gives a complete explanation of the new analytical method developed. This chapter also provides comparisons of oil production rate and cumulative oil steam ratio among the new model, the Jeff Jones model and the simulation results. Finally, main conclusions of this research are given in Chapter V. 


\section{CHAPTER II}

\section{THEORETICAL BACKGROUND}

This chapter consists of four sections. First section of this chapter provides a description of the reservoir mechanics of steamflooding. Second section of this chapter gives detailed explanation of the methodologies used in steamflood production performance prediction. The third section of this chapter is a literature review of currently available analytical models for steamflood prediction. Since this work is a modification of the Jeff Jones model, the Jeff Jones model will be discussed in more detail and is given in the fourth section.

\subsection{Steamflooding Mechanism}

Steamflooding uses separate injection and production wells to improve both the rate of production and the amount of oil that will ultimately be produced. Heat from the injected steam reduces the viscosity of the oil as the injected fluid drives the oil from injector to producer.

As steam moves through the reservoir between the injector and producer, it typically creates five regions of different temperatures and fluid saturations. ${ }^{9}$ All of these regions are shown in Fig. 2.1. 

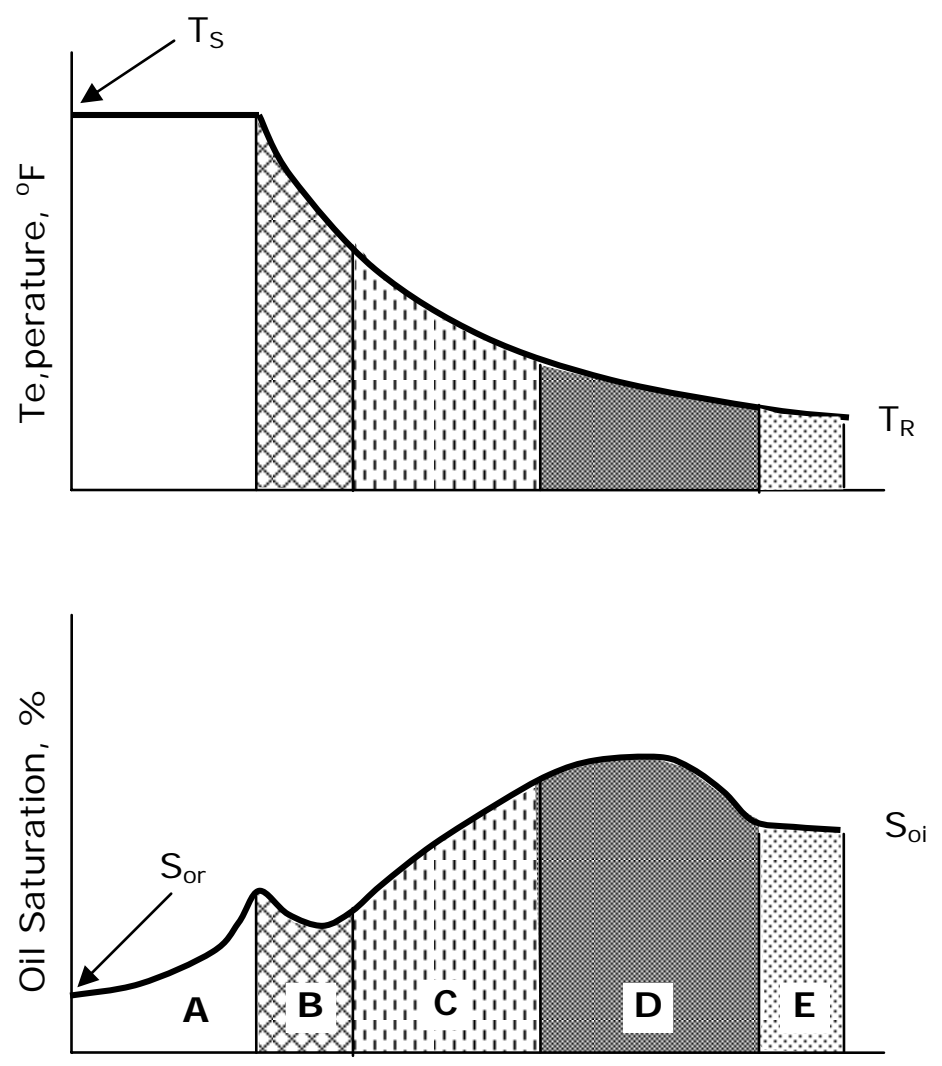

From Injection Well to Producing Well

$\mathrm{S}_{\mathrm{oi}}$
Legend

A Steam Zone

B Solvent Bank

C Hot water Bank

D Oil Bank-Cold Condensate zone

E Reservoir Fluid Zone

$T_{R}$ Reservoir Temperature

$\mathbf{T}_{\mathrm{S}}$ Steam Temperature

$S_{\text {oi }}$ I nitial Oil Saturation

Sor Residual Oil Saturation

Fig. 2.1-Steamflood typical temperature and saturation profile (after $\mathrm{Hong}^{9}$, 1994).

As steam enters the reservoir, it forms a steam saturated zone around the wellbore. This zone, at about the temperature of injected steam, expands as more steam is injected. Ahead of the steam saturated zone (A), steam condenses into water as it loses heat to the formation and forms a hot condensate zone $(B, C)$. Pushed by continued steam injection, the hot condensates carries some heat ahead of the steam front into the cooler regions further from the injector. Eventually, the condensate loses its heat to the formation, and its temperature is reduced to the initial reservoir temperature.

Because different oil displacement mechanisms are active in each zone, oil saturation varies between injector and producer. The active mechanism and hence, the 
saturation depend mainly on thermal properties of the oil. In the steam zone (A), oil saturation reaches its lowest value because the oil is subject to the highest temperature. The actual residual saturation achieved is independent of initial saturation but rather depends on temperature and crude oil composition. Oil is moved from the steam zone to the hot condensate zone $(\mathrm{B}, \mathrm{C})$ by steam distillation at the steam temperature, creating a solvent bank (B) of distilled light ends just ahead of the steam front. Gas is also stripped from the oil in this region.

In the hot condensate zone, the solvent bank (B) generated by the steam zone extracts additional oil from the formation to form an oil-phase miscible drive. The high temperature in this zone reduces the oil viscosity and expands the oil to produce saturations lower than those found in a conventional waterflood.

The mobilized oil is pushed ahead by the advancing steam (A) and hot water (C) fronts. By the time the injected steam has condensed and cooled to reservoir temperature (in the cold condensate zone), an oil bank (D) has formed. Thus, oil saturation in this zone is actually higher than initial oil saturation. Displacement here is representative of a waterflood. Finally, in the reservoir fluid zone (E), temperature and saturation approach the initial conditions.

The decrease in oil viscosity $\left(\mu_{o}\right)$ with increasing temperature is the most important mechanism for recovering heavy oils. As the reservoir temperature increases during steam injection, the viscosity of oil $\left(\mu_{o}\right)$ decreases. The viscosity of water $\left(\mu_{w}\right)$ also decreases, but to a lesser degree. The net result of increasing temperature is to improve the water-oil mobility ratio, $M$, defined as follows. ${ }^{9}$

$$
M=\frac{\mu_{o} k_{w}}{\mu_{w} k_{o}}
$$


where $k_{w}$ and $k_{o}$ are the effective permeabilities to water and oil respectively.

With lower oil viscosity, the displacement and area sweep efficiencies are improved. Thus, a hot waterflood will recover more heavy oil than a conventional waterflood because at high temperatures the heavy oil behaves more like a light oil.

The change in oil viscosity with temperature is usually reversible. In other words, when the temperature decreases again, the oil viscosity reverts approximately to its original value. $^{9}$

This reversible of the change in oil viscosity with temperature may account for oil banking. When a steam front moves through a reservoir, the temperature immediately ahead of the front increases, thereby decreasing the oil viscosity. Oil is readily displaced from the high temperature region to an area where the temperature may be considered lower. In this low temperature region, the oil viscosity increases again, thus retarding the oil flow; consequently, a large amount of oil accumulates as on oil bank. This bank, often observed when steamflooding heavy oil, is responsible for high oil production rates and low water/oil ratios just prior to or at the time of heat breakthrough at the producing well. $^{9}$

\subsection{Prediction of Steamflood Performance}

Steamflood performance can be predicted using a statistical model, numerical model or analytical model. Statistical models are commonly based on the historical data of steam flood performance from other reservoirs which have the same oil and rock properties. Numerical models require a large amount of data input about the reservoir (geometry and distribution of properties), its fluids (saturation, pressures, properties, and initial 
conditions), wells (location, interval opens, skin effect, and well model to be used), and operational variables (rates, pressures and the constraints of both). Table 2.1 indicates the amount of information required by a numerical model. ${ }^{10}$

TABLE 2.1-TYPICAL DATA REQUIRED BY THERMAL RESERVOIR SIMULATORS (AFTER PRATTS ${ }^{10}$ )

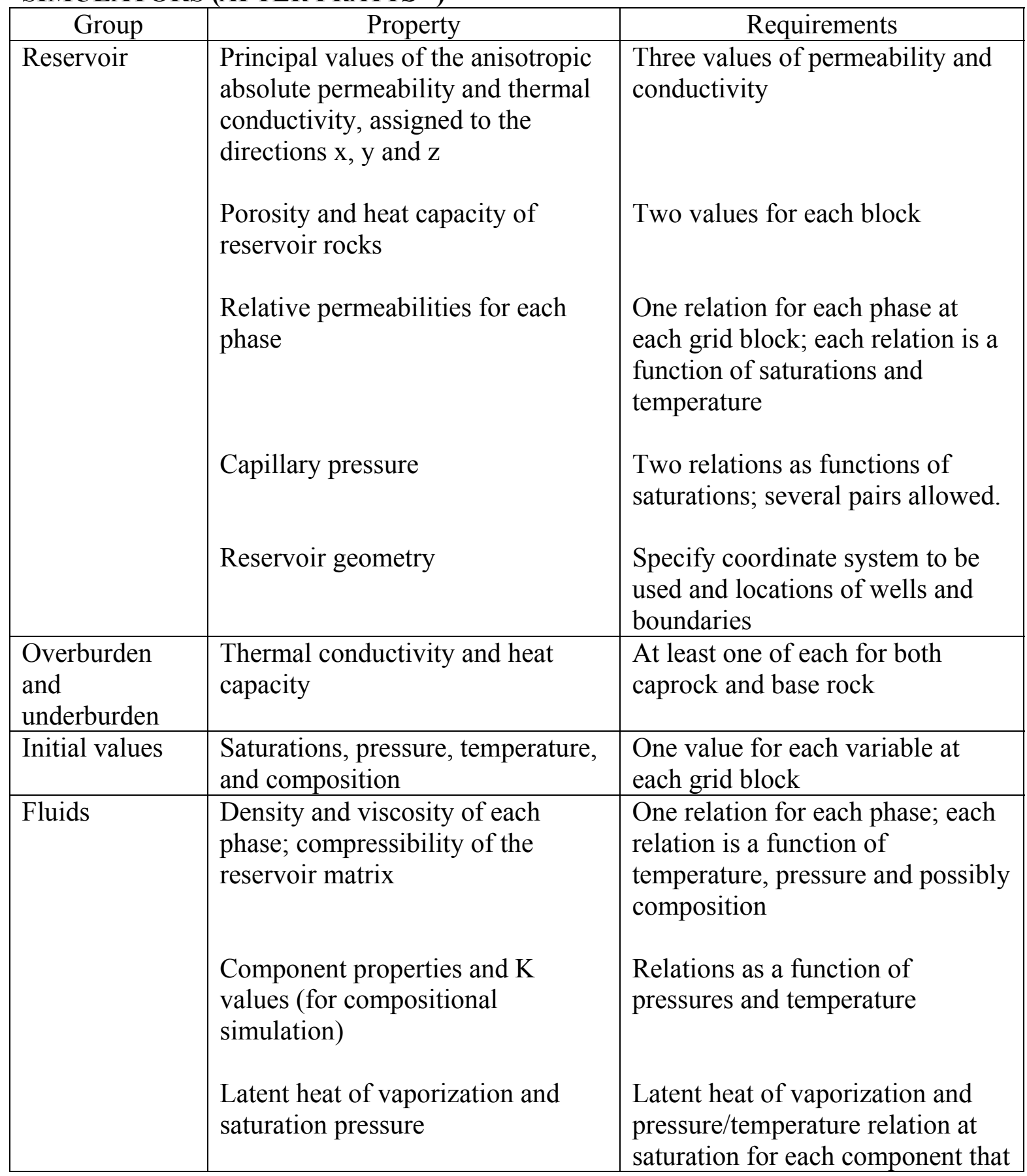


TABLE 2.1 (CONTINUED)

\begin{tabular}{|c|c|c|}
\hline Group & Property & Requirements \\
\hline & $\begin{array}{l}\text { Enthalpy and internal energy of } \\
\text { each phase }\end{array}$ & $\begin{array}{l}\text { undergoes a phase change } \\
\text { A relation for each quantity for } \\
\text { each phase as a function of } \\
\text { temperature, pressure, and } \\
\text { possibly composition }\end{array}$ \\
\hline $\begin{array}{l}\text { Well and } \\
\text { boundary } \\
\text { conditions }\end{array}$ & Rates, pressures, and temperatures & $\begin{array}{l}\text { Maximum and minimum values, } \\
\text { constraints and penalties }\end{array}$ \\
\hline
\end{tabular}

Specifically, reservoir properties such as permeability and porosity are required inputs for each grid block, and several sets of relative permeabilities and capillary pressures usually can be used to describe the reservoir. In other words, the simulator requires more information about the distribution of properties in the reservoir than is normally available.

By contrast, the analytical models generally require the entering of few but critical data. ${ }^{10}$ Frequently, displacement is assumed to be piston-like. This means that there is a sharp drop in the oil saturation across the displacement front, leaving a uniformly low amount of oil in the swept zone. There are several analytical and semianalytical methods for estimating steamflood production rate. In all of these models, certain simplifying assumptions have to be made to solve the complex heat and fluid flow equations. In the analytical methods, the reservoir is typically assumed to be homogenous. Since, it is much faster to obtain results from analytical models than from simulation, analytical models are still useful tools for preliminary forecasting purposes and sensitivity studies. In addition, the models provide a better insight than simulation into the physics of the thermal process. 


\subsection{Literature Review}

Several analytical models for steamflood production performance have been published. In this section, a literature review covering the main analytical models will be presented.

Marx and Langenheim Method (1959). ${ }^{1}$ Many of currently available simplified methods are based on the reservoir heating model of Marx and Langenheim (1959). The Marx and Langenheim (1959) model considers the injection of hot fluid into a well at constant rate and temperature. The operation element consists of a radial flow system, concentric about the point of injection. They assumed the temperature of the heated zone to be uniform at the downhole temperature of the injected fluid $\left(T_{s}\right)$ and the reservoir temperature outside the heated zone to be at the initial and reference temperature $\left(T_{R}\right)$. Marx-Langenheim's temperature model is schematically depicted in Fig. 2.2.

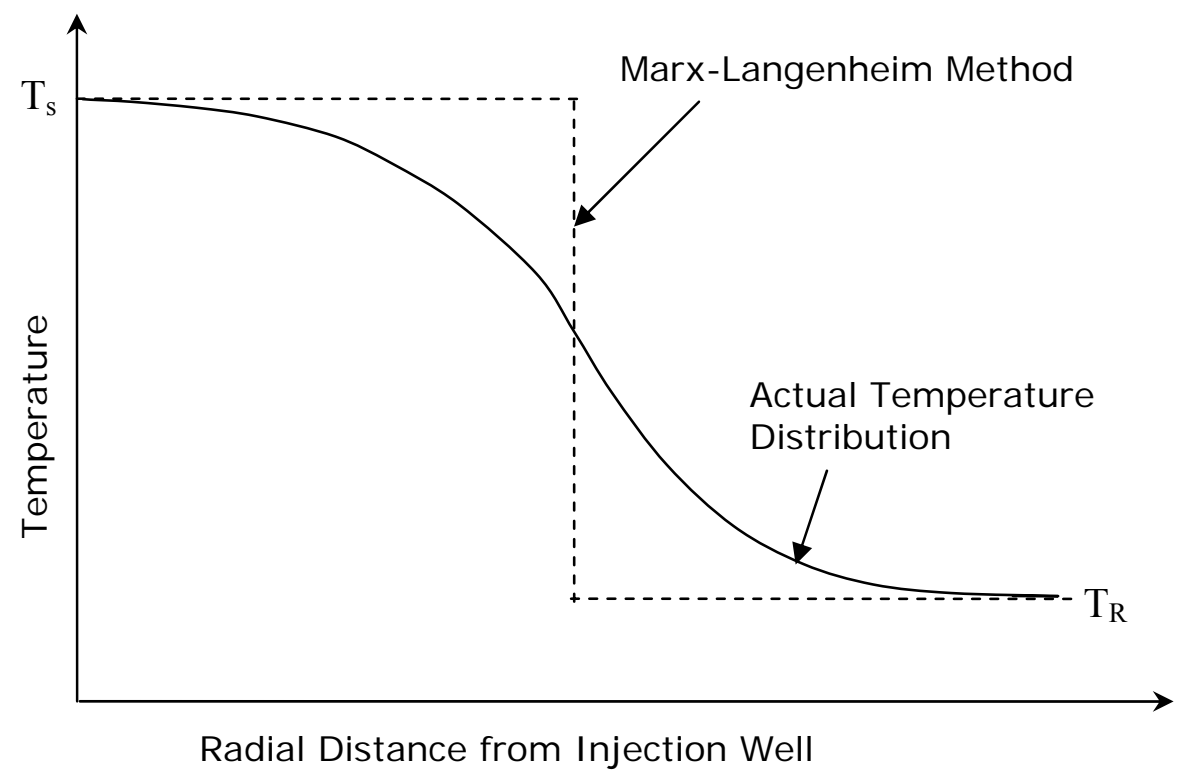

Fig. 2.2-Temperature profile of Marx-Langenheim model. 
Their model is basically based on a heat balance relationship between the rate of heat injected, the rate of heat loss to the over and underlying strata and the rate of heat flow into the reservoir.

Mandl and Volek Method (1969). ${ }^{2}$ Subsequent to the Marx-Langenheim model, Mandl and Volek developed a more rigorous reservoir heating model, which considers hot water transport ahead of the condensing steam front. They introduced a certain critical time, $t_{c}$, which depends on reservoir thickness, temperature, and quality of the steam. The critical time marks an important change in the heat flow across the condensation front, which are purely conductive during $0<t<t_{c}$, becomes predominantly convective at $t \geq t_{c}$. Convective heat transport from the steam zone into the liquid zone does not start at the beginning of a steam-drive process, but rather at a later time, i.e. the critical time. Before the critical time, the Marx-Langenheim model is the same as that of Mandl and Volek's model. However, after the critical time, description for the steam zone growth must be developed by making use of upper and lower bounds for the exact solution of the problem.

Boberg and Lantz Method (1966). ${ }^{3}$ The Boberg and Lantz developed a model for cyclic steam injection, based on the Marx-Langenheim model. Their model assumes that there is sufficient reservoir energy to produce oil at the initial reservoir temperature $\left(T_{R}\right)$ prior to steam injection. The Boberg and Lantz method works quite well for relatively thin reservoirs with sufficient energy to produce under unstimulated conditions. But their method is not satisfactory for thick, low-pressure reservoirs where the bulk of the produced oil must come from the heated zone. 
Newman Method (1975). ${ }^{4}$ The Newman method accounts for steam override. Model equations developed by Newman enable estimation of the rate of steam zone thickness increase and areal extent; the volume of oil displaced from the steam zone and the underlying hot water zone; the reduced injection rate, which will maintain a constant steam zone area; and the additional oil displaced after steam injection is stopped.

Myhill and Stegemeier Method (1978). ${ }^{5}$ The Myhill and Stegemeier method is essentially an energy relationship based on Marx and Langenheim's model. The steam zone growth is calculated using a slightly modified version of Mandl and Volek's method, so that the steam zone volume would vanish when no steam is injected. The oil steam ratio is calculated assuming oil produced is equal to steam-zone pore volume times the change in oil saturation.

Gomma Method (1980). ${ }^{6}$ The Gomma method is based on oil recovery correlations for a typical heavy-oil reservoir with an unconsolidated sand matrix. It was developed by determining the sensitivity of different parameters on a typical heavy oil project using a numerical steamflood simulator. The simulator was first used to historymatch a Kern River Field steamflood project. It was then used to determine the sensitivity of oil recovery to several parameters. Based on the results of the sensitivity studies, correlations were developed for predicting oil recovery performance.

\subsection{Jeff Jones' Method}

Jeff Jones Method (1981). ${ }^{7}$ Jeff Jones presents a model based on work published by Van Lookeren ${ }^{11}$ and Myhill-Stegemeier. Jeff Jones' model is divided into two different parts. The first part of the model calculates an optimal steam injection rate (to the nearest 5 
B/D) for a given set of steam and reservoir parameters by the method proposed by Van Lookeren. The second part of the model uses the optimal steam rate (or a given steam rate) and related data calculated in the first part in conjunction with additional inputs to predict the oil production history. Myhill-Stegemeier's oil displacement rate is converted to Jeff Jones' oil production rate based on correlation with 14 different steamflood projects. The conversion of Myhill-Stegemeier's displacement rate to the production rate is done by assuming that steamflooding process has the following three major stages of production. The first production stage is dominated by initial oil viscosity and possibly is affected by reservoir fillup if a significant void exists. The second stage of production normally is dominated by hot oil mobility and reservoir permeability. At the second stage, the production rate is essentially the displacement rate. The third phase of production is dominated by the remaining mobile fraction of original oil in place. Fig. 2.3 gives an illustration of these three stages.

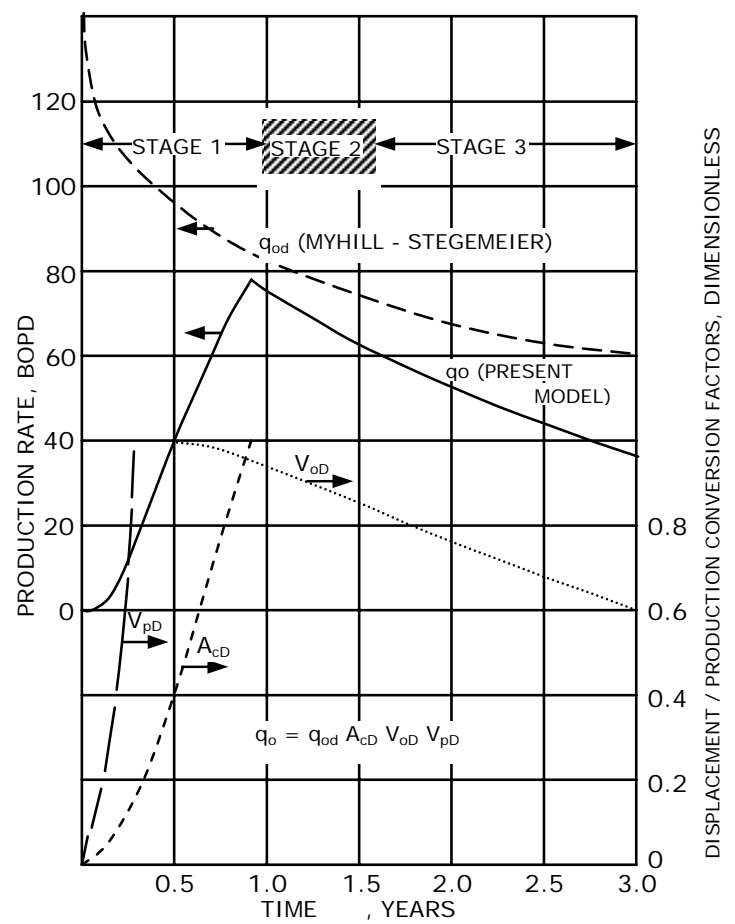

Fig. 2.3-Three production stages of Jeff Jones' model (Jones ${ }^{7}$, 1981). 
Appendix A gives equations used for oil displacement $\left(q_{o d}\right)$ calculations. This oil displacement calculation is essentially the same as in the Myhill-Stegemeier's method but with some simplifications. Major simplifications noticed are: (1) Assumption that heat capacity of the base rock and caprock is 1.2 times heat capacity of reservoir rock, (2) Simplification of equation used for overall reservoir thermal efficiency $\left(E_{h \mathrm{~s}}\right)$ calculation, and (3) using a correlation to calculate dimensionless critical time $\left(t_{c D}\right)$. These simplifications lead to some inaccuracies which are removed in the new model by not making these simplifications.

Jeff Jones' “Capture Efficiency” converts Myhill-Stegemeier's oil displacement rate $\left(q_{o d}\right)$ to actual oil production rate. Jeff Jones' "Capture Efficiency" consists of three elements, $A_{c D}, V_{o D}, V_{p D}$. The product of these three elements yields the "Capture Efficiency". That is,

Capture Efficiency $=A_{c D} \times V_{o D} \times V_{p D}$

Formulas for $A_{c D}, V_{o D}$ and $V_{p D}$ are given in Eq. 2.3, Eq. 2.4 and Eq. 2.5. These formulas were determined empirically by Jeff Jones using data from numerous steamflooded fields.

$A_{c D}=\left[\frac{A_{s}}{A\left\{0.11 \ln \left(\mu_{o i} / 100\right)\right\}^{1 / 2}}\right]^{2}$.

(with these limits: $0 \leq A_{c D} \leq 1.0$ and $A_{c D}=1.0$ at $\mu_{o} \leq 100 \mathrm{cp}$ ).

$V_{o D}=\left(1-\frac{N_{d}}{N} \frac{S_{o i}}{\Delta S_{o}}\right)^{1 / 2}$

(with the limits: $0 \leq V_{o D} \leq 1.0$ ). 
$V_{p D}=\left(\frac{V_{s, i n j} 5.62}{4360 A h_{n} \phi S_{g}}\right)^{2}$

(with these limits: $0 \leq V_{p D} \leq 1.0$ and $V_{p D}=1.0$ at $S_{g}=0$ ).

The area steamed $\left(A_{S}\right)$ in $A_{c D}$ calculation is from Marx and Langenheim's model:

$$
A_{s}=\frac{Q_{i n j} h_{n} M_{1}}{4 k_{h}\left(t_{s}-t_{f}\right) M_{2} \times 43,560}\left(e^{t_{D}} \operatorname{erfc} \sqrt{t_{D}}+2 \sqrt{t_{D} / \pi}-1\right),
$$

where

$Q_{i n j}=14.6 \times i_{s} \times\left\{h_{f}+f_{s} h_{f g}-C_{w}\left(T_{f}-32\right)\right\}$,

and

$h_{f}=91 \times p_{s}^{0.2574}$.

Jeff Jones' oil production rate is then given as,

$$
\begin{aligned}
q_{o} & =q_{o d} \times \text { Capture Efficiency } \\
& =q_{o d} \times A_{c D} \times V_{o D} \times V_{p D} .
\end{aligned}
$$




\section{CHAPTER III}

\section{NUMERICAL SIMULATION}

Numerical reservoir simulators for steamflood prediction performance have been extensively used in the past 20 years. Advances in reservoir simulation techniques have made it possible to model virtually all the important reservoir phenomena. The availability of high-speed and low-cost computers in the recent past allowed the use of more detailed and accurate numerical models at reasonable cost and with reduced computing time.

Numerical steamflood simulators are similar to other reservoir simulators, with the exception that thermal effects are considered. They are based on a mathematical model of steamflooding derived from the basic laws of conservation of mass and energy. The law of conservation of a quantity states that:

Accumulation $=$ Input - Output + Sources - Sinks

Fluid flow in the reservoir associated with production and injection causes the transfer of mass from one location to another. This is generally modeled with the empirical Darcy's law. Heat is also carried with the mass. In addition, conduction causes the transfer of heat, which is usually modeled with Fourier's law. ${ }^{10}$

The simulator used to perform this study was CMG's STARS version 2003. It is a three-phase multi-component thermal simulator that can handle a wide range of processes such as steam drive, cyclic steam injection, in-situ combustion, polymer flooding, foam 
and emulsion flow. Three simulation concepts used in this study are explained later in this chapter followed by description of the simulation models for SPE comparison, San Ardo and Hamaca cases.

\subsection{Symmetrical Element}

Simulation of steamflood model can be done by taking advantage of a symmetrical element of one repeatable pattern unit. Symmetrical elements are used frequently in thermal simulation for a number of reasons: ${ }^{12}$

1. Compared with black-oil models, thermal models require much more CPU and storage per grid block. Therefore, less blocks can be used for a given computer storage limit.

2. Thermal EOR processes require more grid blocks per well or per pattern, since fronts are sharp and distinct.

3. Accuracy can be maximized for use in test and sensitivity runs.

4. Some results from one element may be generalized to other elements and pattern.

5. Pattern interference can be investigated by sensitivity runs with different injection share or production share.

6. Full-pattern or multipattern runs can be done once an acceptable course grid is obtained.

The minimal symmetrical element used in a 5-spot pattern simulation study is a 1/8-pattern element. A 1/8-pattern element of an inverted 5-spot model is illustrated in

Fig. 3.1. Simulation of a $1 / 8$-pattern element is preferred than other simulation styles 
(1/4- pattern element or full pattern) because it is less time-consuming and more costefficient than others.

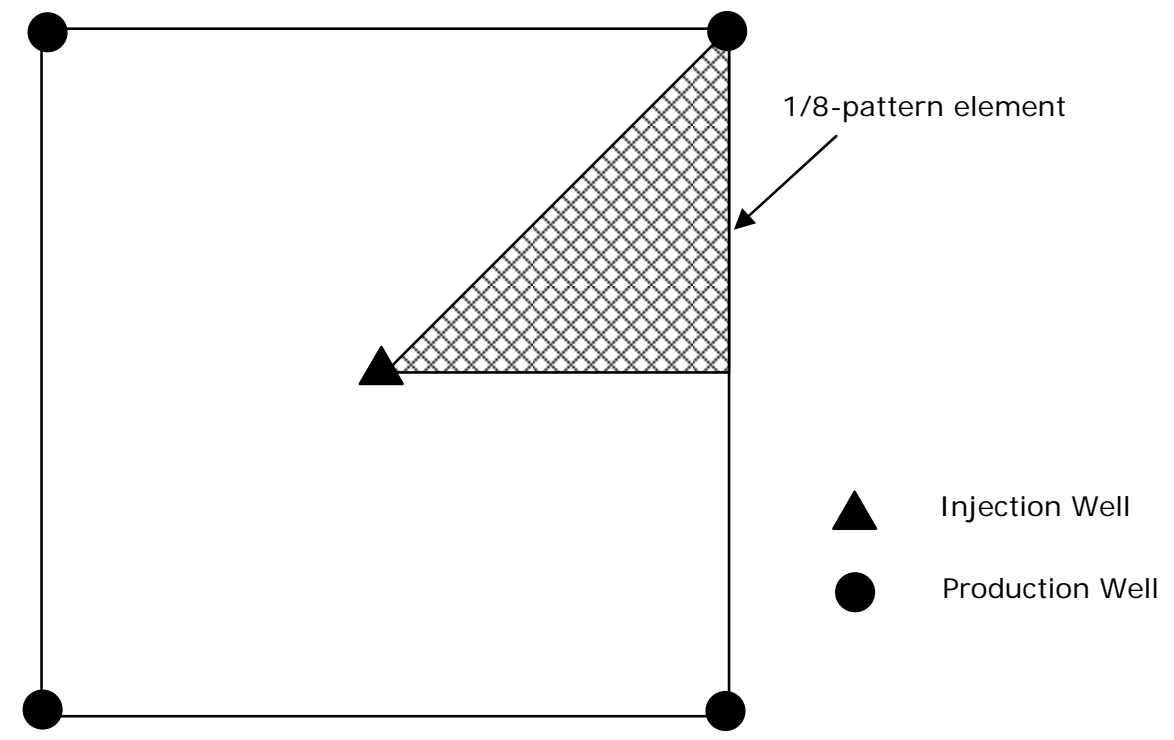

(a) Plan View

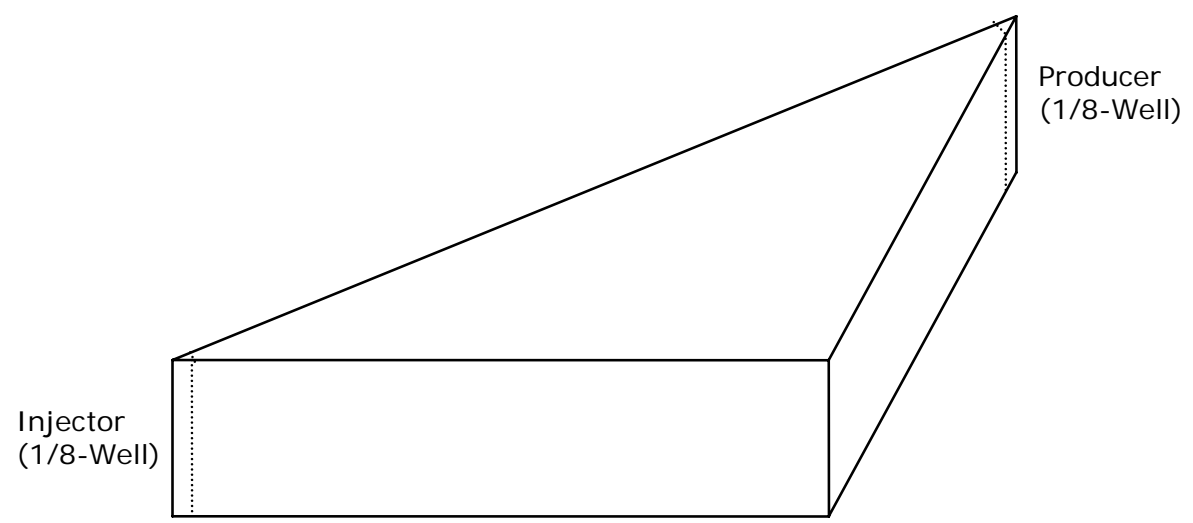

(b) 3D View

Fig. 3.1-1/8 element of inverted 5-spot pattern model: (a) plan view; (b) 3D view.

\subsection{Grid Orientation Effect}

This 1/8-pattern element can be simulated using two different approaches of grid orientation system: (a) diagonal grid and (b) parallel grid, as given in Fig. 3.2. 


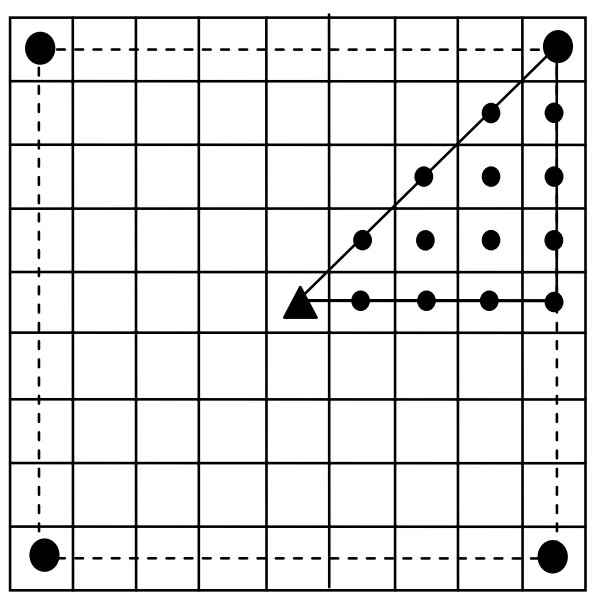

(a) Diagonal Grid

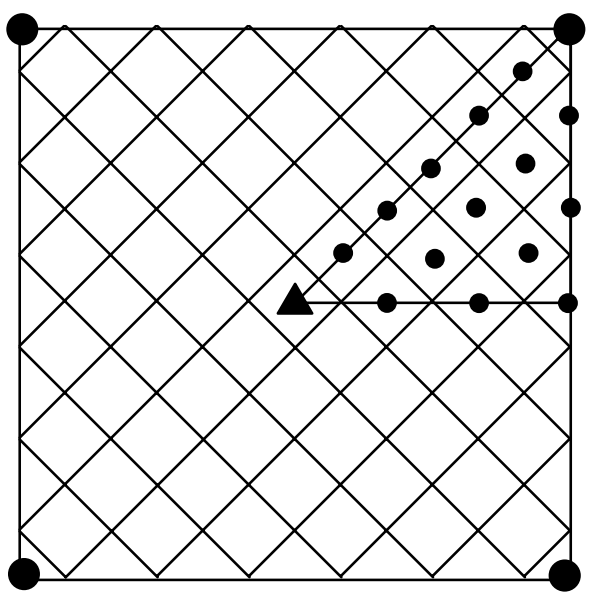

(b) Parallel Grid

- Injection Well
-
Production Well
Center of grid block

Fig. 3.2-Five spot pattern grids: (a) diagonal grid; (b) parallel grid.

The five-point difference scheme conventionally used in numerical simulation can introduce significant disparity in results for equivalent parallel and diagonal grids. This disparity was noted by Todd et al. ${ }^{13}$ for adverse-mobility ratio waterfloods and later by Coats et al. ${ }^{14}$ for steamfloods. Abou-Kasem and Aziz ${ }^{15}$ reported a detailed comparison of the nine-point difference and other numerical schemes as remedies to the grid orientation problem in $1 / 4$ of a five-spot steamflood pattern. They concluded that the nine-point scheme significantly reduces the grid orientation effect.

A schematic diagram of flow directions considered in the five and nine-point, finite-difference formulations is presented in Fig. 3.3. The five-point formulation only considers flow between a block and the four blocks that are adjacent to its boundaries. 
The nine-point formulation considers this flow as well as the flow between the block and the four blocks located at its corners. ${ }^{16}$

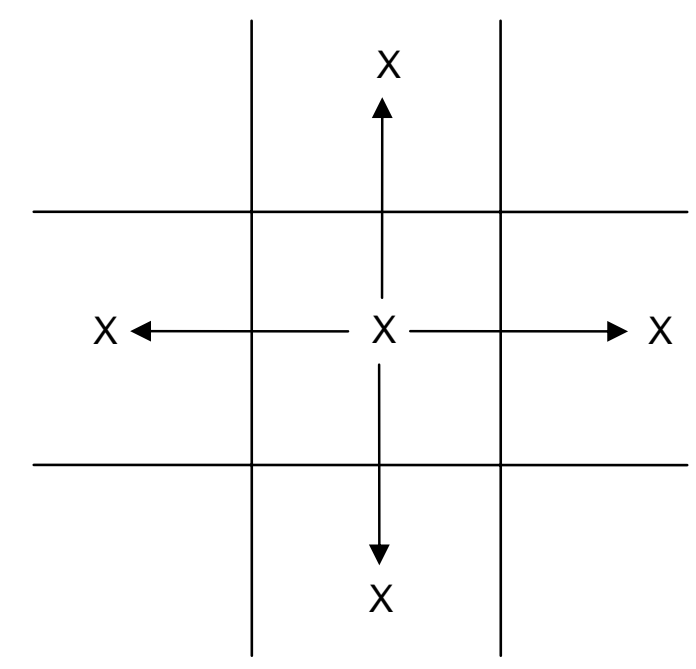

(a) Five-Point Formulation

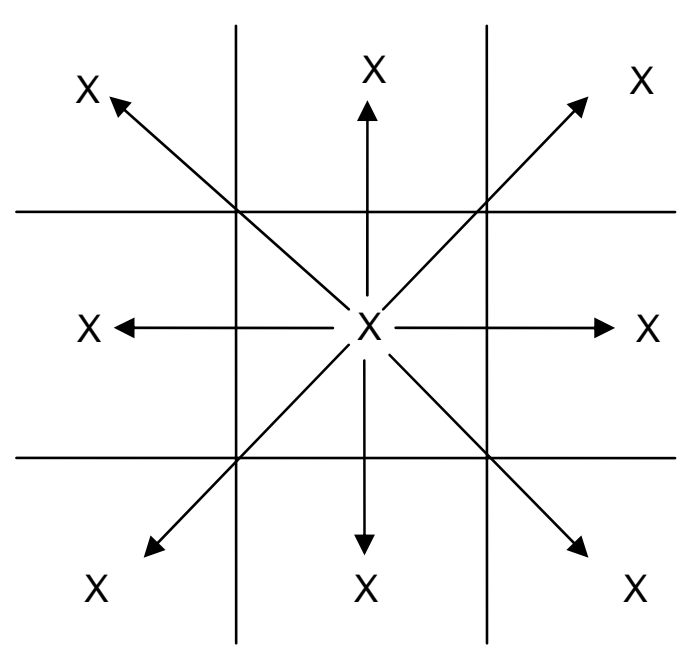

(b) Nine-Point Formulation

Fig. 3.3-Five and nine-point, finite-difference formulation (after Yanosik and McCraken $^{16}$, 1979).

Fig. 3.4 compares full pattern oil rate results for five-point and nine-point formulation. It indicates that the nine-point different scheme significantly reduced the grid orientation effect. ${ }^{17}$ 


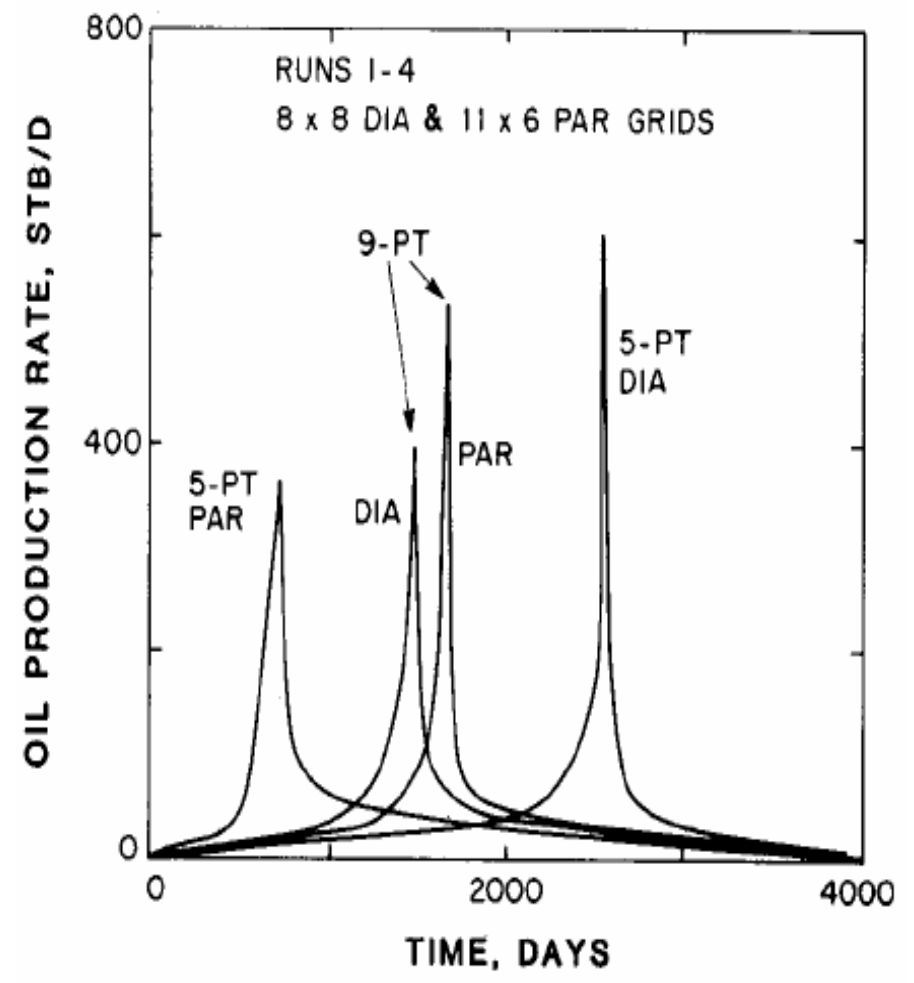

Fig. 3.4-Five-point vs nine-point formulation on oil production rate in 1/8 five-spot (Coats and Ramesh ${ }^{17}$, 1987).

\subsection{Block Geometry Modifier}

In order to put grid nodes on injector-producer lines in a block-centered grid system, an oversized grid must be specified. ${ }^{12}$ This grid is then modified by using block geometry modifiers. Fig. 3.5 illustrates this idea for the parallel grid system. 


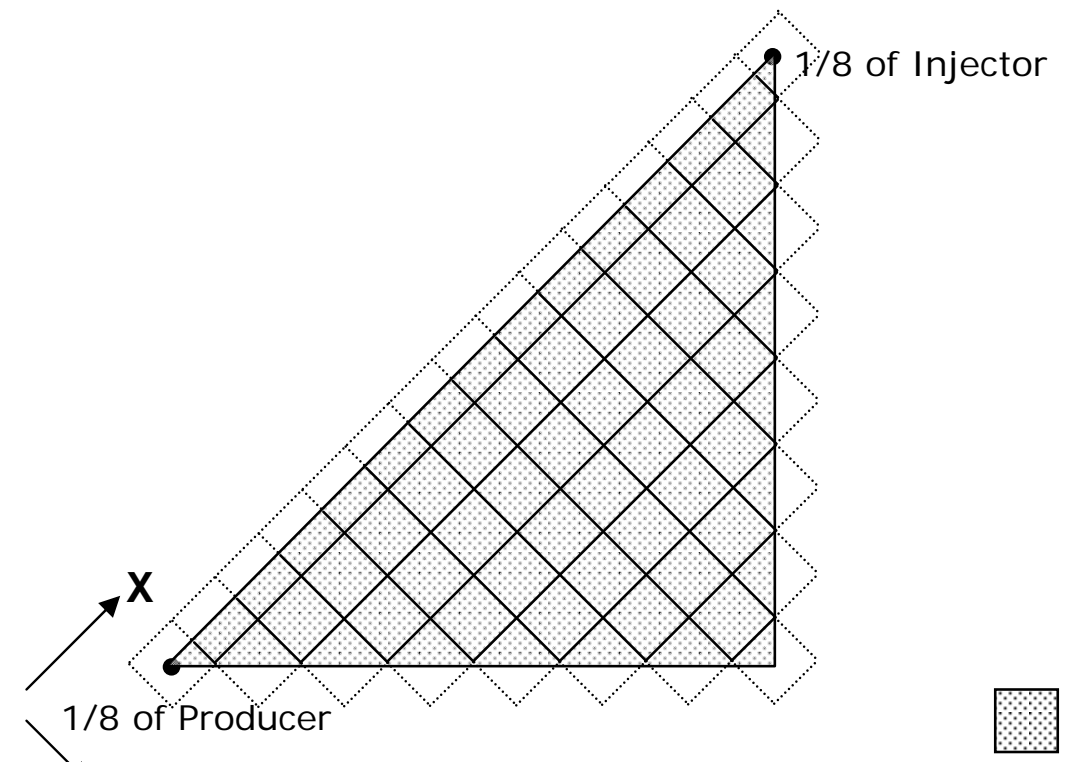

Active cell

(a) X-Y View

Inactive cell

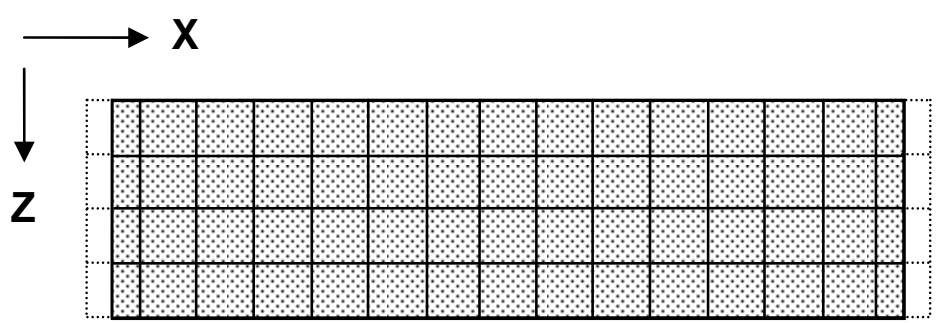

(b) X-Z View

Fig. 3.5-Active and inactive cells in a 1/8 five-spot pattern model.

All the grids at the edges and corners of the model are oversized, only half of the grids at the edges are active and only one-eighth of the grids at the corners are active. In order to get proper input parameters to be used in simulation, these grids are modified as given in Table 3.1. 


\section{TABLE 3.1-MODIFICATION PARAMETERS FOR EDGES AND CORNER- GRIDS}

\begin{tabular}{|c|c|c|}
\hline \multirow{2}{*}{ Parameter } & \multicolumn{2}{|c|}{ Value for } \\
\hline & Grids at Edges & Grids at Corners \\
\hline Porosity & $1 / 2$ of value at normal grid & $1 / 8$ of value at normal grid \\
\hline $\begin{array}{l}\text { Transmisibility at z- } \\
\text { direction }\end{array}$ & $1 / 2$ of value at normal grid & $1 / 8$ of value at normal grid \\
\hline Grid block rock volume & $1 / 2$ of value at normal grid & $1 / 8$ of value at normal grid \\
\hline $\begin{array}{l}\text { Heat transmissibility at } \\
\text { z-direction }\end{array}$ & $1 / 2$ of value at normal grid & $1 / 8$ of value at normal grid \\
\hline
\end{tabular}

Block geometry modifier in CMG STARS is done automatically by using *VAMOD and *VATYPE keywords.

\subsection{SPE Comparative Case Simulation Model}

SPE comparative case model is a modified version of Case No. 2a of "Fourth SPE Comparative Solution Project: Comparison of Steam Injection Simulators" by Azis et.al. ${ }^{8}$ SPE comparative case model simulates one-eighth of a five-spot repeatable pattern described as follows.

1. Initial reservoir properties

Initial reservoir properties for SPE Comparative Case are given in Table 3.2. 
TABLE 3.2-INITIAL RESERVOIR PROPERTIES

\begin{tabular}{|l|c|c|}
\hline \multicolumn{1}{|c|}{ Properties } & Values & Units \\
\hline Oil gravity & 14 & ${ }^{\circ} \mathrm{API}$ \\
\hline Initial pressure & 75 & $\mathrm{psia}$ \\
\hline Initial temperature & 125 & ${ }^{\circ} \mathrm{F}$ \\
\hline Net oil sand thickness & 120 & $\mathrm{ft}$ \\
\hline Initial oil saturation & 55 & $\%$ \\
\hline Initial water saturation & 45 & $\%$ \\
\hline Permeability & 1000 & $\mathrm{md}$ \\
\hline Porosity & 30 & $\%$ \\
\hline In-situ oil viscosity at $125^{\circ} \mathrm{F}$ & 487 & $\mathrm{cp}$ \\
\hline
\end{tabular}

2. Simulation model grid

Three simulation grid models are used for SPE comparative case model, depending on the simulated area. $23 \times 12 \times 12$ grid system is used for area of $2.5 \mathrm{ac}, 31 \times 16 \times 12$ for area of 5 ac, and $45 \times 23 \times 8$ for area of 10 ac. Fig. 3.6 to Fig. 3.8 show these grid systems.

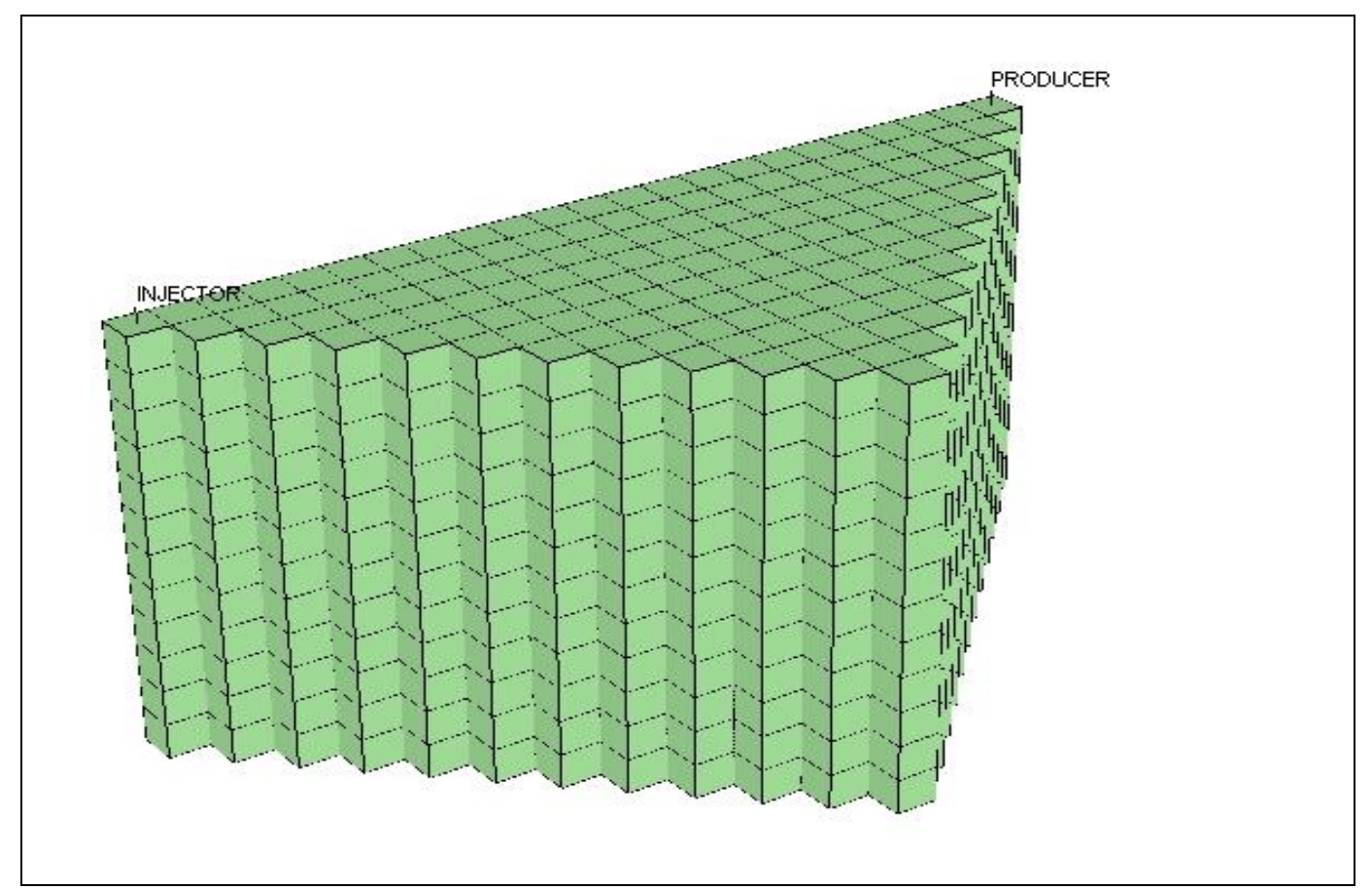

Fig. 3.6-Simulation grid for area of 2.5 ac, SPE comparative case model. 


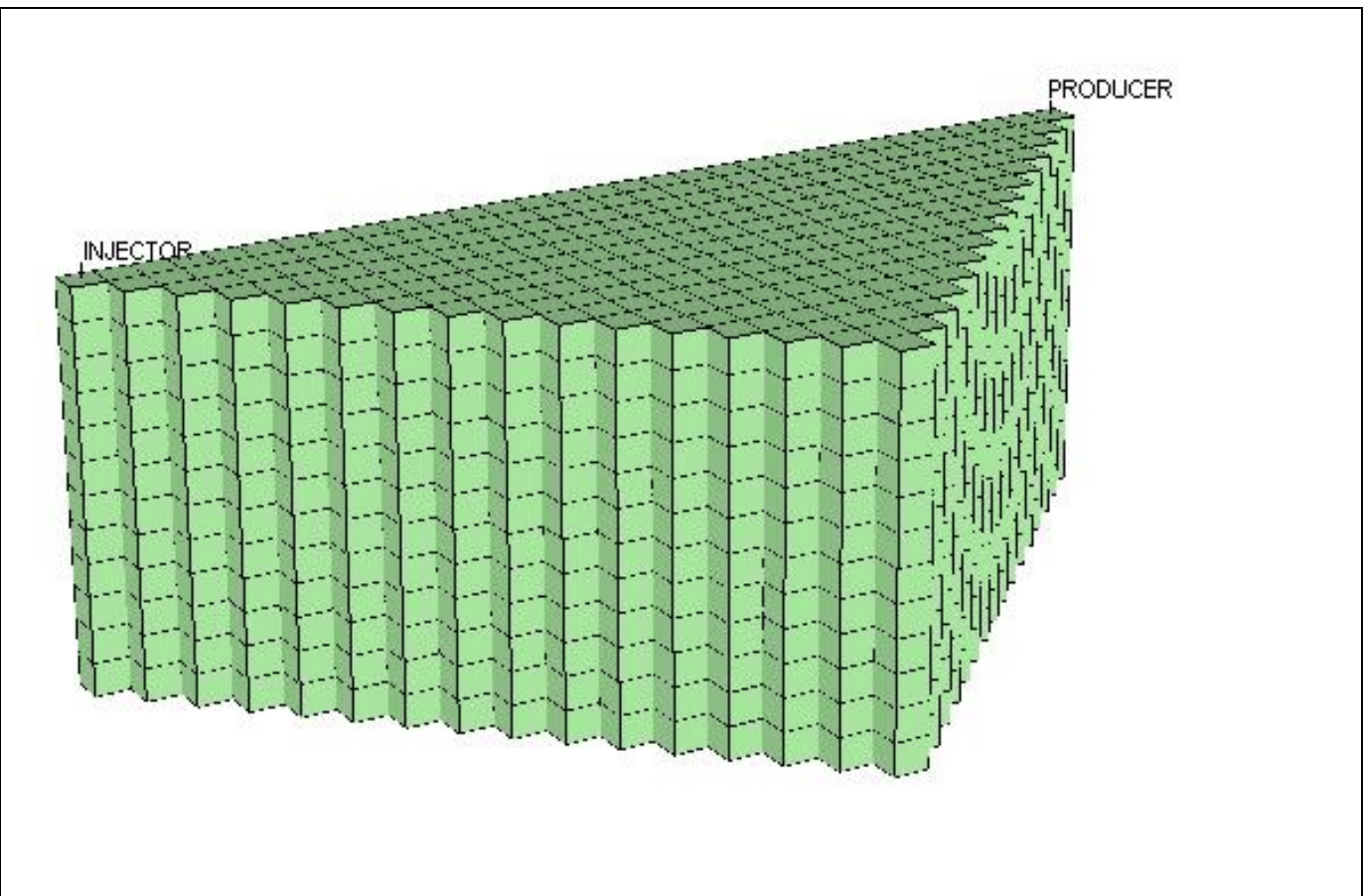

Fig. 3.7-Simulation grid for area of 5.0 ac, SPE comparative case model.

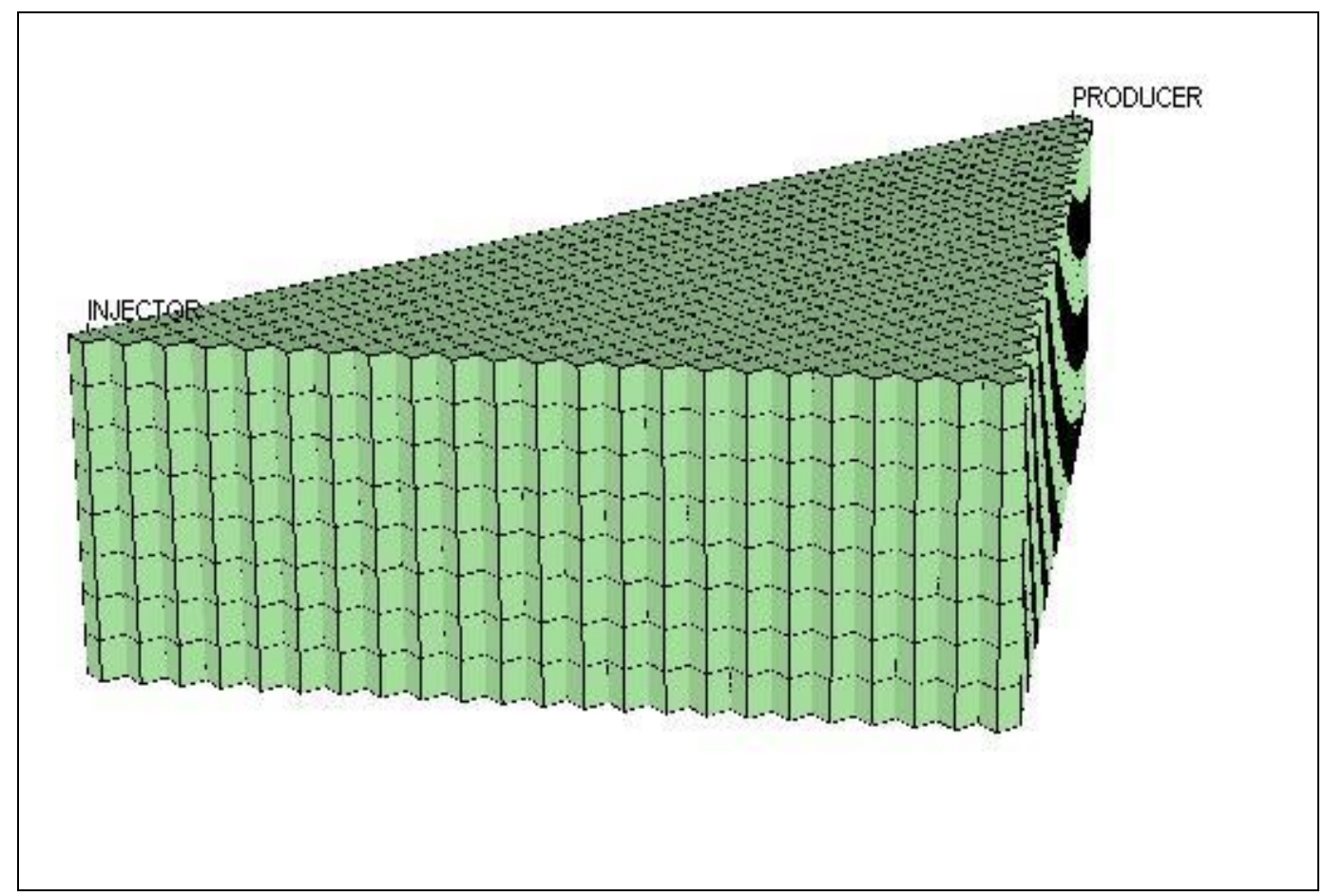

Fig. 3.8-Simulation grid for area of 10 ac, SPE comparative case model. 
Table 3.3 shows the cell dimensions for each of the area simulated for the SPE comparative case model.

TABLE 3.3 CELL DIMENSIONS FOR SPE COMPARATIVE CASE MODEL

\begin{tabular}{|c|c|c|c|}
\hline \multirow{2}{*}{ Area (Acre) } & \multicolumn{3}{|c|}{ Cell Dimensions (ft) } \\
\cline { 2 - 4 } & $\mathrm{i}$ & $\mathrm{j}$ & $\mathrm{K}$ \\
\hline 2.5 & 10.61 & 10.61 & 10 \\
\hline 5 & 11 & 11 & 10 \\
\hline 10 & 10.607 & 10.607 & 15 \\
\hline
\end{tabular}

3. Rock properties

- $\quad$ Thermal conductivity of reservoir $=24 \mathrm{BTU} /\left(\mathrm{ft}-\mathrm{D}-{ }^{\circ} \mathrm{F}\right)$

- Heat capacity of reservoir $=35 \mathrm{BTU} /\left(\mathrm{ft}^{3}\right.$ of rock- $\left.{ }^{\circ} \mathrm{F}\right)$

- Heat capacity of overburden and underburden $=42 \mathrm{BTU} /\left(\mathrm{ft}^{3}\right.$ of rock- $\left.{ }^{\circ} \mathrm{F}\right)$

4. Fluid properties

Water properties. Pure water is assumed and standard water properties are used.

Oil properties. Density at standard condition is $60.68 \mathrm{lbm} / \mathrm{ft}^{3}$. Compressibility is $5 \times$ $10^{-6} \mathrm{psi}^{-1}$. The molecular weight is 600 . Viscosity data is shown in Table 3.4.

\section{TABLE 3.4-TEMPERATURE-VISCOSITY RELATIONSHIP FOR SPE COMPARATIVE CASE}

\begin{tabular}{|c|c|}
\hline Temperature $\left({ }^{\circ} \mathrm{F}\right)$ & Viscosity $(\mathrm{cp})$ \\
\hline 75 & 5780 \\
\hline 100 & 1380 \\
\hline 150 & 187 \\
\hline 200 & 47 \\
\hline 250 & 17.4 \\
\hline 300 & 8.5 \\
\hline 350 & 5.2 \\
\hline 500 & 2.5 \\
\hline
\end{tabular}


5. Relative permeability data

The relative permeability expressions for water/oil system and water/gas system are based on Corey relationships as follows:

For water/oil system,

$$
\begin{aligned}
& k_{r w}=k_{r w r o}\left(\frac{S_{w}-S_{w i r}}{1-S_{\text {orw }}-S_{w i r}}\right)^{2.5}, \\
& k_{\text {row }}=k_{\text {roiw }}\left(\frac{1-S_{\text {orw }}-S_{w}}{1-S_{\text {orw }}-S_{\text {iw }}}\right)^{2} .
\end{aligned}
$$

For gas/oil system,

$$
\begin{aligned}
& k_{\text {rog }}=k_{\text {roiw }}\left(\frac{1-S_{w i r}-S_{o r g}-S_{g}}{1-S_{w i r}-S_{g c}}\right)^{2}, \\
& k_{r g}=k_{r g r o}\left(\frac{S_{g}-S_{g c}}{1-S_{i w}-S_{g c}}\right)^{1.5} .
\end{aligned}
$$

The residual oil saturation (water/oil system) $S_{\text {orw }}=0.15$, the residual oil saturation (gas oil system), $S_{\text {org }}=0.10$, and the critical gas saturation, $S_{g c}=0.06$. Oil relative permeability at interstitial water saturation, $k_{\text {roiw }} \approx 0.4$, water relative permeability at residual oil saturation (water/oil system) $k_{r w r o}=0.1$, and gas relative permeability at residual oil saturation (gas/oil system) $k_{\text {rgro }}=0.2$. Fig. 3.9 and Fig. 3.10 show relative permeability curves for SPE comparative case model. 


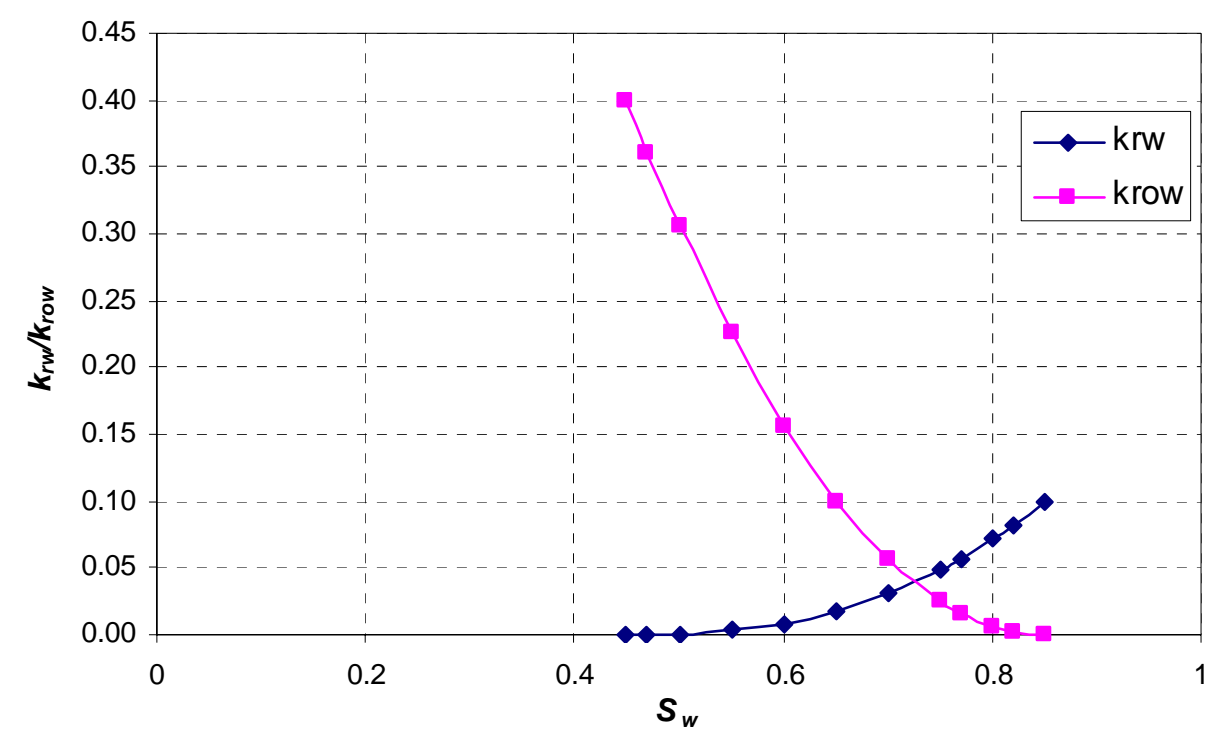

Fig.3.9-Relative permeability curve (water/oil system) for SPE comparative case.

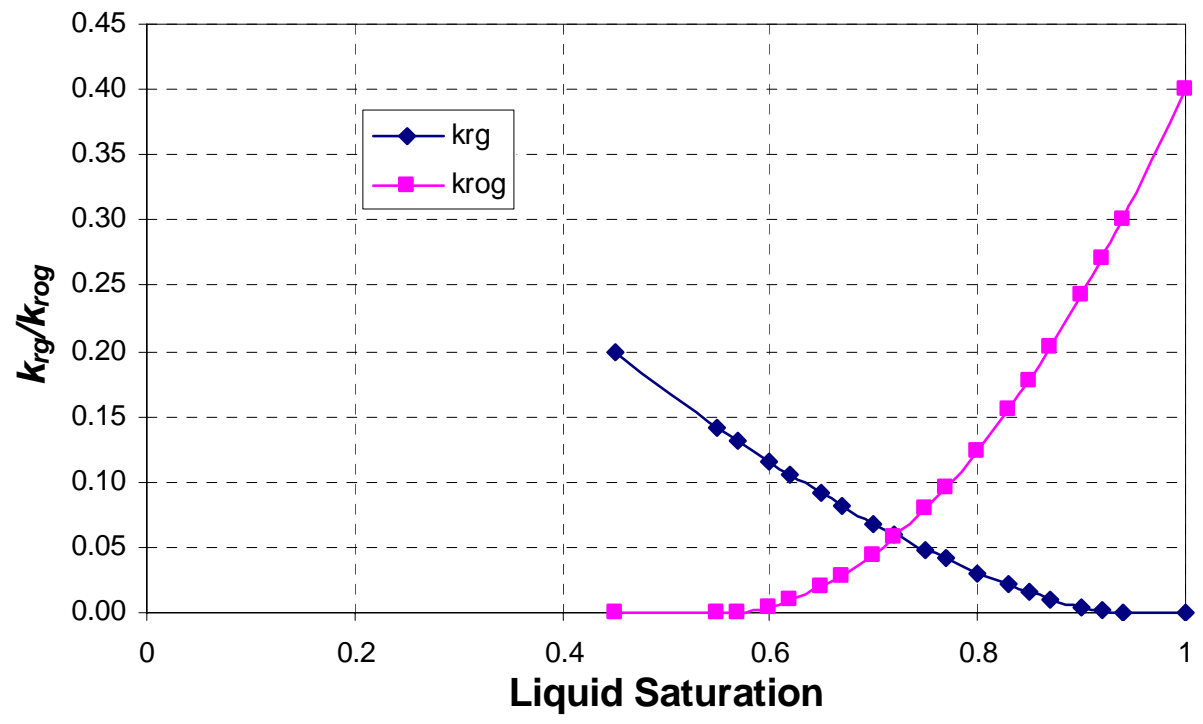

Fig. 3.10-Relative permeability curve (gas/oil system) for SPE comparative case.

6. Operating conditions

Steam is injected at a temperature of $545^{\circ} \mathrm{F}$. The quality of the steam at bottom hole condition is 0.7 . Minimum bottom hole pressure at producer is 17 psia. 


\subsection{San Ardo Simulation Model}

The San Ardo simulation study was conducted with the available information from Lombardi reservoir in San Ardo field. ${ }^{18}$ San Ardo model simulates one-eighth of a 10acre five-spot repeatable pattern described as follows.

1. Initial reservoir properties

Initial reservoir properties for San Ardo model are given in Table 3.5.

TABLE 3.5-INITIAL RESERVOIR PROPERTIES FOR SAN ARDO MODEL

\begin{tabular}{|l|c|c|}
\hline \multicolumn{1}{|c|}{ Properties } & Values & Units \\
\hline Oil gravity & 12 & ${ }^{\circ} \mathrm{API}$ \\
\hline Formation top & 1900 & $\mathrm{ft}$ \\
\hline Initial pressure & 275 & $\mathrm{psia}$ \\
\hline Initial temperature & 127 & ${ }^{\circ} \mathrm{F}$ \\
\hline Net oil sand thickness & 115 & $\mathrm{ft}$ \\
\hline Initial oil saturation & 73.3 & $\%$ \\
\hline Initial water saturation & 26.7 & $\%$ \\
\hline Permeability & 6922 & $\mathrm{md}$ \\
\hline Porosity & 34.5 & $\%$ \\
\hline In-situ oil viscosity at 275 psia & 3000 & $\mathrm{cp}$ \\
\hline
\end{tabular}

2. Simulation model grid

$45 \times 23 \times 8$ grid system is used to simulate one-eighth of a 10 -acre five-spot repeatable pattern. Fig. 3.8 shows this grid system. The cell dimensions are $\mathrm{i}=$ $10.61 \mathrm{ft}, \mathrm{j}=10.61 \mathrm{ft}$ and $\mathrm{k}=14.375 \mathrm{ft}$.

3. Rock properties

- Thermal conductivity of reservoir $=24 \mathrm{BTU} /\left(\mathrm{ft}-\mathrm{D}-{ }^{\circ} \mathrm{F}\right)$

- Heat capacity of reservoir $=35.02 \mathrm{BTU} /\left(\mathrm{ft}^{3}\right.$ of rock- $\left.{ }^{\circ} \mathrm{F}\right)$

- Heat capacity of overburden and underburden $=60 \mathrm{BTU} /\left(\mathrm{ft}^{3}\right.$ of rock- $\left.{ }^{\circ} \mathrm{F}\right)$ 
4. Fluid properties

A live, black oil model (2 pseudo-components and water) is used for the simulation.

Water properties. Pure water is assumed and standard water properties are used.

Oil properties. Oil consists of two components: "Oil" and "Gas" with the properties as given in Table 3.6. Table 3.7 gives dead oil viscosity value for San Ardo's oil.

TABLE 3.6-OIL COMPONENT PROPERTIES FOR SAN ARDO MODEL

\begin{tabular}{|c|c|c|}
\hline Component name & Oil & Gas \\
\hline Molecular weight, (CMM) & 456.015 & 16.7278 \\
\hline Critical pressure (PCRIT), psia & 179.02 & 670.46 \\
\hline Critical temperature (TCRIT), ${ }^{\circ} \mathrm{F}$ & 1036.21 & -107.35 \\
\hline $\begin{array}{l}\text { First coefficient in the correlation for gas-liquid } \mathrm{K} \\
\text { value }(\mathrm{KV} 1) \text {, psi }\end{array}$ & $5.165 \mathrm{E}+6$ & $1.534 \mathrm{E}+5$ \\
\hline $\begin{array}{l}\text { Fourth coefficient in the correlation for gas-liquid } \\
\mathrm{K} \text { value (KV4), }{ }^{\circ} \mathrm{F}\end{array}$ & -15362.5 & -1914.1 \\
\hline $\begin{array}{l}\text { Fifth coefficient in the correlation for gas-liquid } \\
\mathrm{K} \text { value (KV5), }{ }^{\circ} \mathrm{F}\end{array}$ & -459.67 & -459.67 \\
\hline $\begin{array}{l}\text { Partial molar density at reference pressure and } \\
\text { temperature (MOLDEN), lbmol/cft }\end{array}$ & $1.356 \mathrm{E}-01$ & $4.515 \mathrm{E}-02$ \\
\hline $\begin{array}{l}\text { Liquid Compressibility at constant temperature } \\
\text { (CP), 1/psi }\end{array}$ & $3.805 \mathrm{E}-06$ & $3.754 \mathrm{E}-03$ \\
\hline $\begin{array}{l}\text { First coefficient of the thermal expansion } \\
\text { coefficient }(\mathrm{CT} 1), 1 /{ }^{\circ} \mathrm{F}\end{array}$ & $1.660 \mathrm{E}-04$ & $1.910 \mathrm{E}-03$ \\
\hline
\end{tabular}


TABLE 3.7-TEMPERATURE - VISCOSITY RELATIONSHIP FOR SAN ARDO OIL

\begin{tabular}{|c|c|}
\hline Temperature $\left({ }^{\circ} \mathrm{F}\right)$ & Viscosity $(\mathrm{cp})$ \\
\hline 50 & 500000 \\
\hline 100 & 20000 \\
\hline 150 & 1500 \\
\hline 200 & 240 \\
\hline 250 & 60 \\
\hline 300 & 20 \\
\hline 350 & 8 \\
\hline 400 & 3.5 \\
\hline
\end{tabular}

5. Relative permeability data

Temperature-dependent relative permeability data is used in San Ardo model. Fig.

3.11 and Fig. 3.12 show water-oil and gas-oil relative permeability plots of San Ardo oil at four temperatures.
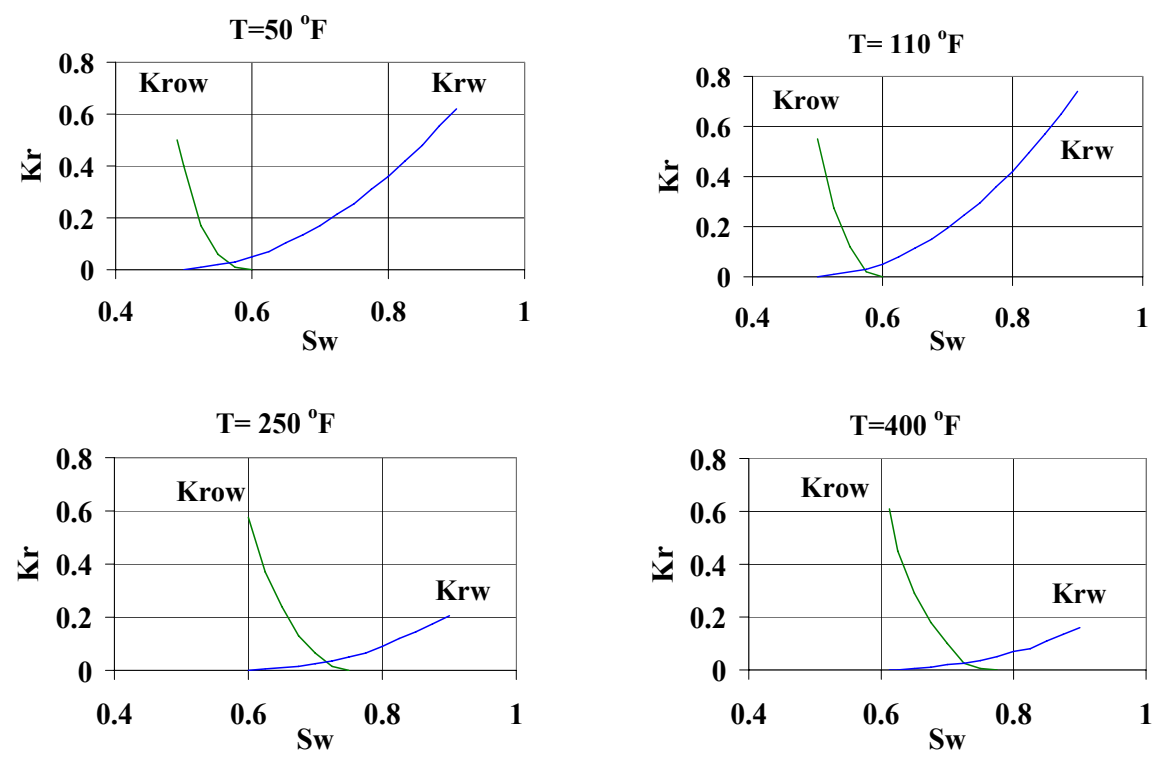

Fig. 3.11-Water-oil relative permeability curves with temperature dependence, San Ardo model. 

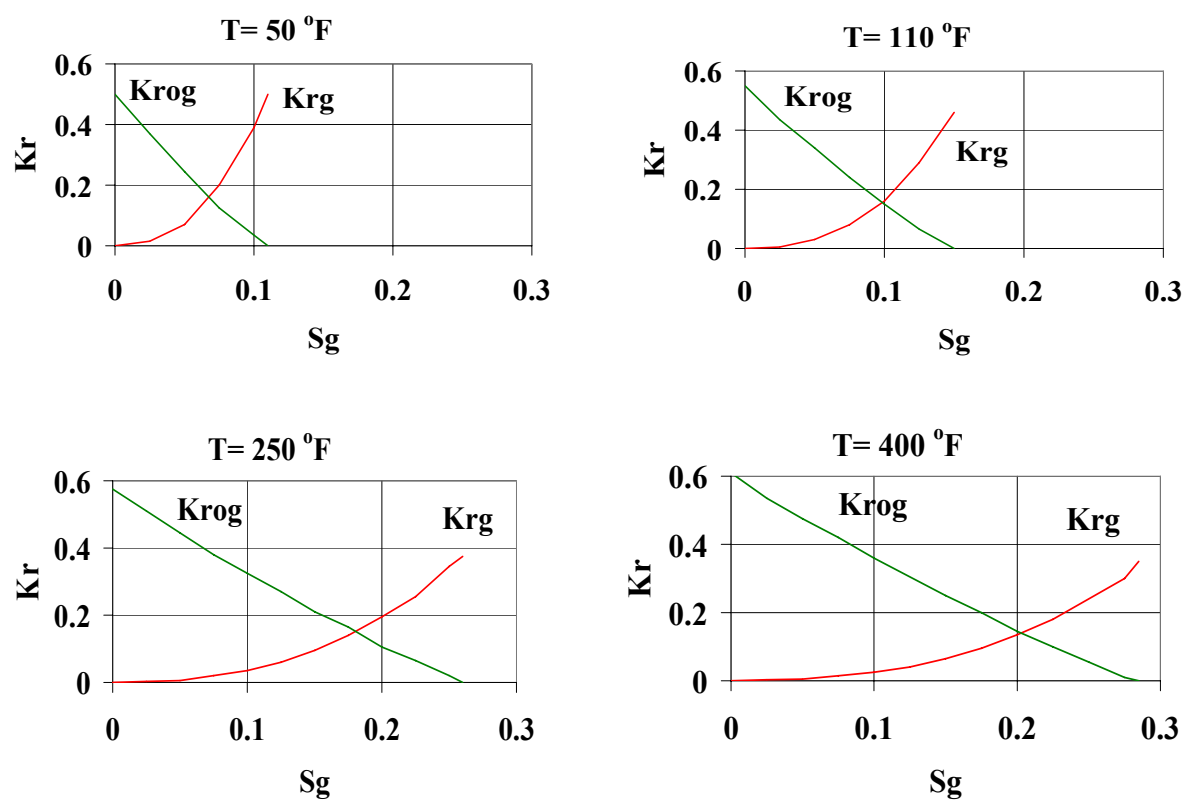

Fig. 3.12-Gas-oil relative permeability curves with temperature dependence, San Ardo model.

6. Operating conditions

Steam is injected at a temperature of $582.3^{\circ} \mathrm{F}$. The quality of the steam at bottom hole condition is 0.8 . Minimum Bottom hole pressure at producer is $15 \mathrm{psia}$.

\subsection{Hamaca Simulation Model}

Hamaca model simulates one-eighth of a five-spot repeatable pattern described as follows. ${ }^{19}$

1. Initial reservoir properties

Initial reservoir properties for Hamaca model are given in Table 3.8. 
TABLE 3.8-INITIAL RESERVOIR PROPERTIES FOR HAMACA MODEL

\begin{tabular}{|l|c|c|}
\hline \multicolumn{1}{|c|}{ Properties } & Values & Units \\
\hline Initial pressure & 275 & $\mathrm{psia}$ \\
\hline Initial temperature & 125 & ${ }^{\circ} \mathrm{F}$ \\
\hline Net oil sand thickness & 100 & $\mathrm{ft}$ \\
\hline Initial oil saturation & 83.2 & $\%$ \\
\hline Initial water saturation & 16.8 & $\%$ \\
\hline Permeability & 12000 & $\mathrm{md}$ \\
\hline Porosity & 30 & $\%$ \\
\hline In-situ oil viscosity at $125^{\circ} \mathrm{F}$ & 25000 & $\mathrm{cp}$ \\
\hline
\end{tabular}

2. Simulation model grid

$45 \times 23 \times 8$ grid system is used to simulate one-eighth of a 10 -acre five-spot repeatable pattern. Fig. 3.8 shows this grid system. The cell dimensions are $\mathrm{i}=$ $10.61 \mathrm{ft}, \mathrm{j}=10.61 \mathrm{ft}$ and $\mathrm{k}=12.5 \mathrm{ft}$.

3. Rock properties

- Thermal conductivity of reservoir $=24 \mathrm{BTU} /\left(\mathrm{ft}-\mathrm{D}-{ }^{\circ} \mathrm{F}\right)$

- Heat capacity of reservoir $=35 \mathrm{BTU} /\left(\mathrm{ft}^{3}\right.$ of rock- $\left.{ }^{\circ} \mathrm{F}\right)$

- Heat capacity of overburden and underburden $=60 \mathrm{BTU} /\left(\mathrm{ft}^{3}\right.$ of rock- $\left.{ }^{\circ} \mathrm{F}\right)$

4. Fluid properties

Water properties. Pure water is assumed and standard water properties are used.

Oil properties. Density at standard condition is $63.18 \mathrm{lbm} / \mathrm{ft}^{3}$. Compressibility is 5 $\times 10^{-6} \mathrm{psi}^{-1}$. The molecular weight is 511.78 . Table 3.9 gives dead oil viscosity value for Hamaca's oil. 
TABLE 3.9-TEMPERATURE - VISCOSITY RELATIONSHIP FOR HAMACA OIL

\begin{tabular}{|c|c|}
\hline Temperature $\left({ }^{\circ} \mathrm{F}\right)$ & Viscosity (cp) \\
\hline 122 & 25000.00 \\
\hline 170 & 8077.48 \\
\hline 190 & 3047.18 \\
\hline 210 & 1277.60 \\
\hline 230 & 588.57 \\
\hline 240 & 412.51 \\
\hline 260 & 214.80 \\
\hline 280 & 120.05 \\
\hline 300 & 71.46 \\
\hline 320 & 44.99 \\
\hline 340 & 29.79 \\
\hline 360 & 20.62 \\
\hline 370 & 17.42 \\
\hline 380 & 14.86 \\
\hline 390 & 12.78 \\
\hline 400 & 11.09 \\
\hline 410 & 9.70 \\
\hline 420 & 8.54 \\
\hline 430 & 7.58 \\
\hline 440 & 6.77 \\
\hline 450 & 6.09 \\
\hline 460 & 5.50 \\
\hline 470 & 5.01 \\
\hline 480 & 4.58 \\
\hline 490 & 4.20 \\
\hline 500 & 3.88 \\
\hline 1000 & 3.88 \\
\hline
\end{tabular}

5. Relative permeability data

Fig. 3.13 and Fig. 3.14 show oil-water and gas-oil relative permeability plots used in the simulation model. Temperature dependent relative permeability data were not available. 


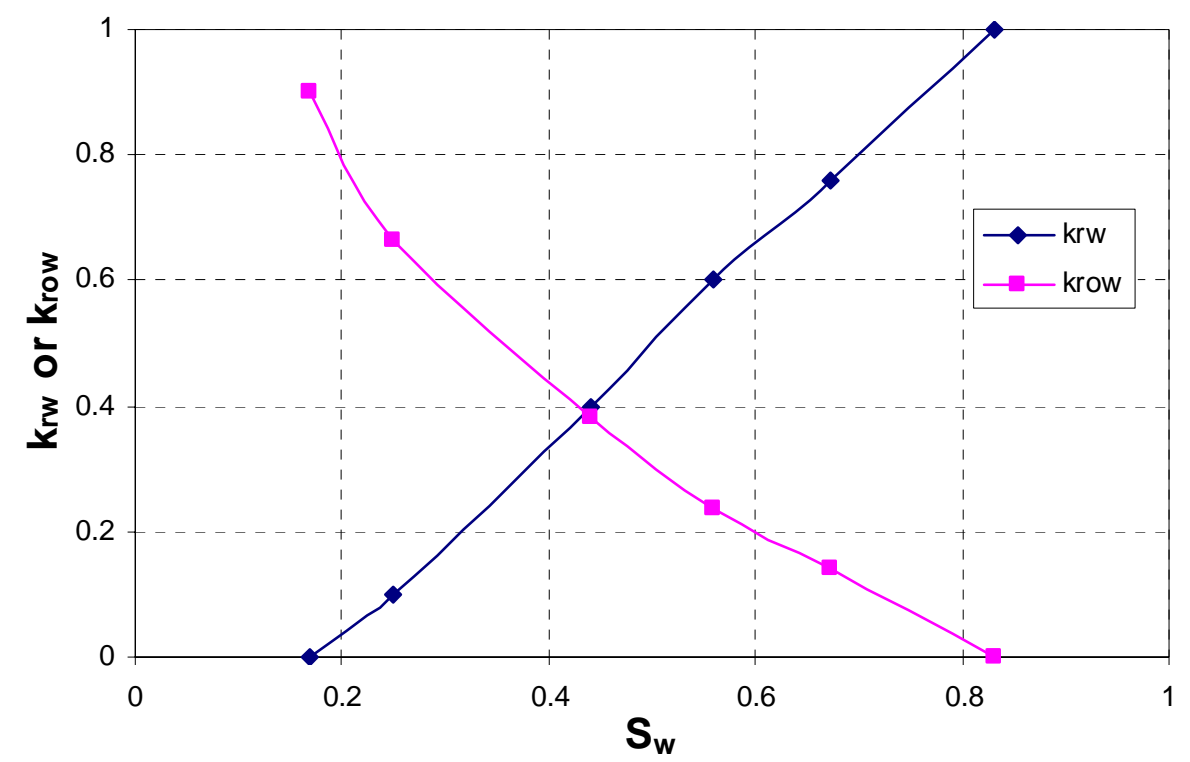

Fig. 3.13-Water-oil relative permeability, Hamaca model.

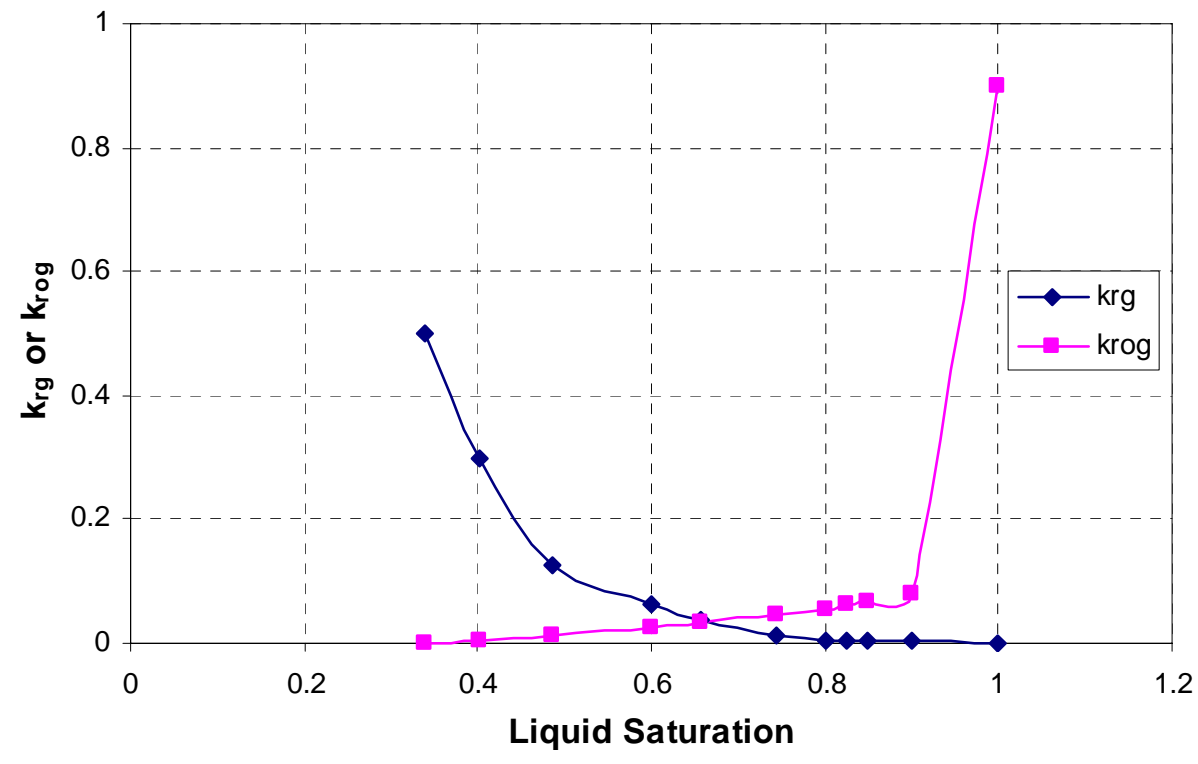

Fig. 3.14-Gas-oil relative permeability, Hamaca model.

\section{Operating conditions}

Steam is injected at a temperature of $600^{\circ} \mathrm{F}$. The quality of the steam at bottom hole condition is 0.8 . Minimum bottom hole pressure at producer is 90 psia. 


\section{CHAPTER IV}

\section{NEW STEAMFLOOD MODEL}

As described in section 2.4, in the Jeff Jones model, the capture factor consists of three components, $A_{c D}, V_{o D}$ and $V_{p D}$. The first two components had to be modified to obtain satisfactory match of oil production rate based on the new model and simulation. The component $V_{O D}$ in the new model is unchanged from that in the Jeff Jones model because we have only studied the case where initial gas saturation is zero. Modification of $A_{c D}$ and $V_{o D}$ is described in the following.

First, as in the Jeff Jones model, oil production consists of three stages (Stage I, II and III) as schematically shown in Fig. 4.1.

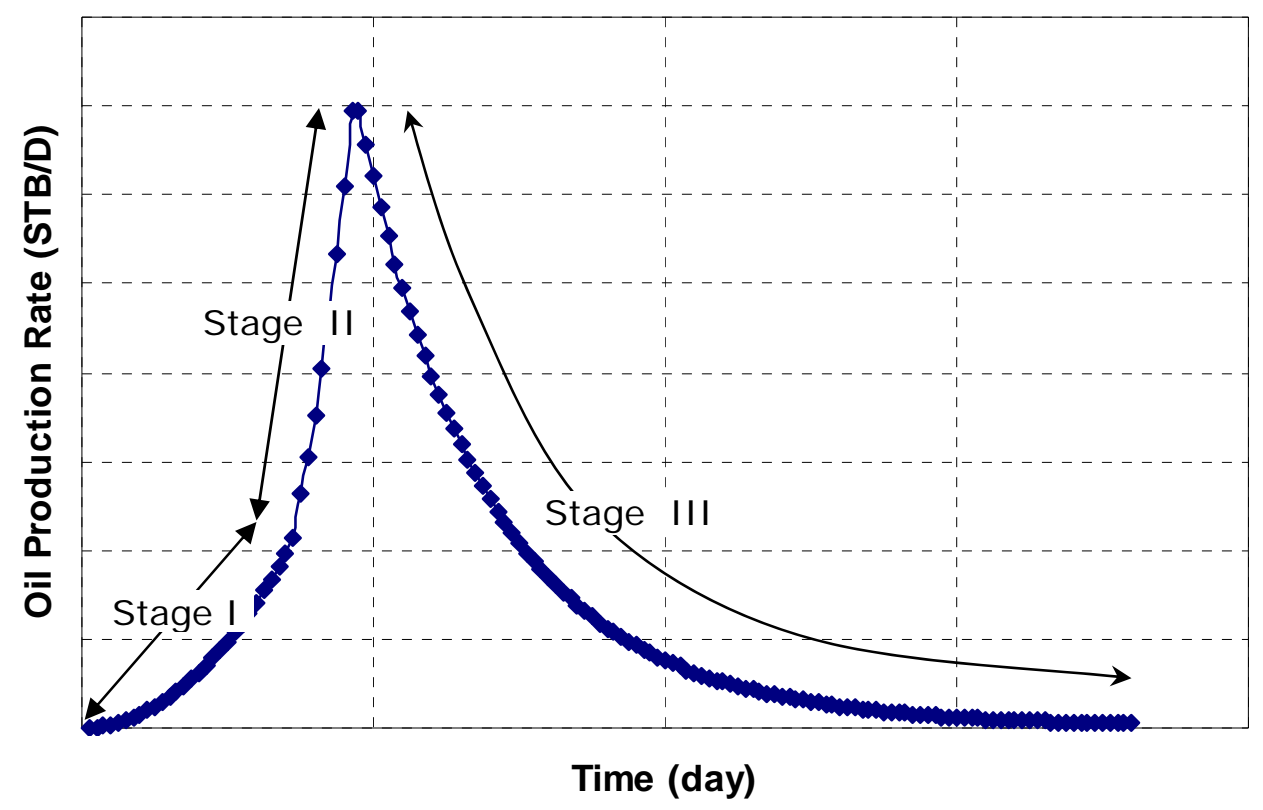

Fig. 4.1-New model: three different stages of oil production under steam drive. 
Stage I is related to cold oil production. As described by Jeff Jones, this stage is dominated by initial oil viscosity and possibly is affected by reservoir fillup if a significant initial gas saturation exists. During reservoir fillup, free gas initially in the reservoir is displaced by steam injected. This process ends after all of the moveable gas is displaced from the reservoir. $V_{p D}$ is the capture factor component that describes this reservoir fillup phenomenon. This new model uses the same $V_{p D}$ expression as given by the Jeff Jones model:

$V_{p D}=\left(\frac{V_{s, i n j} \times 5.62}{43,560 A h_{n} \phi S_{g}}\right)^{2}$.

(limits: $0 \leq V_{p D} \leq 1.0$ and $V_{p D}=1.0$ at $S_{g}=0$ )

$A_{C D}$ expresses viscosity and area dependence in oil production rate for the Stage I. Based on Jeff Jones model, $A_{c D}$ is given by

$$
A_{c D}=\left[\frac{A_{s}}{A\left\{0.11 \ln \left(\mu_{o i} / 100\right)\right\}^{1 / 2}}\right]^{2} .
$$

(limits: $0 \leq A_{c D} \leq 1.0$ and $A_{c D}=1.0$ at $\mu_{o} \leq 100 \mathrm{cp}$ )

In this study, we found that steam injection rate has quite a significant effect on oil production rate in Stage I, and thus on $A_{c D}$. From Eq. 4.2, it can be seen that the constant in the denominator, 011 , would have to vary with steam injection rate. In the new model, this constant is replaced by $\alpha$ as follows.

$$
A_{c D}=\left[\frac{A_{s}}{A\left\{\alpha \ln \left(\mu_{o i} / 100\right)\right\}^{1 / 2}}\right]^{2} .
$$

(limits: $0 \leq A_{c D} \leq 1.0$ and $A_{c D}=1.0$ at $\mu_{o} \leq 100 \mathrm{cp}$ )

Correlation between $\alpha$ and steam injection rate was developed by making several simulation runs of SPE comparative model, each run with a different steam injection rate. By trial-and-error, $\alpha$ for each steam injection rate was determined as that which gave the 
best match of oil production rate based on the new model and simulation. A graph of $\alpha$ versus steam injection rate is shown in Fig. 4.2, indicating the following linear relationship:

$\alpha=0.00015 i_{s}+0.05$.

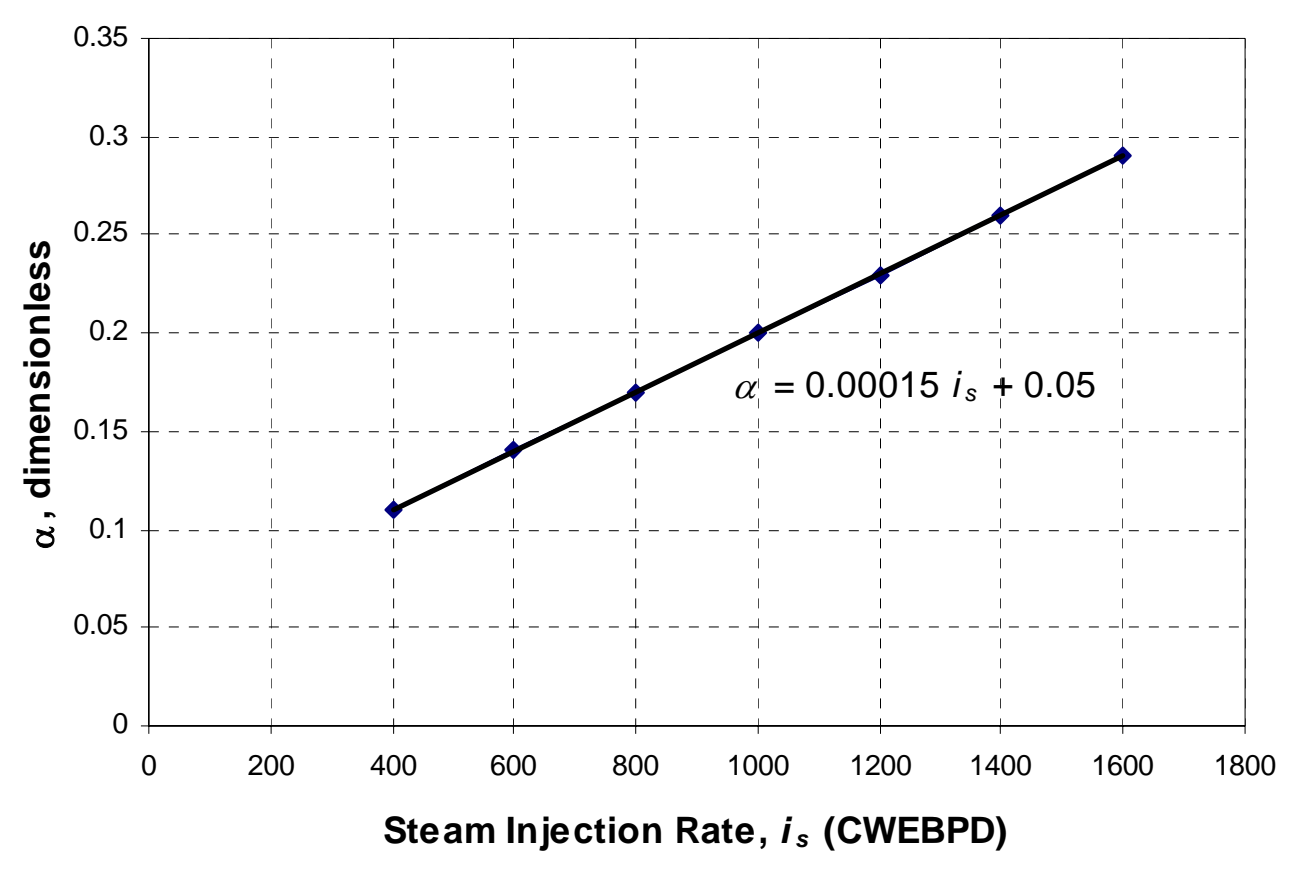

Fig. 4.2- $\alpha$ vs injection rate relationship.

Note that, in the new model, calculations of $A_{s}$ and $Q_{i n j}$ are as in the Jeff Jones model, as given in Eq. 2.6 and Eq. 2.7.

Stage II is related to the oil bank breakthrough. Oil bank is the region where a large amount of hot oil with lower viscosity is accumulated. At the beginning of steamflooding process, the oil bank region is formed near the injector. Producer still produces cold oil near to it which is not affected by the steam temperature. As the volume of steam injected increases, the oil bank region is pushed towards the producer. At the 
same time, the oil viscosity in the reservoir continues to decrease, increasing the oil production rate.

When the oil bank region arrives at the producer, a large amount of the hot oil breaks through and results in a sharp increase in oil production. Oil production rate at this time will be significantly higher than the Myhill-Stegemeier oil displacement rate. This happens because the oil displaced previously, which is not produced but stored in the oil bank region, is produced at this time.

To account for the viscosity change due to heating, the viscosity value for $A_{c D}$ in Stage II is described as an average viscosity between hot oil region and cold oil region as given in Eq. 4.5.

$\bar{\mu}_{o}=\frac{\mu_{o i}\left(A-A_{s}\right)+\mu_{o T_{\text {steam }}} A_{s}}{A}$.

With this average viscosity value, the value of $A_{c D}$ will increase faster to properly describe the oil bank breakthrough. $A_{c D}$ expression for Stage II of the new model is:

$A_{c D}=\left[\frac{A_{s}}{A\left\{\alpha \ln \left(\bar{\mu}_{o} / 100\right)\right\}^{1 / 2}}\right]^{4}$

(limits: $1.0<A_{c D} \leq A_{c D \text { max }}$ and $A_{c D}=1.0$ at $\bar{\mu}_{o} \leq 100 \mathrm{cp}$ )

Stage III is dominated by the remaining mobile portion of original oil-in-place as expressed in $V_{o D} . V_{o D}$ of the Jeff Jones model is given as

$V_{o D}=\left(1-\frac{N_{d}}{N} \frac{S_{o i}}{\Delta S_{o}}\right)^{1 / 2}$.

(limits: $0 \leq V_{o D} \leq 1.0$ ) 
In this study, we observed that the simulation results always gave exponential trends for oil rate decline in the Stage III. Thus, the Jeff Jones $V_{O D}$ expression was modified from its square-root format to an exponential form. Also, in the Jeff Jones model, $V_{o D}$ may decline from a value of 1 in Stage I, while in the new model, $V_{o D}$ starts to decline only at start of stage III. Thus, in the new model, $V_{o D}$ is expressed as follows.

$V_{o D}=A_{c D \max }\left\{\operatorname{Exp}\left[-\beta\left(\frac{N_{D_{\max }}}{N} \frac{S_{o i}}{\Delta S_{o}}\right)\right]\right\}$.

(limits: $A_{c D \text { max }} \geq V_{o D} \geq 0$ )

where, $A_{c D_{\max }}$ is $A_{c D}$ where oil production rate = injection rate, and $N_{D_{\max }}=N_{D}$ from Myhill-Stegemeier calculation - $N_{D}$ up to $A_{c D \text { max }}$.

We found that production decline rate was dependent on the steam injection rate. Thus, as can be seen in Eq. 4.8, the exponent had to vary with steam injection rate. To do this, we incorporated the parameter, $\beta$, in the exponent. We made several simulation runs using the SPE comparative solution model. By trial-and-error, we found that $\beta$ is linearly dependent on a dimensionless parameter, $N_{c}$, as shown in Fig. 4.3 and the following equation.

$\beta=17.93 N_{c}+1.3401$.

$N_{c}$ is the ratio of the volume of moveable oil to that of steam injection up to the critical time, $t_{c}$, as given in Eq. 4.10:

$$
N_{c}=\frac{7758 A h \phi\left(1-S_{o r}-S_{w c}\right)}{365 i_{s} t_{c}}
$$

where 
$t_{c}=\frac{t_{c D} h_{t}{ }^{2} M_{1}{ }^{2}}{35040 k_{h} M_{2}}$.

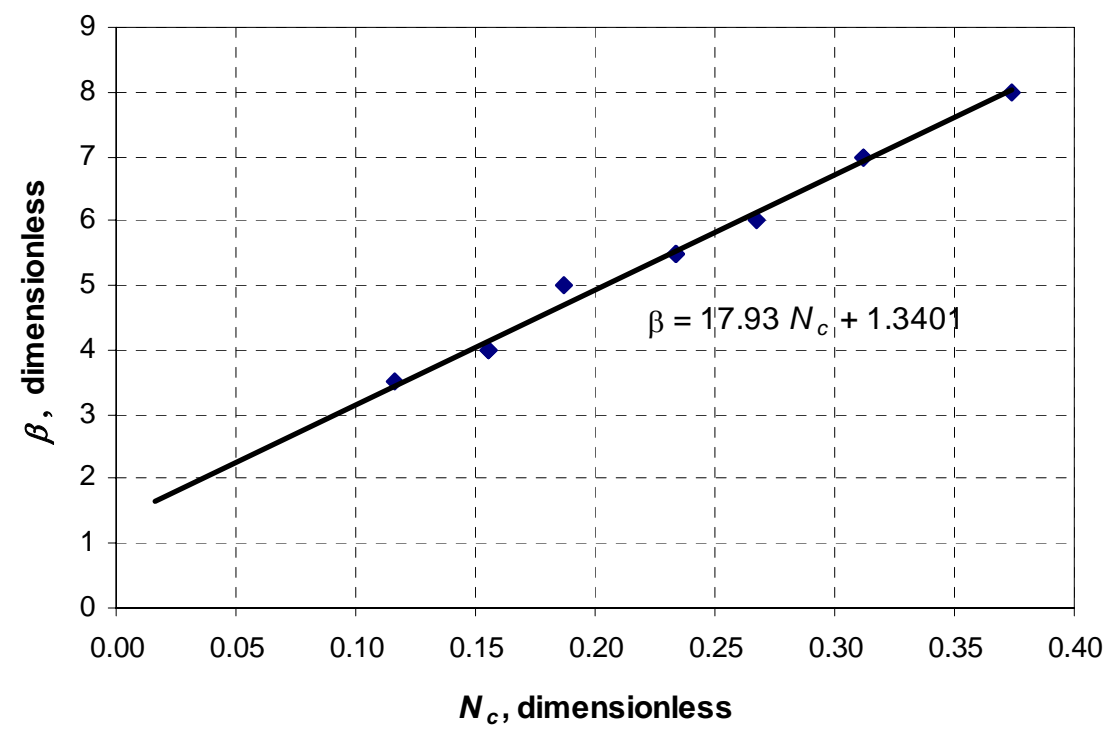

Fig. 4.3- $\beta$ vs $N_{c}$ relationship.

In this study, the two components of capture factor, $A_{c D}$ and $V_{o D}$, were developed using different simulation cases of SPE comparative model. The new model using these new components was then tested for the San Ardo and Hamaca models. Production rates based on the new model and simulation are in good agreement, verifying the validity of the new steamflood model, as described in section 4.2.

\subsection{New Model Calculation Steps}

This section gives in detail the calculation steps for the new model. These calculation steps are divided into two sub-sections:

1. Displacement Calculations

2. Production Calculations 


\subsubsection{Displacement Calculations}

Oil displacement calculations used in the new model is basically the method proposed by Myhill and Stegemeier. ${ }^{5}$ In the Myhill-Stegemeier method, the oil displacement rate is a function of cumulative oil steam ratio $\left(F_{o s}\right)$. This cumulative oil steam ratio is then a function of overall thermal efficiency $\left(E_{h s}\right)$. Overall thermal efficiency can be calculated by the following formula:

$$
\begin{aligned}
E_{h s}= & \frac{1}{t_{D}}\left\{G\left(t_{D}\right)+\left(1-f_{h v}\right) \frac{U\left(t_{D}-t_{c D}\right)}{\sqrt{\pi}}\left[2 \sqrt{t_{D}}-2\left(1-f_{h v}\right) \sqrt{t_{D}-t_{c D}}\right.\right. \\
& \left.\left.-\int_{0}^{t_{c D}} \frac{e^{x} \operatorname{erfc} \sqrt{x} d x}{\sqrt{t_{D}-x}}-\sqrt{\pi} G\left(t_{D}\right)\right]\right\} .
\end{aligned}
$$

The dimensionless time, $t_{D}$, is given by

$t_{D}=\frac{35040 \times k_{h} \times t \times M_{2}}{h_{t}^{2} \times M_{1}^{2}}$,

and the function $G\left(t_{D}\right)$ is given by

$$
G=2 \sqrt{\frac{t_{D}}{\pi}}-1+e^{t_{D}} \operatorname{erfc} \sqrt{t_{D}}
$$

The $\operatorname{erf} \mathcal{c}\left(\sqrt{t_{D}}\right)$ term in Eq. 4.12 and Eq. 4.14 can be approximate from Effinger and Wasson: ${ }^{20}$

$$
\begin{aligned}
e r f c \sqrt{t_{D}}= & \left(0.254829592 K-0.284496736 K^{2}+1.421413741 K^{3}\right. \\
& \left.-1.453152027 K^{4}+1.061405429 K^{5}\right) e^{-t_{D}}
\end{aligned}
$$

where

$$
K=\frac{1}{1+0.3275911 \sqrt{t_{D}}} .
$$

The dimensionless critical time is calculated from the following expression: 
$e^{t_{c D}} \operatorname{erfc} \sqrt{t_{c D}}=1-f_{h v}$,

where $f_{h v}$, the fraction of the heat injected in latent form, is given by:

$$
f_{h v}=\left(1+\frac{C_{w} \Delta T}{f_{s} h_{f g}}\right)^{-1}
$$

The unit function, $U(x)$, in Eq. 4.12 is 0 for $x<0$ and 1 for $x>0$.

Eq. 4.19 gives the relationship between overall thermal efficiency, $E_{h s}$, and cumulative oil steam ratio, $F_{o s}$ :

$$
F_{o s}=\frac{\rho_{w} C_{w}}{M_{1}} \frac{h_{n}}{h_{t}} \Delta S_{o} \phi\left(1+F_{h D}\right) E_{h s} .
$$

$F_{h D}$ is the dimensionless steam quality:

$F_{h D}=\frac{f_{s} h_{f g}}{C_{w} \Delta T}$.

Latent heat of vaporization, $h_{f g}$, is calculated from Ejiogu-Fiori equation ${ }^{21}$ as follows,

$$
h_{f g}=h_{s v}-h_{s c} .
$$

Calculation of the enthalpy of condensate, $\mathrm{h}_{\mathrm{sc}}$, is divided into two pressure ranges:

$$
h_{s c}=77.036 p_{s}^{0.28302}
$$

where $500 \leq p \leq 1500$ psia, and

$h_{s c}=0.12038 p_{s}+430.984$,

where $1500 \leq p \leq 2500$ psia.

Enthalpy of vapor, $h_{s v}$, can be calculated as

$h_{s v}=1204.8-0.000197697\left(p_{s}-453.23\right)^{1.73808}$.

With the preceding information, cumulative oil displacement is calculated as

$N_{d}=F_{o s} V_{s, i n j}$. 
Oil displacement rate can be estimated from the time derivative of cumulative oil displacement function:

$q_{o d}=\frac{N_{d_{n}}-N_{d_{n-1}} .}{\Delta t}$.

\subsubsection{Production Calculations}

The oil production rate is derived from the oil displacement rate as follows,

$q_{o}=q_{o d} A_{c D} V_{o D} V_{p D}$.

These three factors, $A_{c D}, V_{o D}$ and $V_{p D}$ are the three components of the capture factor. Each represents a fraction of the displaced oil that will be produced (or "captured"). $V_{p D}$ is given in Eq. 4.1 $A_{C D}$ is given in Eq. 4.3 and Eq. 4.6 and $V_{o D}$ is given in Eq. 4.8.

Table 4.1 gives comparisons of $A_{c D}, V_{o D}$ and $V_{p D}$ between new model and Jones model. Program listing (in MS Visual Basic) of the new model is given in Appendix E.

\subsection{Oil Production Rate Performance}

13 different cases were conducted to verify the validity of the new model:

1. $\mathrm{SPE}$ comparative model, area $=2.5 \mathrm{ac}$, steam injection rate $=400 \mathrm{~B} / \mathrm{D}$.

2. SPE comparative model, area $=2.5 \mathrm{ac}$, steam injection rate $=600 \mathrm{~B} / \mathrm{D}$

3. SPE comparative model, area $=2.5 \mathrm{ac}$, steam injection rate $=800 \mathrm{~B} / \mathrm{D}$

4. SPE comparative model, area $=5.0 \mathrm{ac}$, steam injection rate $=600 \mathrm{~B} / \mathrm{D}$

5. SPE comparative model, area $=5.0 \mathrm{ac}$, steam injection rate $=800 \mathrm{~B} / \mathrm{D}$

6. SPE comparative model, area $=5.0 \mathrm{ac}$, steam injection rate $=1000 \mathrm{~B} / \mathrm{D}$

7. SPE comparative model, area $=5.0$ ac. steam injection rate $=1200 \mathrm{~B} / \mathrm{D}$ 
TABLE 4.1-FORMULAS FOR CAPTURE FACTOR COMPONENTS: NEW MODEL AND JONES MODEL

\begin{tabular}{|c|c|c|c|c|c|}
\hline \multirow{2}{*}{ Stage } & \multicolumn{2}{|c|}{$A_{c D}$} & \multicolumn{2}{|l|}{$V_{o D}$} & $V_{p D}$ \\
\hline & New Model & Jones Model & New Model & Jones Model & New Model = Jones Model \\
\hline I & $\begin{array}{l}A_{c D}=\left[\frac{A_{s}}{A\left\{\alpha \ln \left(\mu_{o i} / 100\right)\right\}^{1 / 2}}\right]^{2} \\
\text { limits: } 0 \leq A_{c D} \leq 1.0 \text { and } \\
A_{c D}=1.0 \text { at } \mu_{o} \leq 100 \mathrm{cp} . \\
\text { where, } \\
\alpha=0.00015 i_{s}+0.05\end{array}$ & $\begin{array}{l}A_{c D}=\left[\frac{A_{s}}{A\left\{0.11 \ln \left(\mu_{o i} / 100\right)\right\}^{1 / 2}}\right] \\
\text { limits: } 0 \leq A_{c D} \leq 1.0 \text { and } \\
A_{c D}=1.0 \text { at } \mu_{o} \leq 100 \mathrm{cp} .\end{array}$ & 1 & $\begin{array}{l}V_{o D}=\left(1-\frac{N_{d}}{N} \frac{S_{o i}}{\Delta S_{o}}\right)^{1 / 2} \\
\text { limit: } 0 \leq V_{o D} \leq 1.0\end{array}$ & $\begin{array}{l}V_{p D}=\left(\frac{V_{s, i n j} \times 5.62}{43,560 A h_{n} \phi S_{g}}\right)^{2} \\
\text { limits: } 0 \leq V_{p D} \leq 1.0 \text { and } \\
V_{p D}=1.0 \text { at } \mathrm{S}_{\mathrm{g}}=0\end{array}$ \\
\hline II & $\begin{array}{l}A_{c D}=\left[\frac{A_{s}}{A\left\{\alpha \ln \left(\bar{\mu}_{o} / 100\right)\right\}^{1 / 2}}\right]^{4} \\
\text { limits: } 1.0<A_{c D} \leq A_{c D} \\
\text { and } A_{c D}=1.0 \text { at } \bar{\mu}_{o} \leq 100 \\
\text { cp. } \\
\text { where, } \\
\alpha=0.00015 i_{s}+0.05\end{array}$ & 1 & 1 & $\begin{array}{l}V_{o D}=\left(1-\frac{N_{d}}{N} \frac{S_{o i}}{\Delta S_{o}}\right)^{1 / 2} \\
\text { limit: } 0 \leq V_{o D} \leq 1.0\end{array}$ & 1 \\
\hline III & 1 & 1 & $\begin{array}{l}V_{o D}=A_{c D_{\max }}\left\{\operatorname{Exp}\left[-\beta\left(\frac{N_{D_{\max }}}{N} \frac{S_{o i}}{\Delta S_{o}}\right)\right]\right\} \\
\text { limit: } A_{c D_{\max }}>V_{o D} \geq 0 \\
\text { where, } \\
\beta=17.93 N_{c}+1.3401 \\
N_{c}=\frac{7758 A h\left(1-S_{o r}-S_{w c}\right)}{365 i_{s} c_{c}}\end{array}$ & $\begin{array}{l}V_{o D}=\left(1-\frac{N_{d}}{N} \frac{S_{o i}}{\Delta S_{o}}\right)^{1 / 2} \\
\text { limit: } 0 \leq V_{o D} \leq 1.0\end{array}$ & 1 \\
\hline
\end{tabular}


8. SPE comparative model, area $=10.0 \mathrm{ac}$, steam injection rate $=1000 \mathrm{~B} / \mathrm{D}$

9. $\mathrm{SPE}$ comparative model, area $=10.0 \mathrm{ac}$, steam injection rate $=1200 \mathrm{~B} / \mathrm{D}$

10. $\mathrm{SPE}$ comparative model, area $=10.0 \mathrm{ac}$, steam injection rate $=1400 \mathrm{~B} / \mathrm{D}$

11. SPE comparative model, area $=10.0 \mathrm{ac}$, steam injection rate $=1600 \mathrm{~B} / \mathrm{D}$

12. San Ardo model, area $=10.0 \mathrm{ac}$, steam injection rate $=1600 \mathrm{~B} / \mathrm{D}$

13. Hamaca model, area $=10.0 \mathrm{ac}$, steam injection rate $=1600 \mathrm{~B} / \mathrm{D}$.

Fig. 4.4 to Fig. 4.16 give oil rate production performances from simulation, the Jeff Jones model and new model for all of these cases.

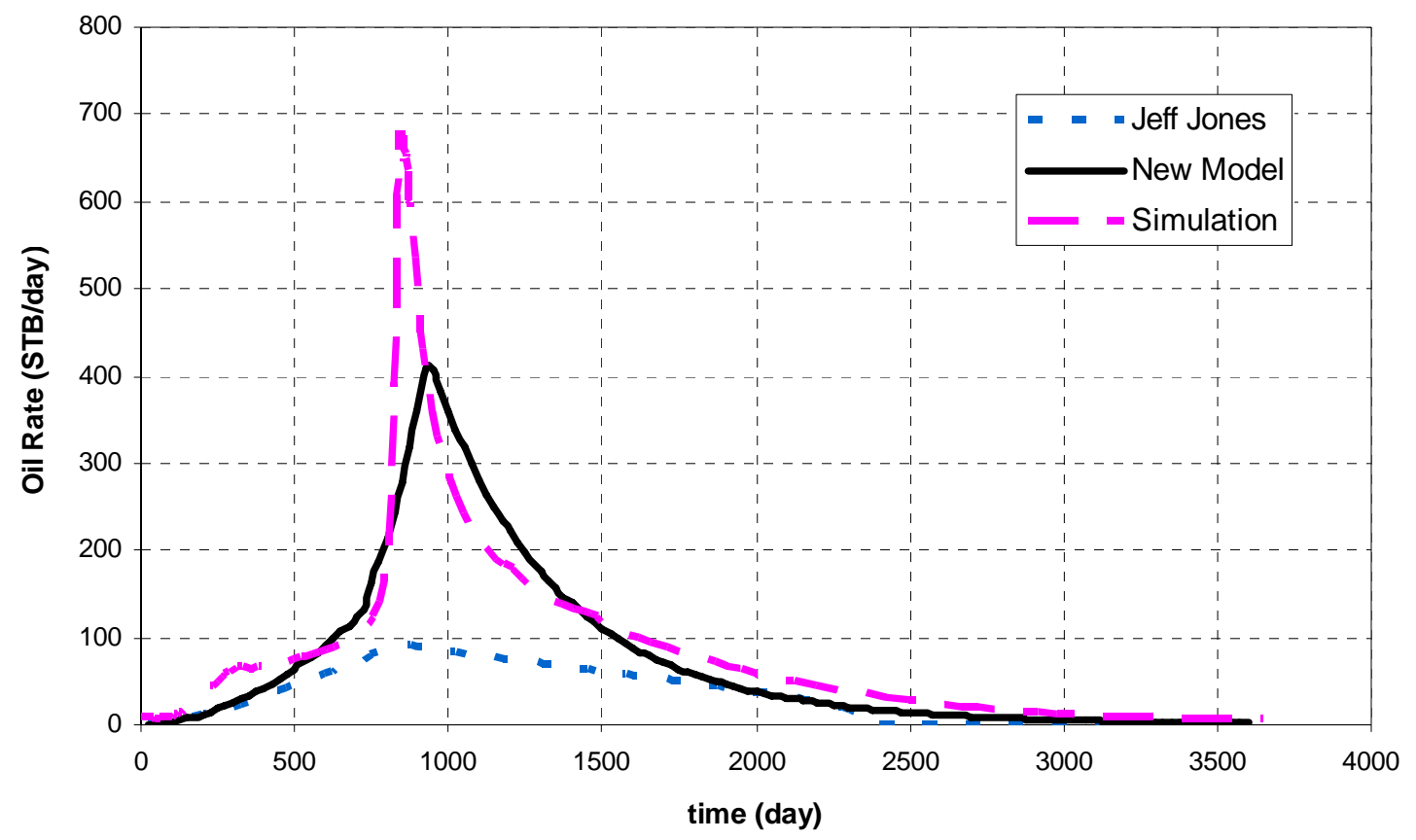

Fig. 4.4-Oil production rate (SPE comparative model, area $=2.5 \mathrm{ac}$, injection rate $=400 \mathrm{~B} / \mathrm{D})$. 


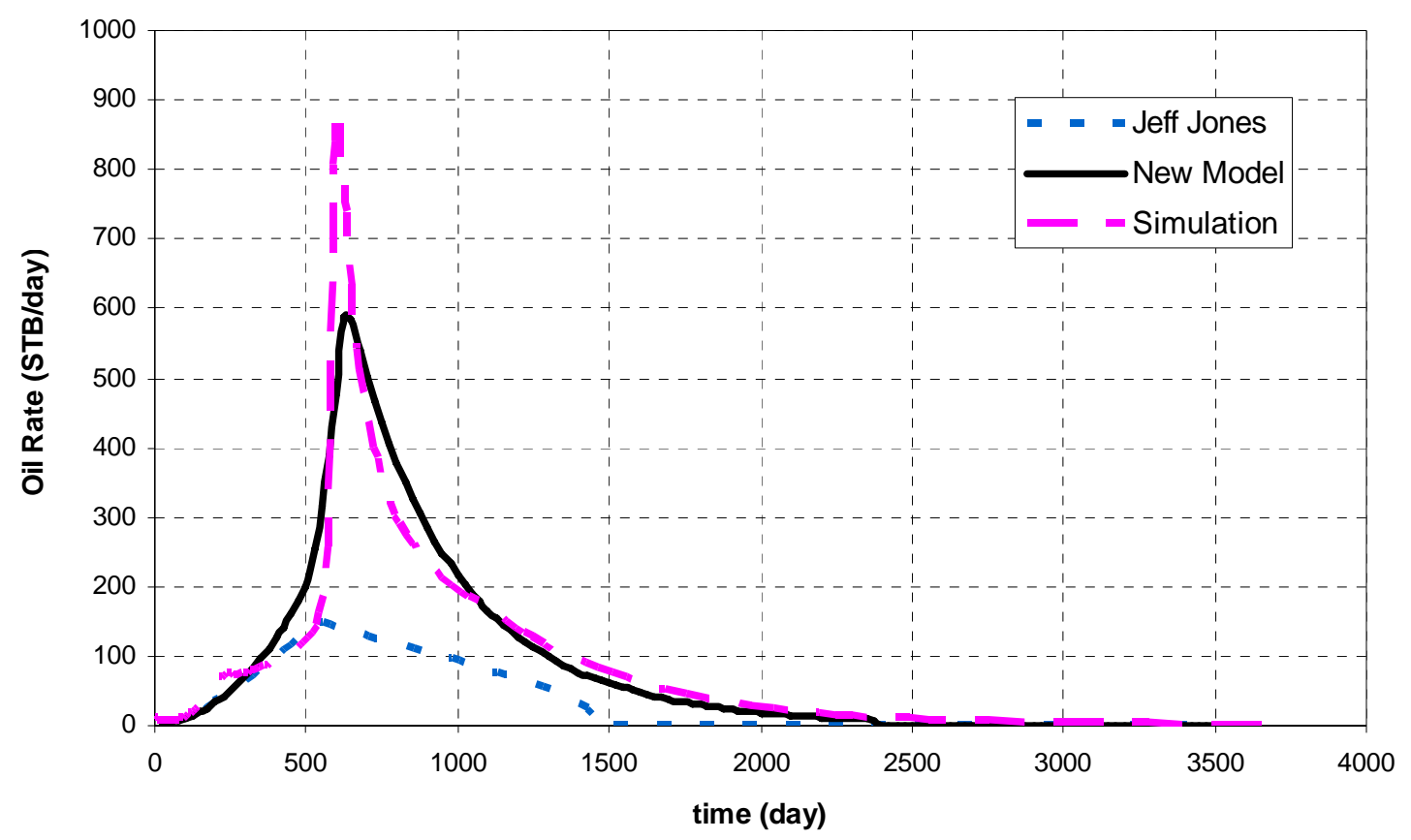

Fig. 4.5-Oil production rate (SPE comparative model, area $=2.5$ ac, injection rate $=$ 600 B/D).

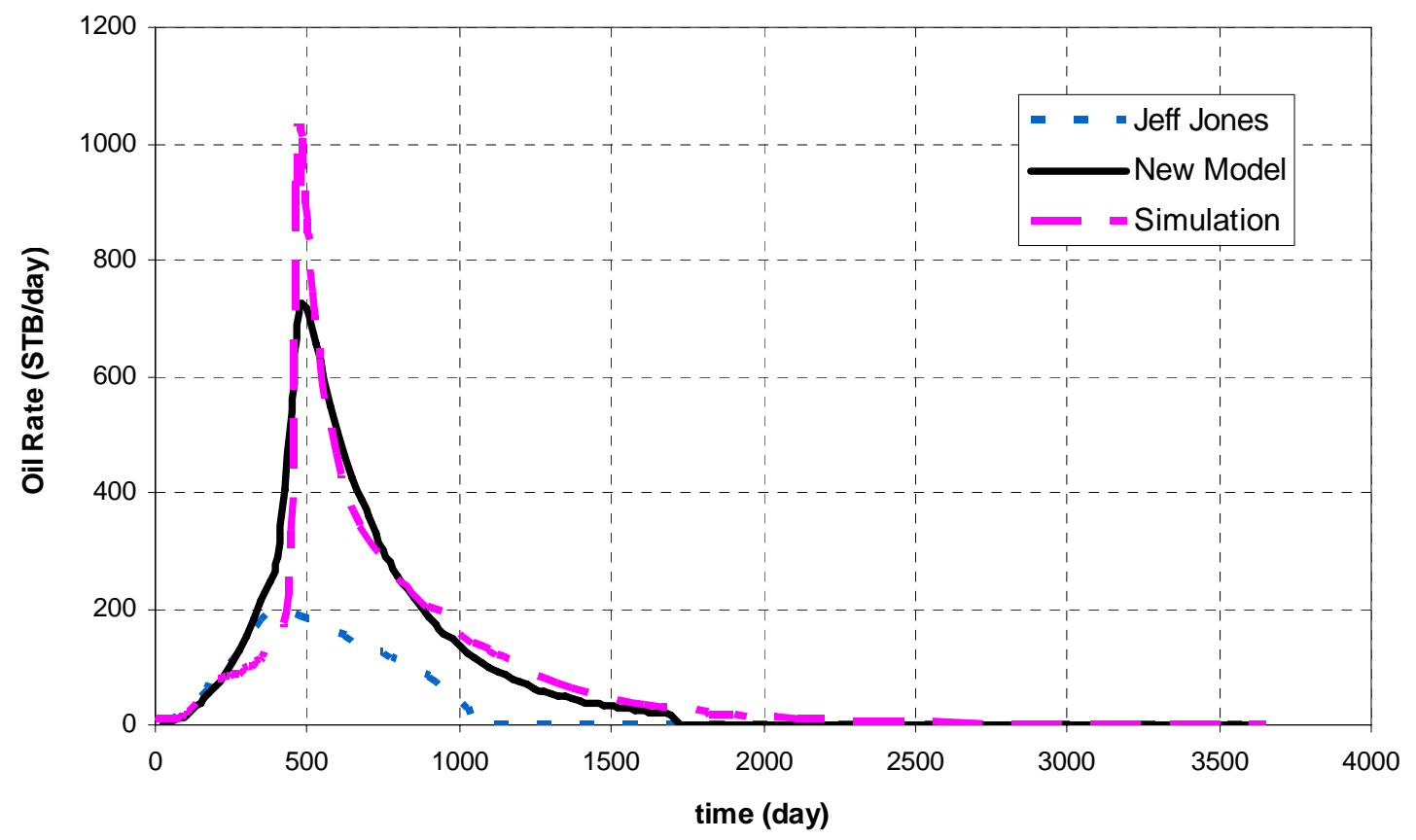

Fig. 4.6-Oil production rate (SPE comparative model, area $=2.5 \mathrm{ac}$, injection rate $=$ 800 B/D). 


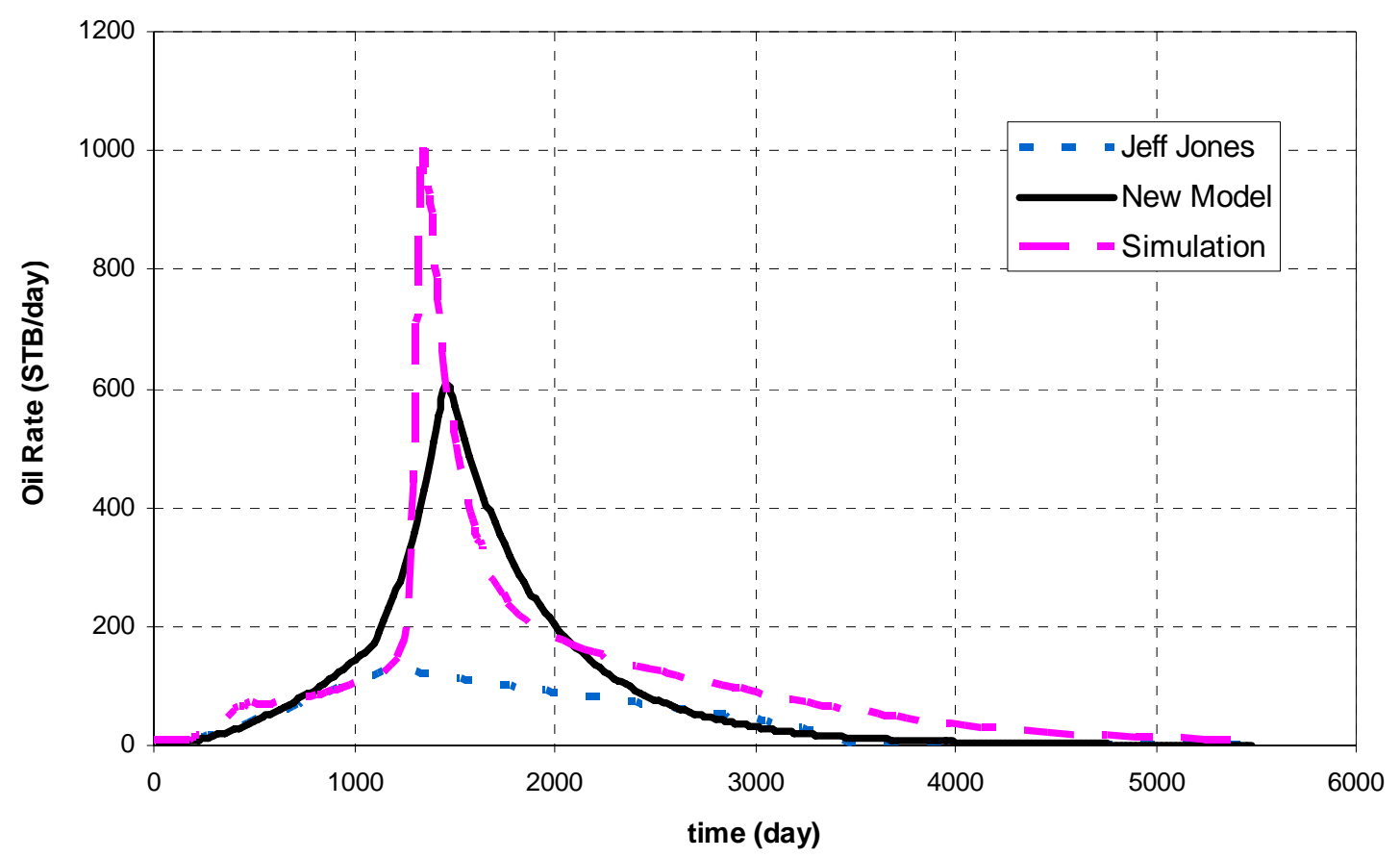

Fig. 4.7-Oil production rate (SPE comparative model, area $=5.0$ ac, injection rate $=$ 600 B/D).

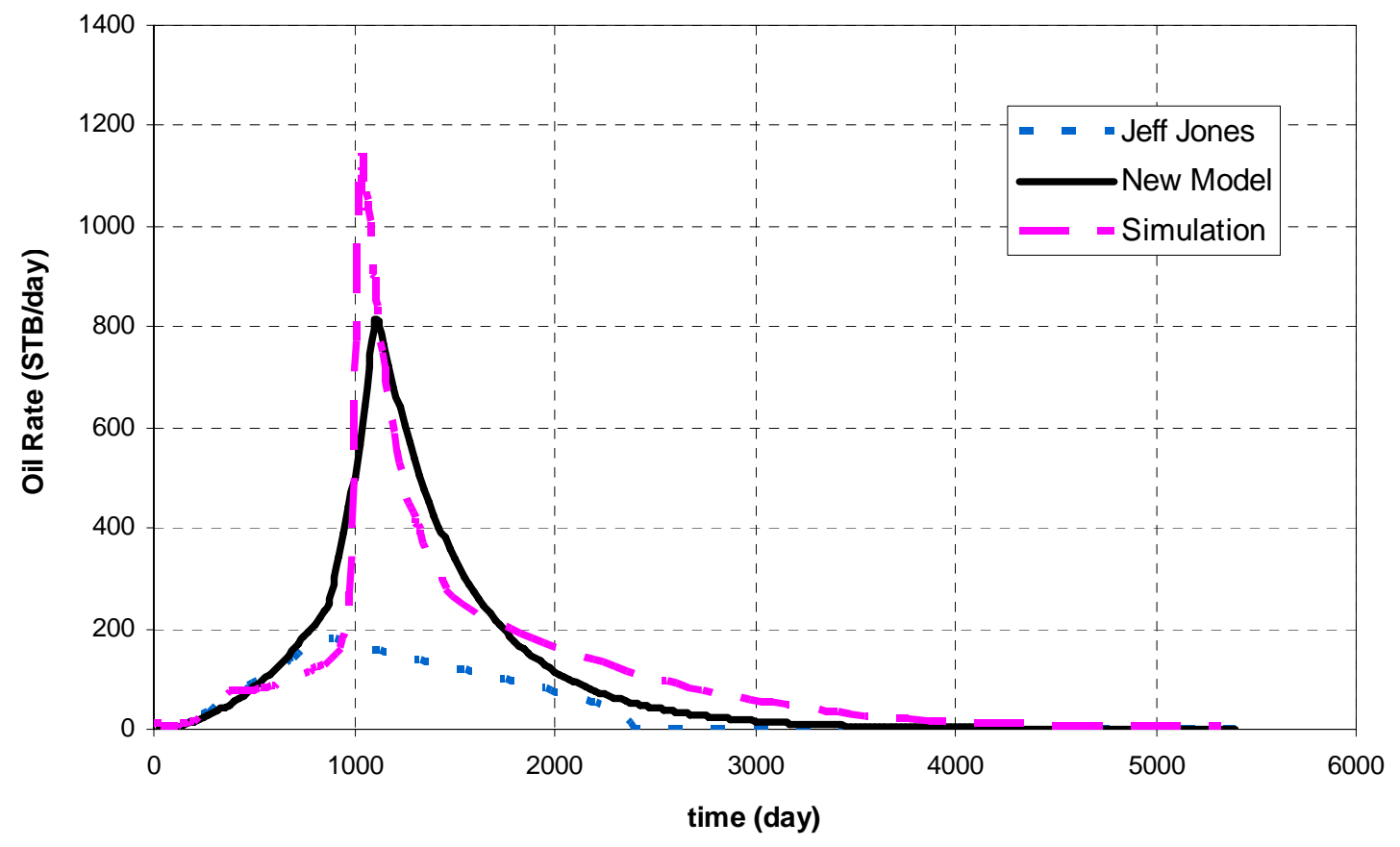

Fig. 4.8-Oil production rate (SPE comparative model, area $=5.0$ ac, injection rate $=$ 800 B/D). 


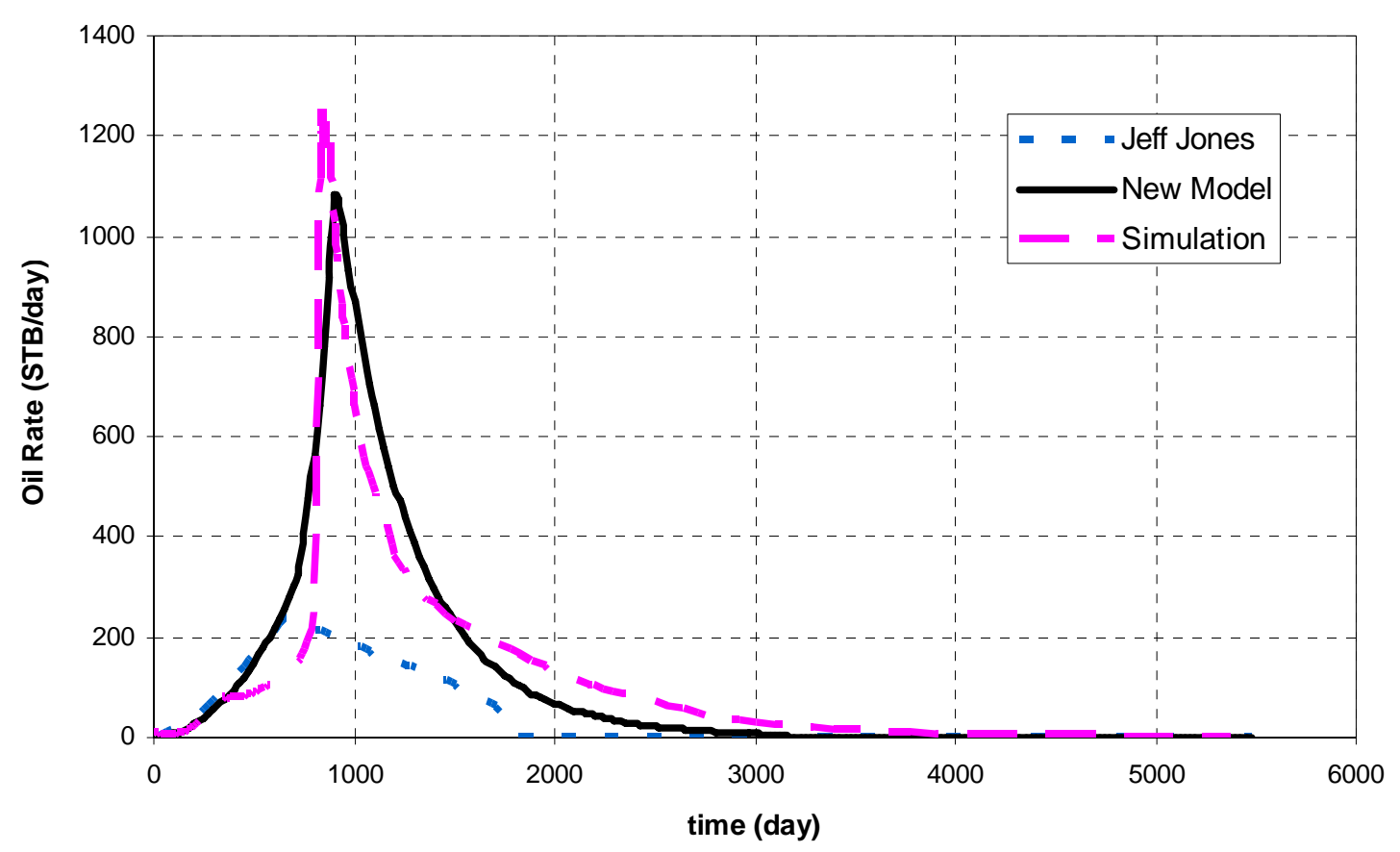

Fig. 4.9-Oil production rate (SPE comparative model, area $=5.0$ ac, injection rate $=$ $1000 \mathrm{~B} / \mathrm{D})$.

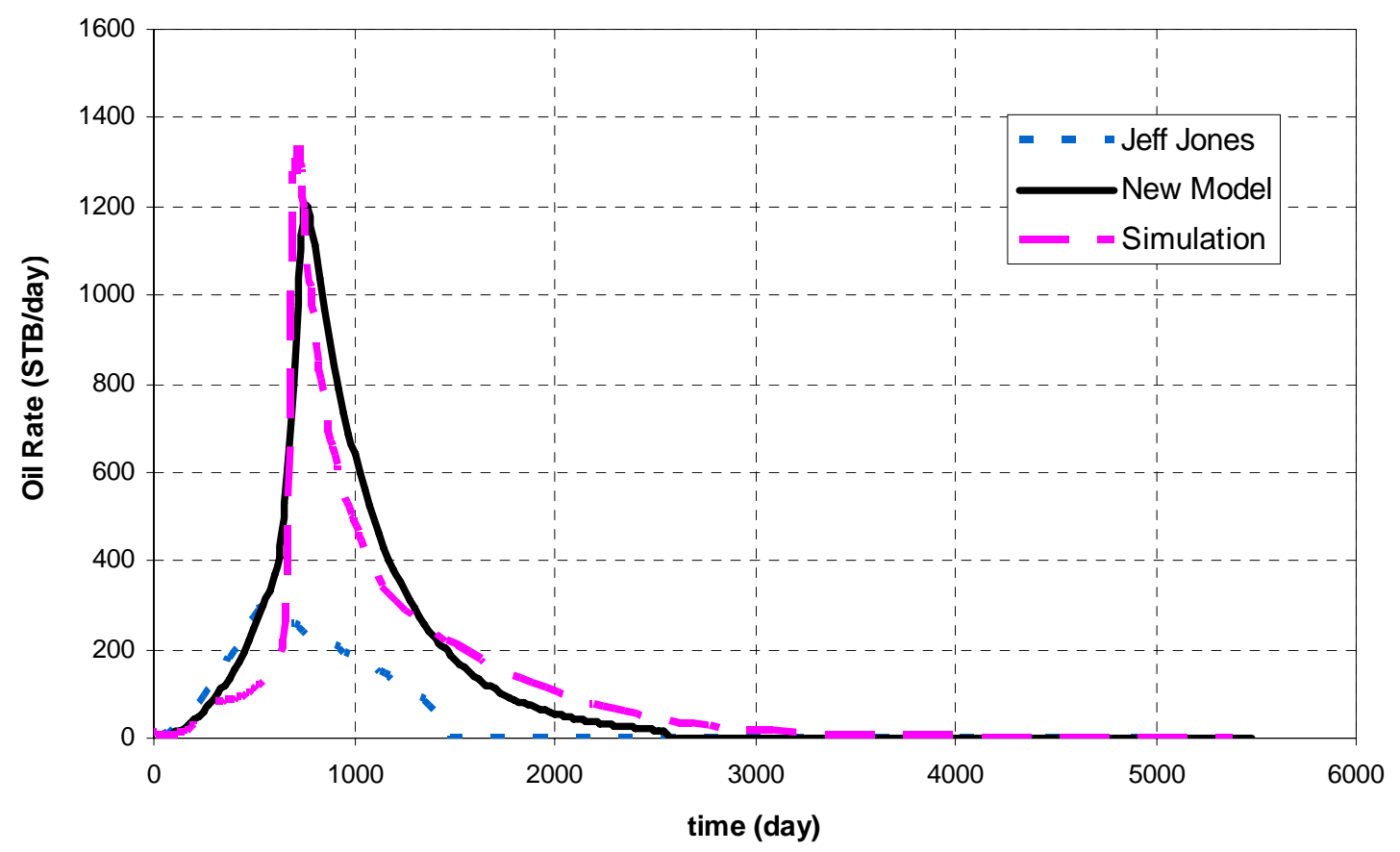

Fig. 4.10-Oil production rate (SPE comparative model, area $=5.0$ ac, injection rate $=1200 \mathrm{~B} / \mathrm{D}$ ). 


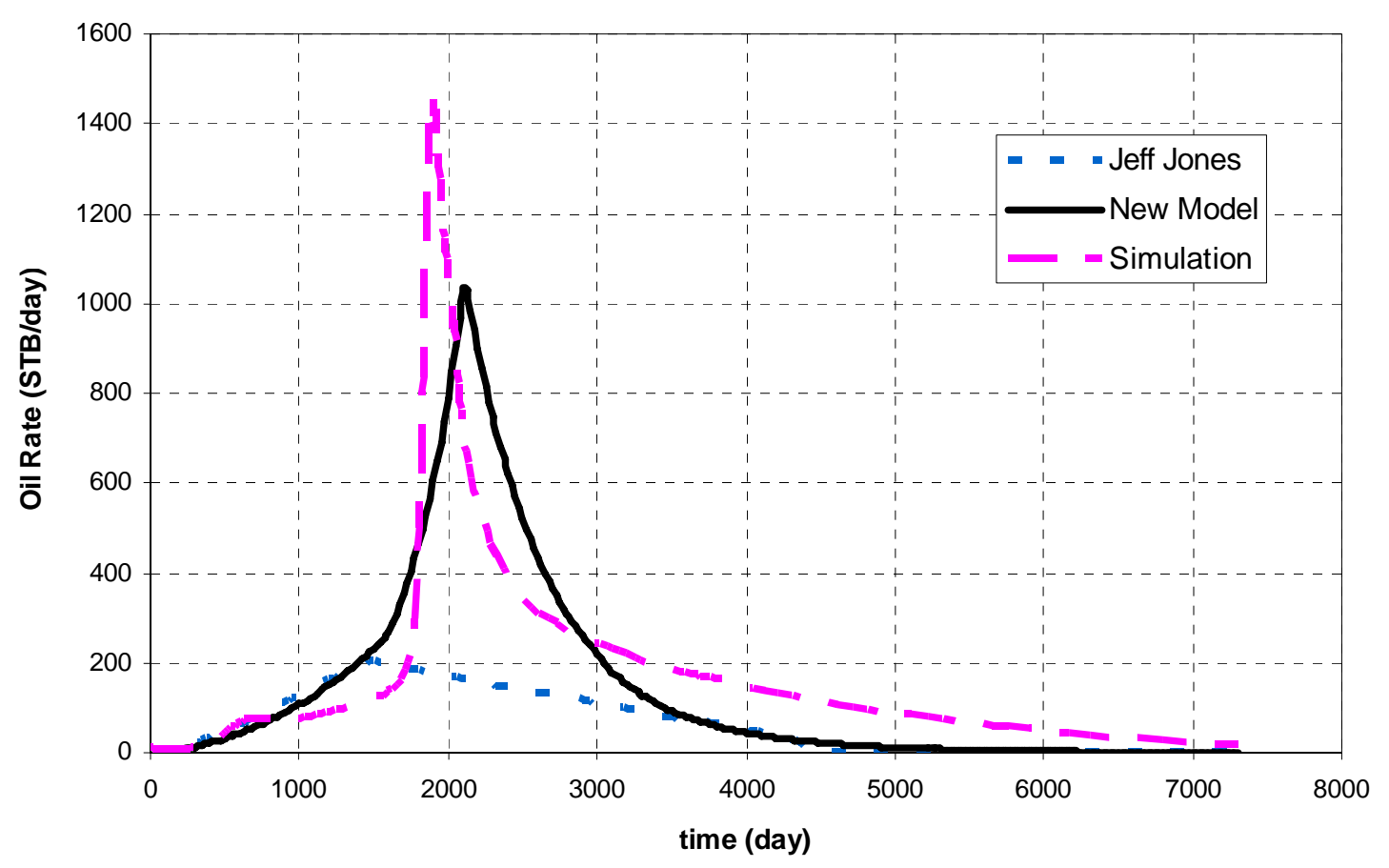

Fig. 4.11-Oil production rate (SPE comparative model, area $=10 \mathrm{ac}$, injection rate $=$ $1000 \mathrm{~B} / \mathrm{D})$.

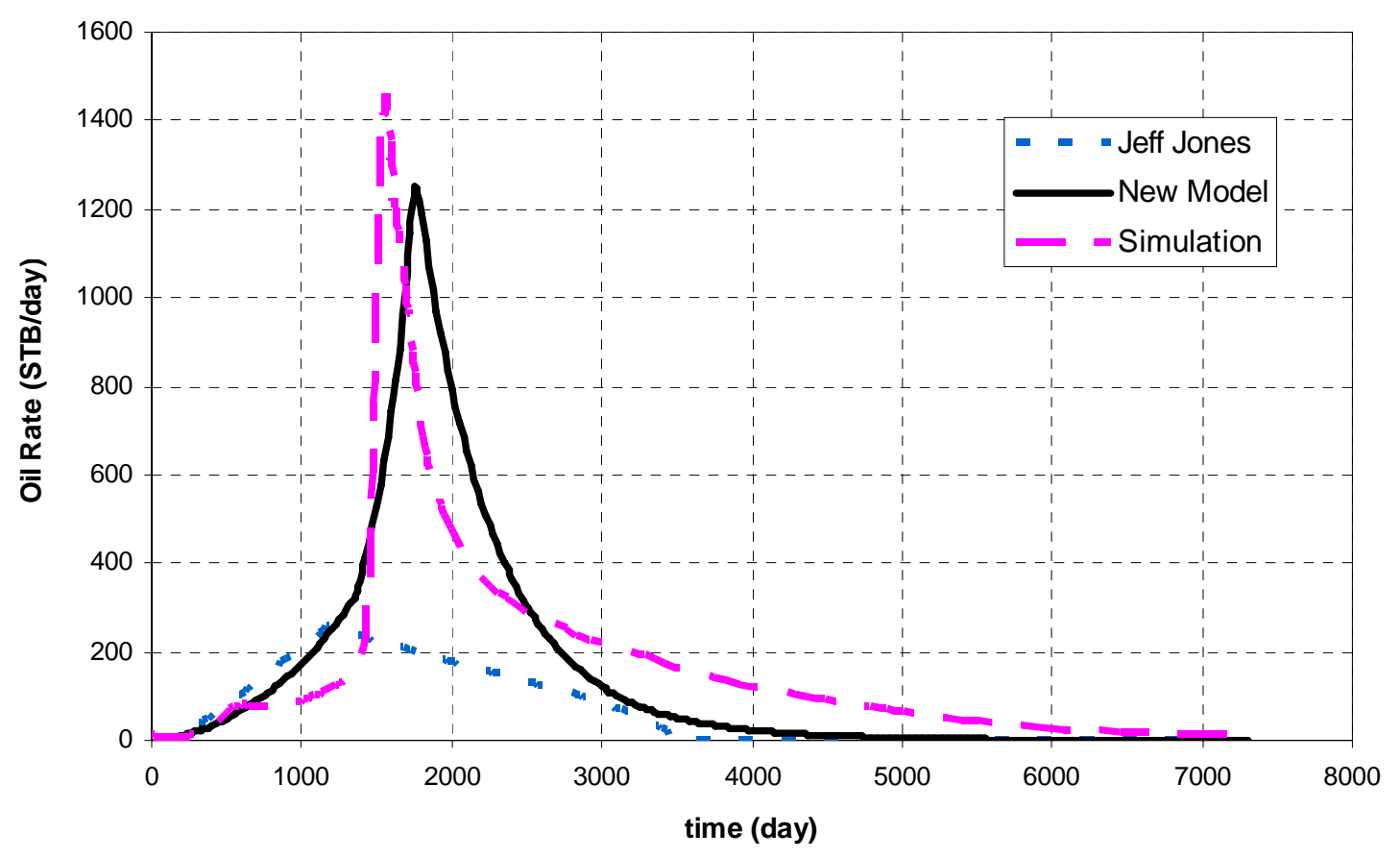

Fig. 4.12-Oil production rate (SPE comparative model, area $=10 \mathrm{ac}$, injection rate $=$ $1200 \mathrm{~B} / \mathrm{D})$. 


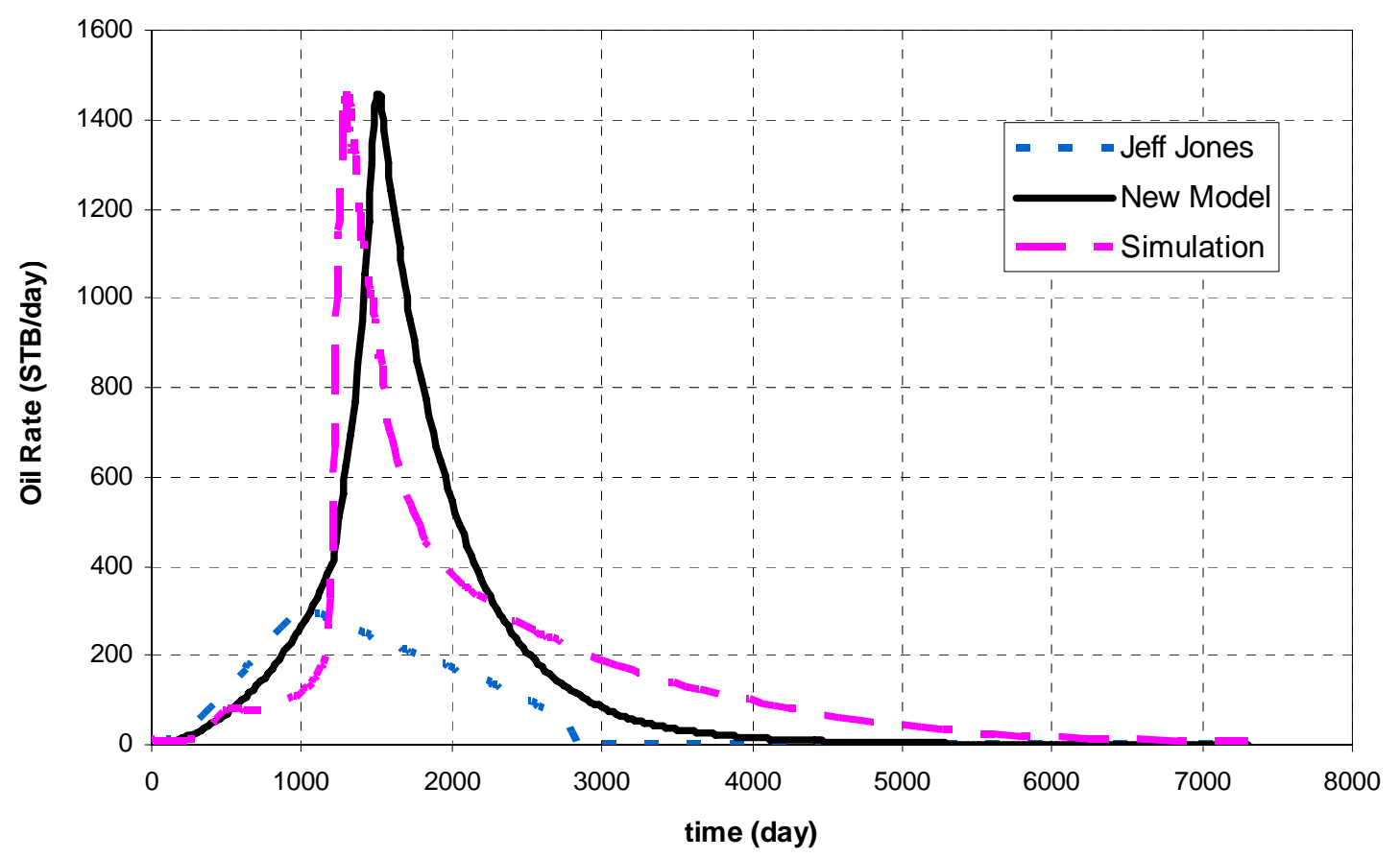

Fig. 4.13-Oil production rate (SPE comparative model, area $=10 \mathrm{ac}$, injection rate $=$ $1400 \mathrm{~B} / \mathrm{D})$.

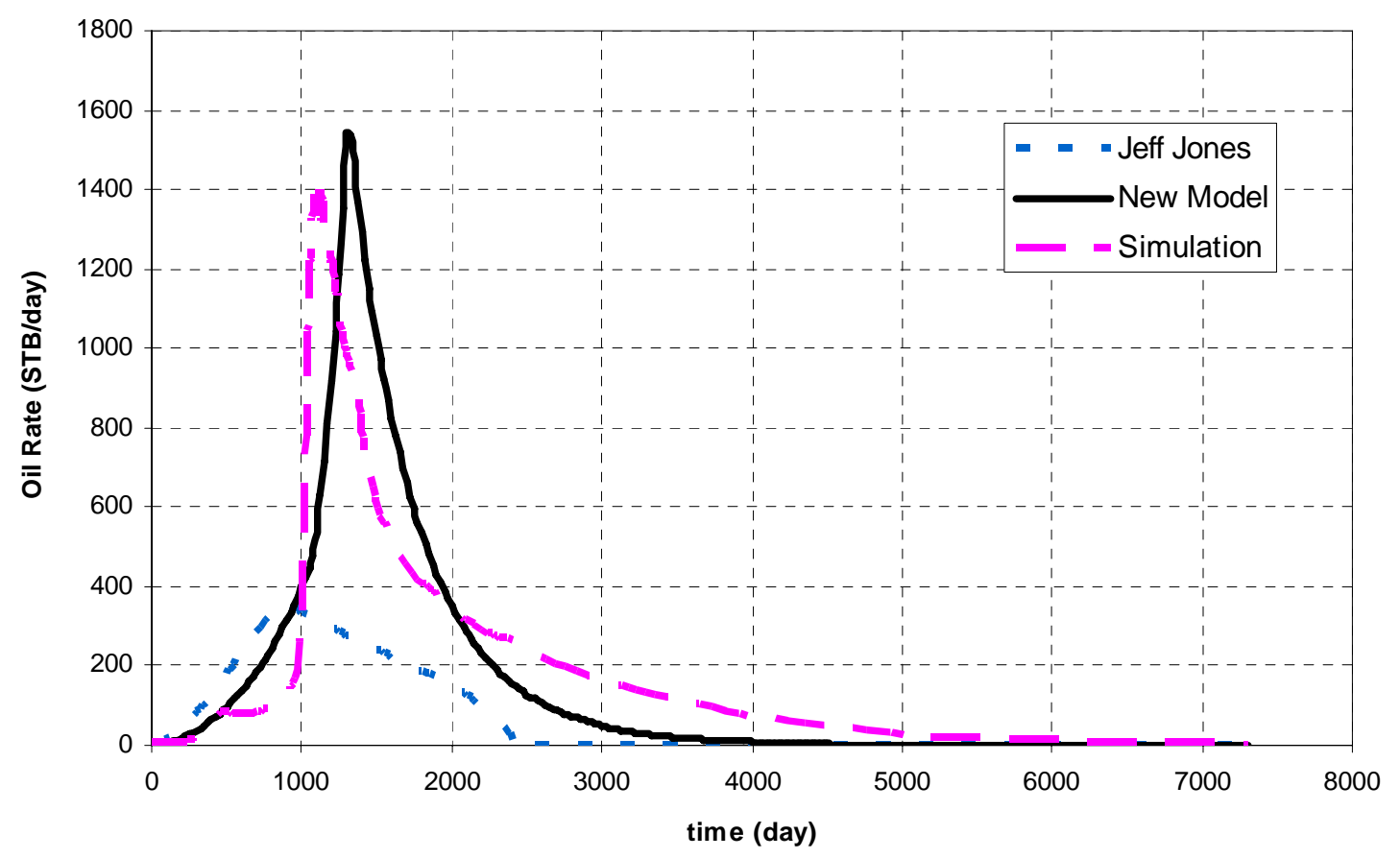

Fig. 4.14-Oil production rate (SPE comparative model, area $=10 \mathrm{ac}$, injection rate $=$ $1600 \mathrm{~B} / \mathrm{D})$. 


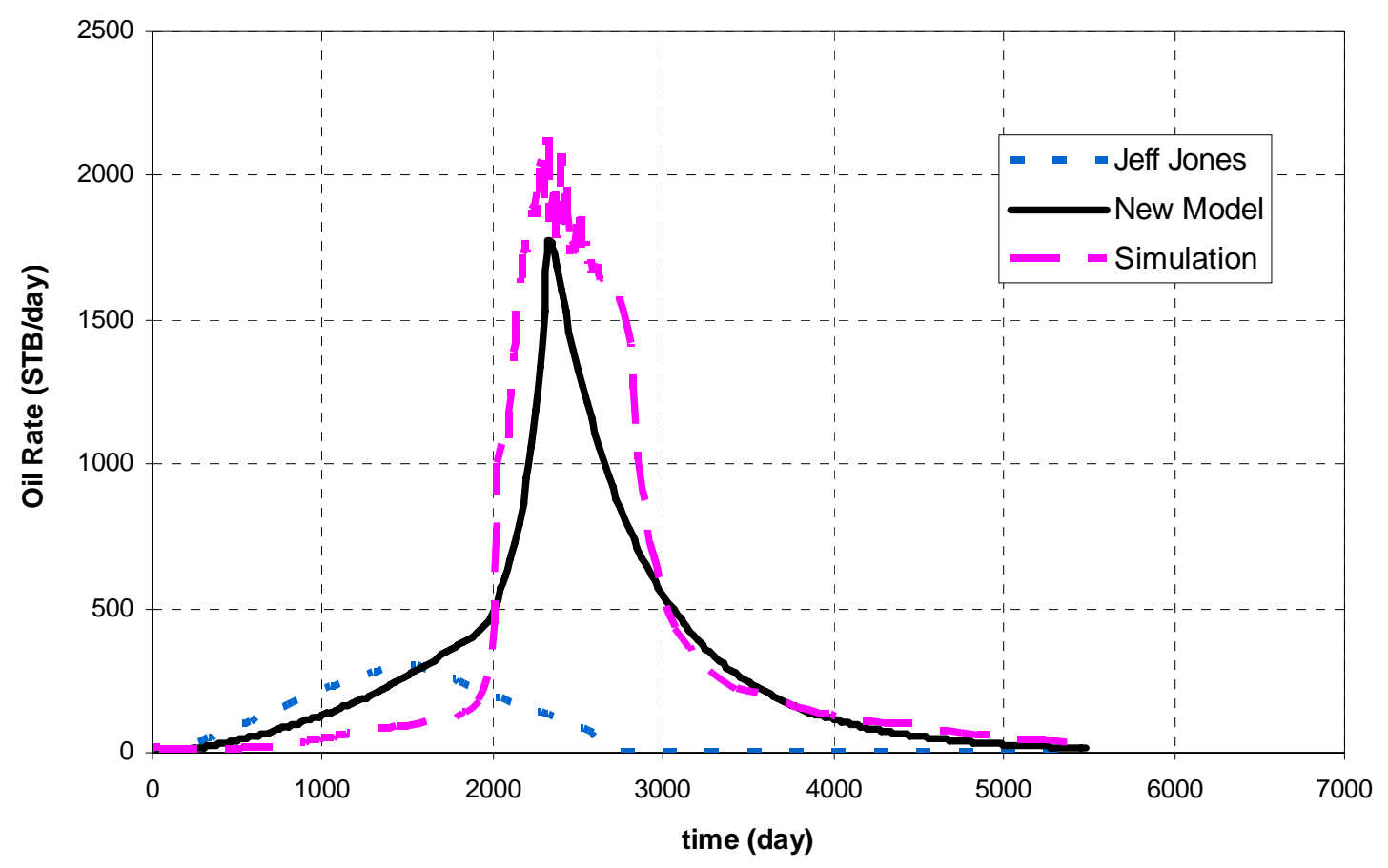

Fig. 4.15-Oil production rate $(S a n$ Ardo model, area $=10 \mathrm{ac}$, injection rate $=1600$ B/D).

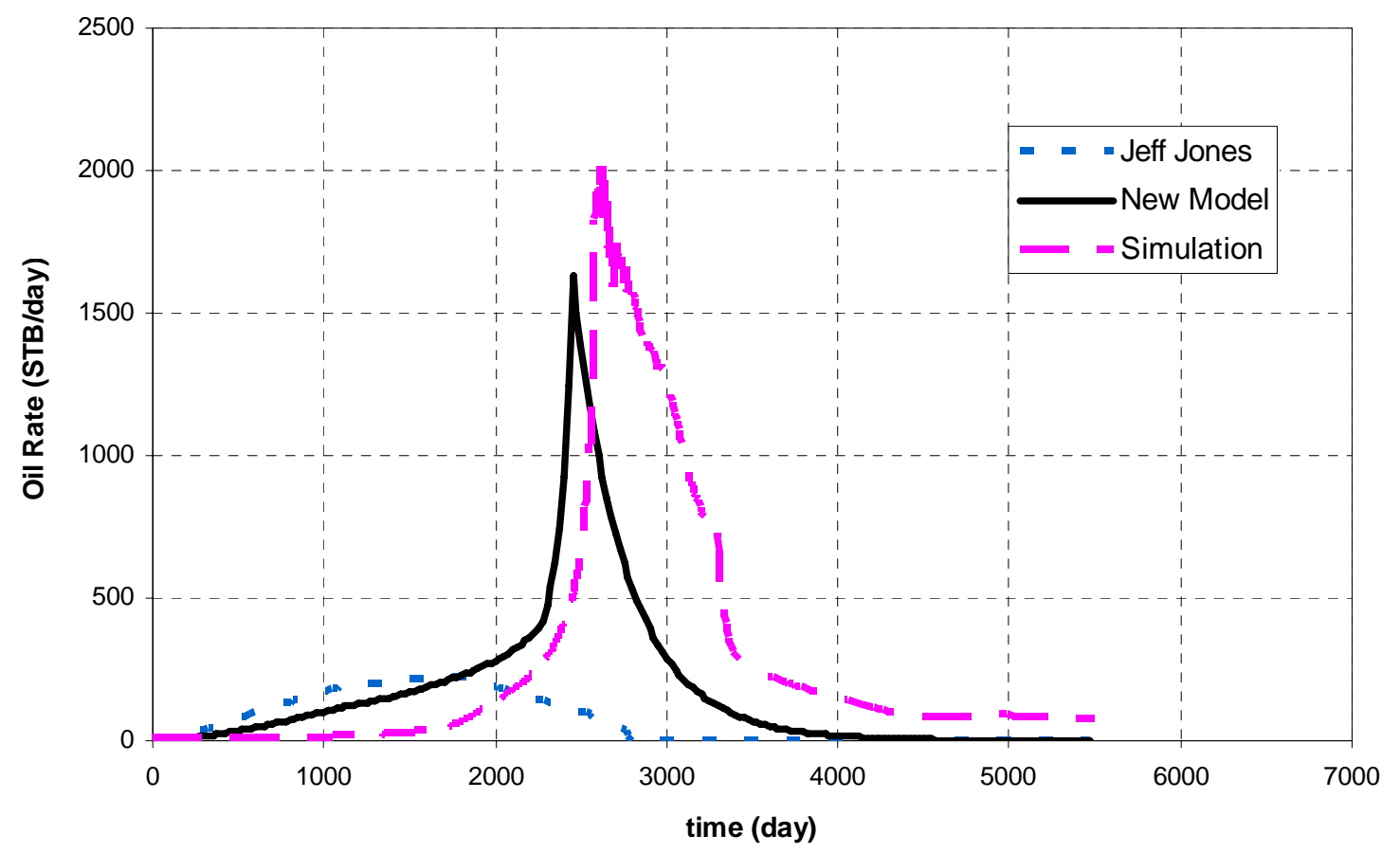

Fig. 4.16-Oil production rate (Hamaca model, area $=10 \mathrm{ac}$, injection rate $=1600$ B/D). 


\subsection{Cumulative Oil Steam Ratio}

Cumulative oil steam ratio (OSR) is defined as cumulative oil produced divided by cumulative steam injected. Fig. 4.17 until Fig. 4.29 gives cumulative oil steam ratio plots for all of the cases. It can be seen that cumulative OSR based on the new model are in good agreement with simulation results.

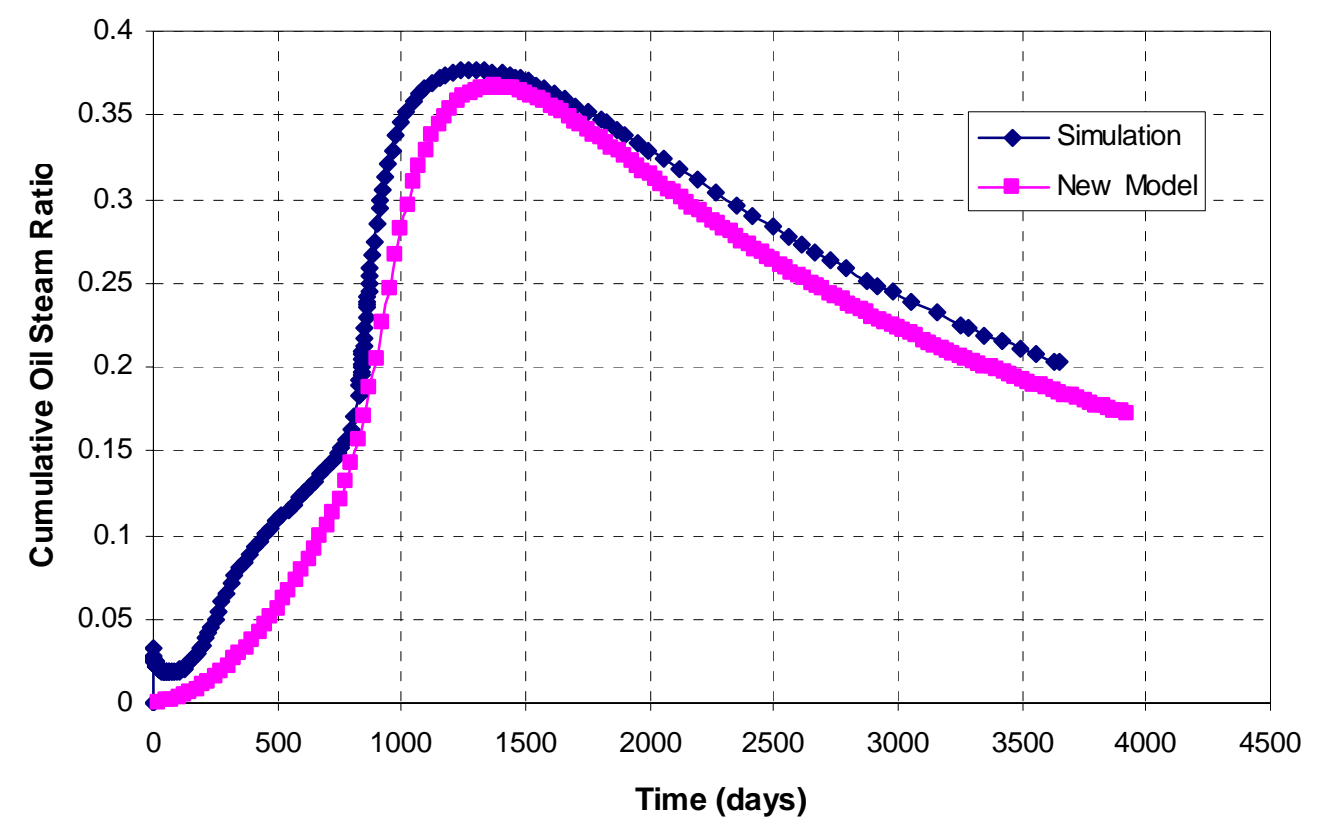

Fig. 4.17-Cumulative oil steam ratio ( $\mathrm{SPE}$ comparative model, area $=2.5 \mathrm{ac}$, injection rate $=400 \mathrm{~B} / \mathrm{D}$ ). 


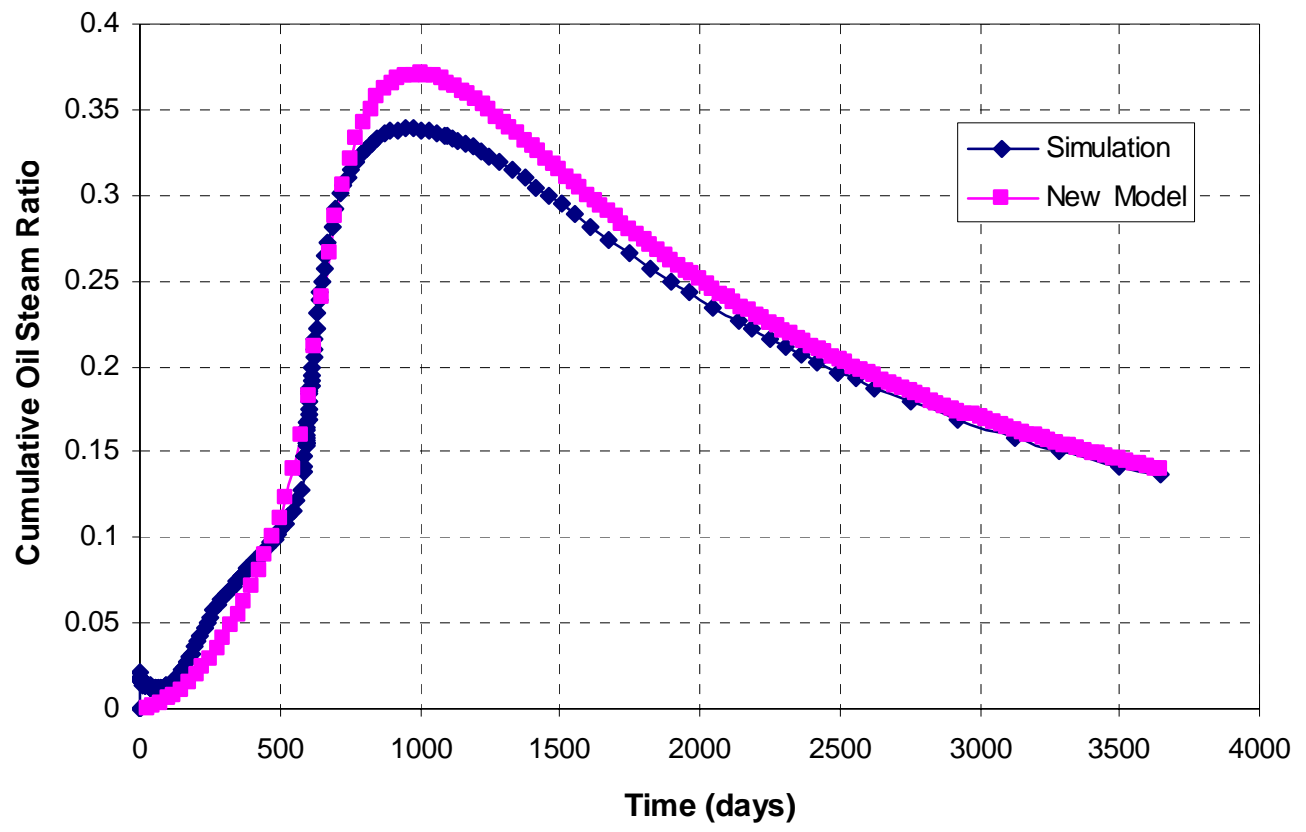

Fig. 4.18-Cumulative oil steam ratio (SPE comparative model, area $=2.5$ ac, injection rate $=600 \mathrm{~B} / \mathrm{D}$ ).

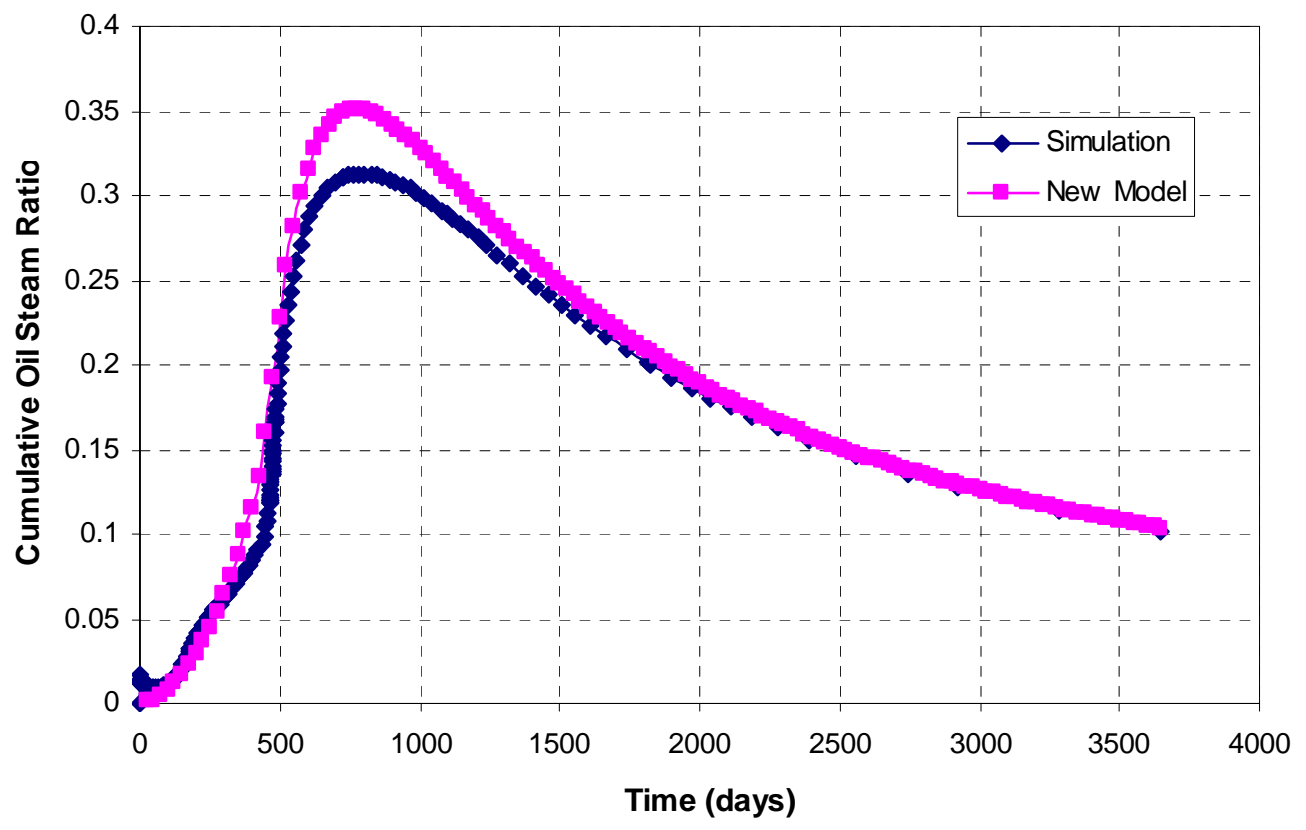

Fig. 4.19-Cumulative oil steam ratio (SPE comparative model, area $=2.5$ ac, injection rate $=800 \mathrm{~B} / \mathrm{D})$. 


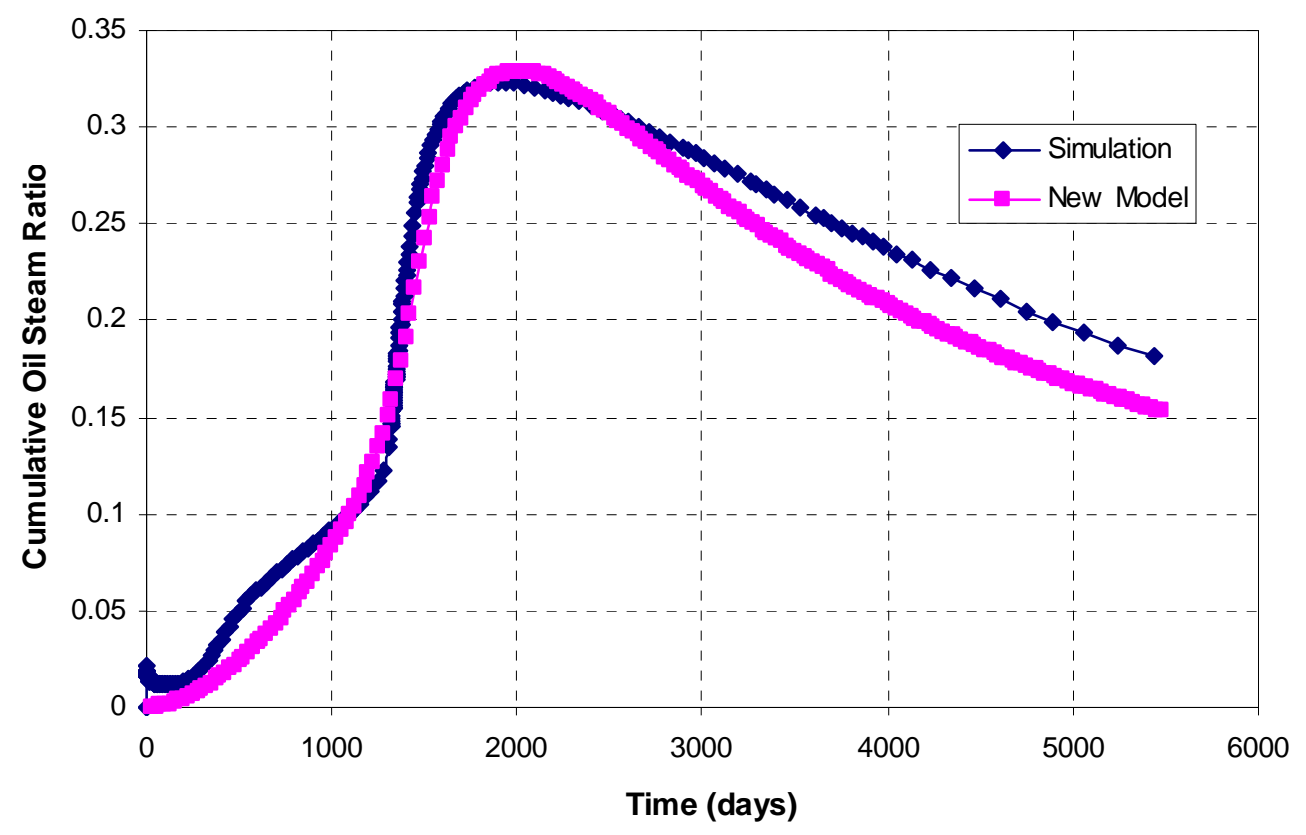

Fig. 4.20-Cumulative oil steam ratio (SPE comparative model, area $=5.0$ ac, injection rate $=600 \mathrm{~B} / \mathrm{D})$.

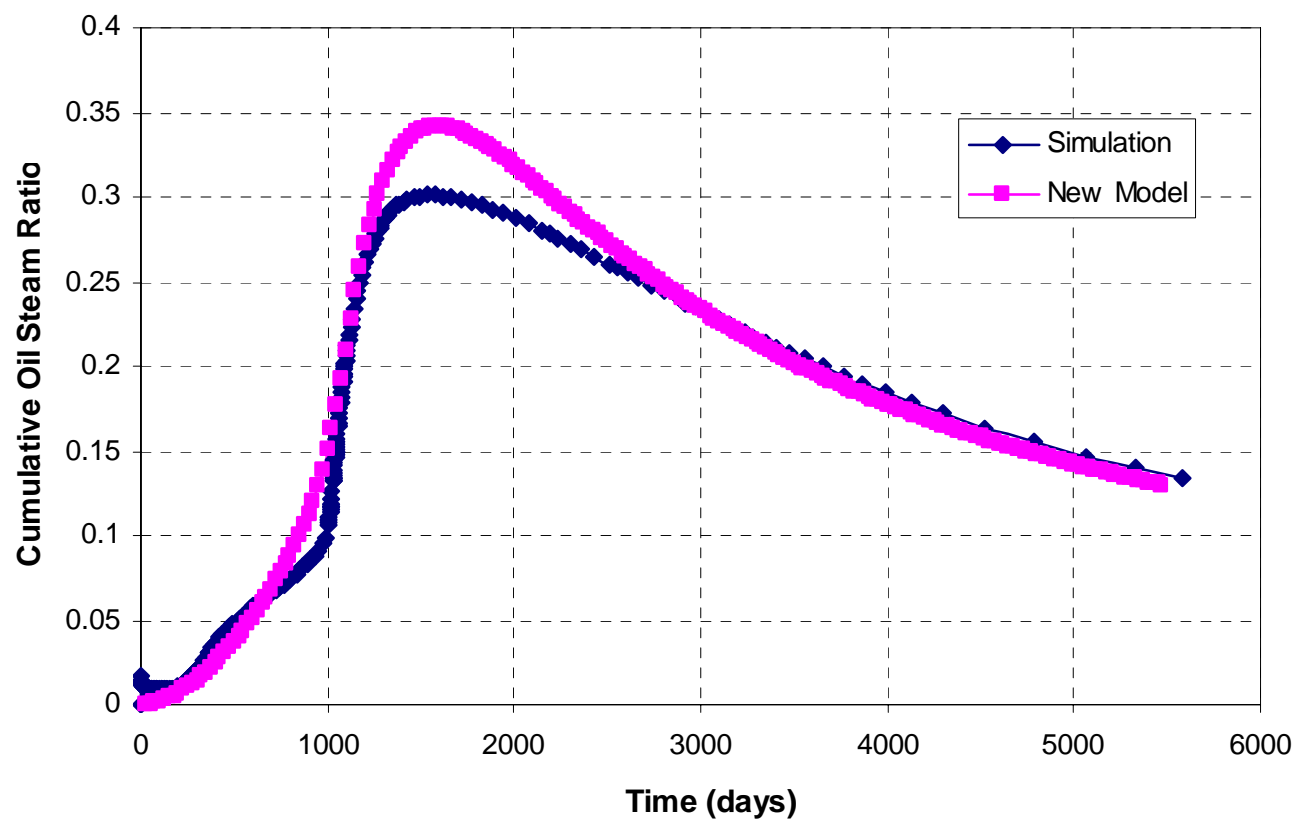

Fig. 4.21-Cumulative oil steam ratio (SPE comparative model, area $=5.0$ ac, injection rate $=800 \mathrm{~B} / \mathrm{D})$. 


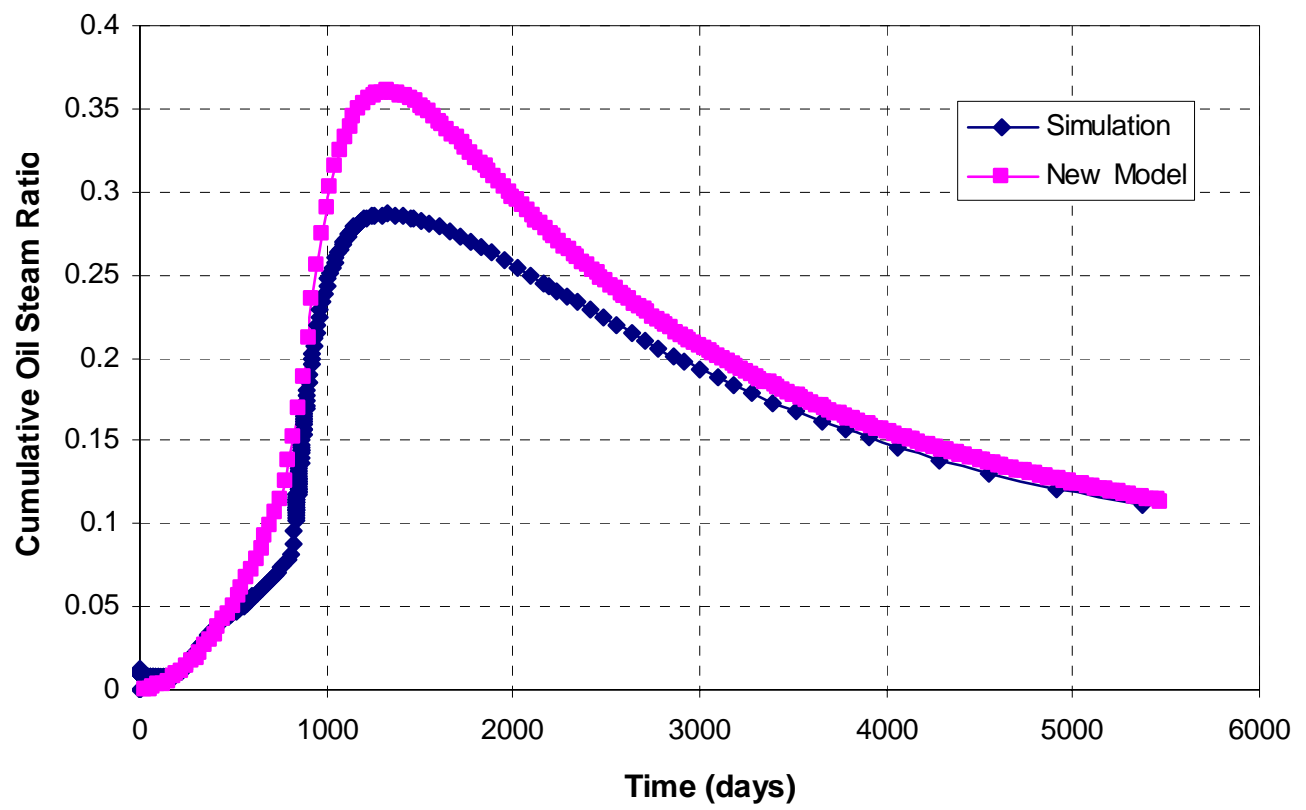

Fig. 4.22-Cumulative oil steam ratio (SPE comparative model, area $=5.0 \mathrm{ac}$, injection rate $=1000 \mathrm{~B} / \mathrm{D}$ ).

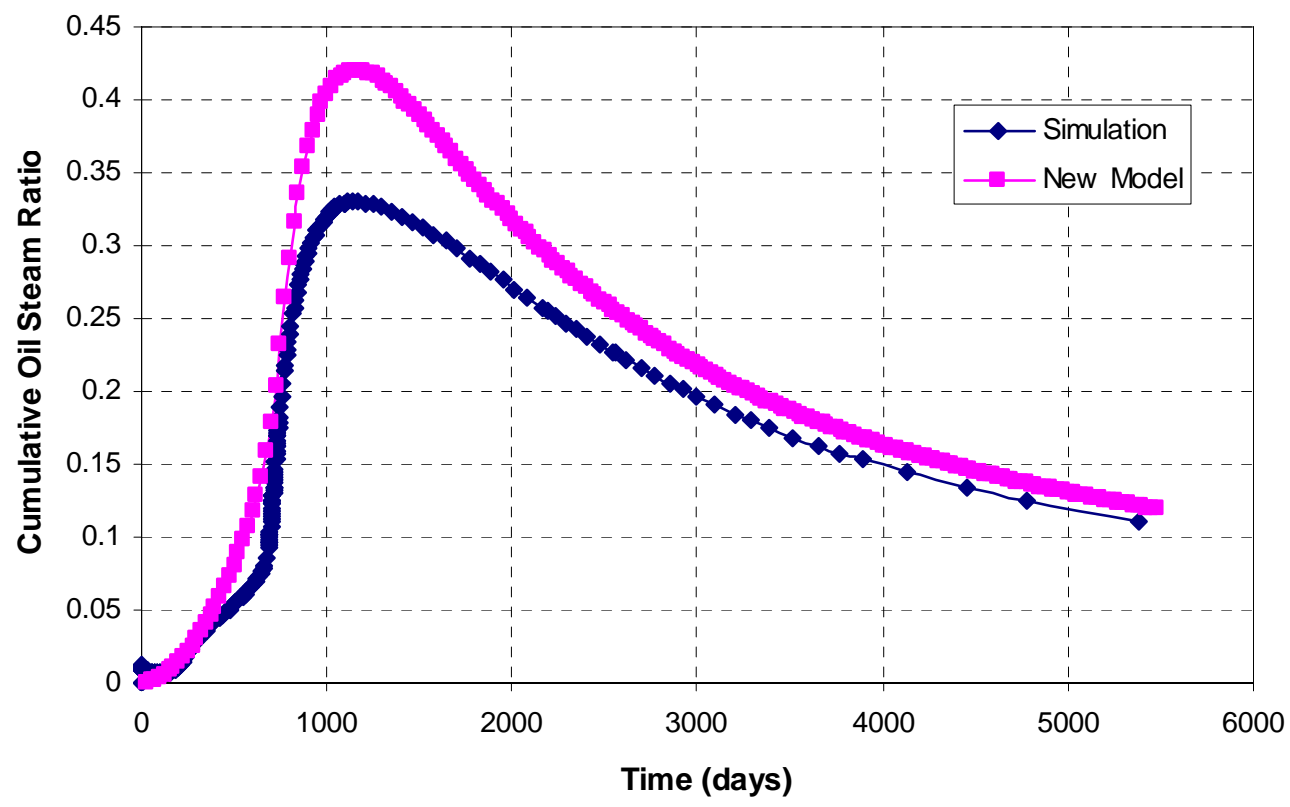

Fig. 4.23-Cumulative oil steam ratio (SPE comparative model, area $=5.0$ ac, injection rate $=1200 \mathrm{~B} / \mathrm{D}$ ). 


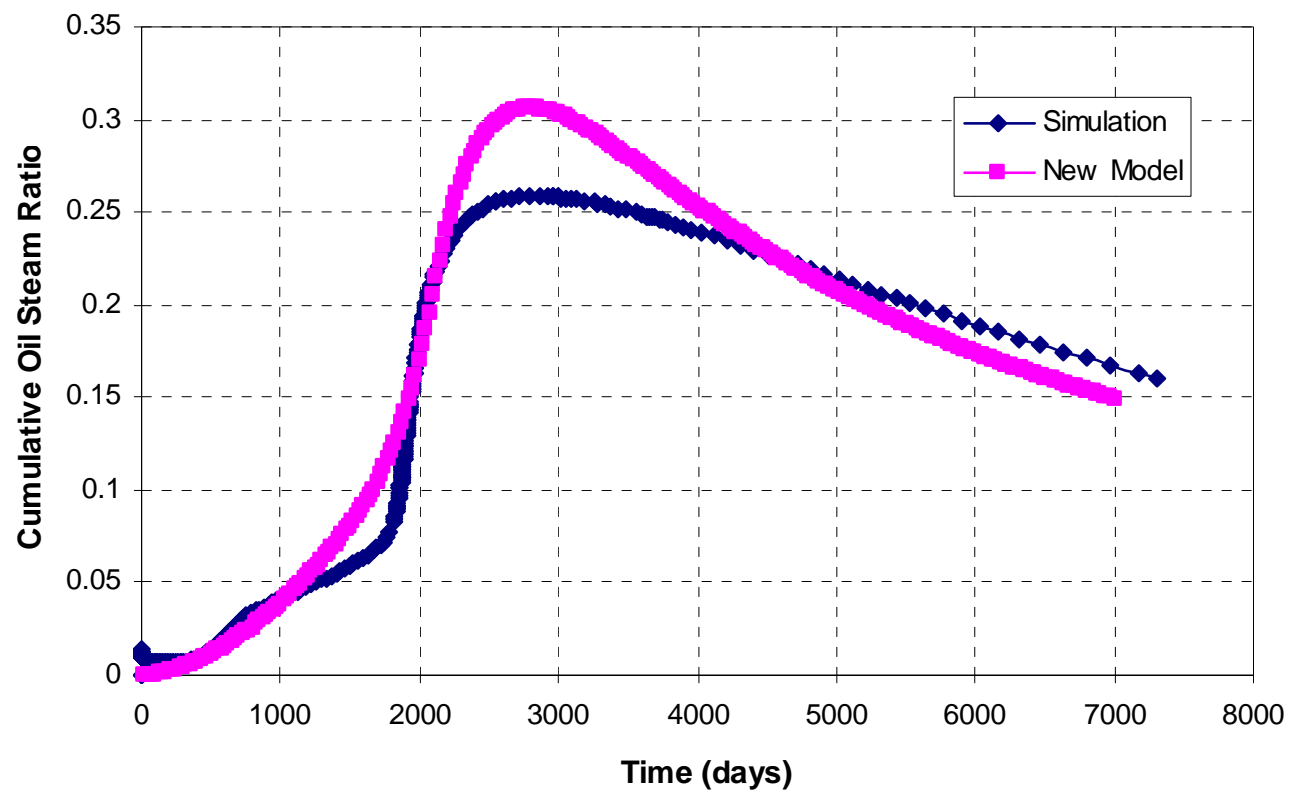

Fig. 4.24-Cumulative oil steam ratio ( $\mathrm{SPE}$ comparative model, area $=10 \mathrm{ac}$, injection rate $=1000 \mathrm{~B} / \mathrm{D}$ ).

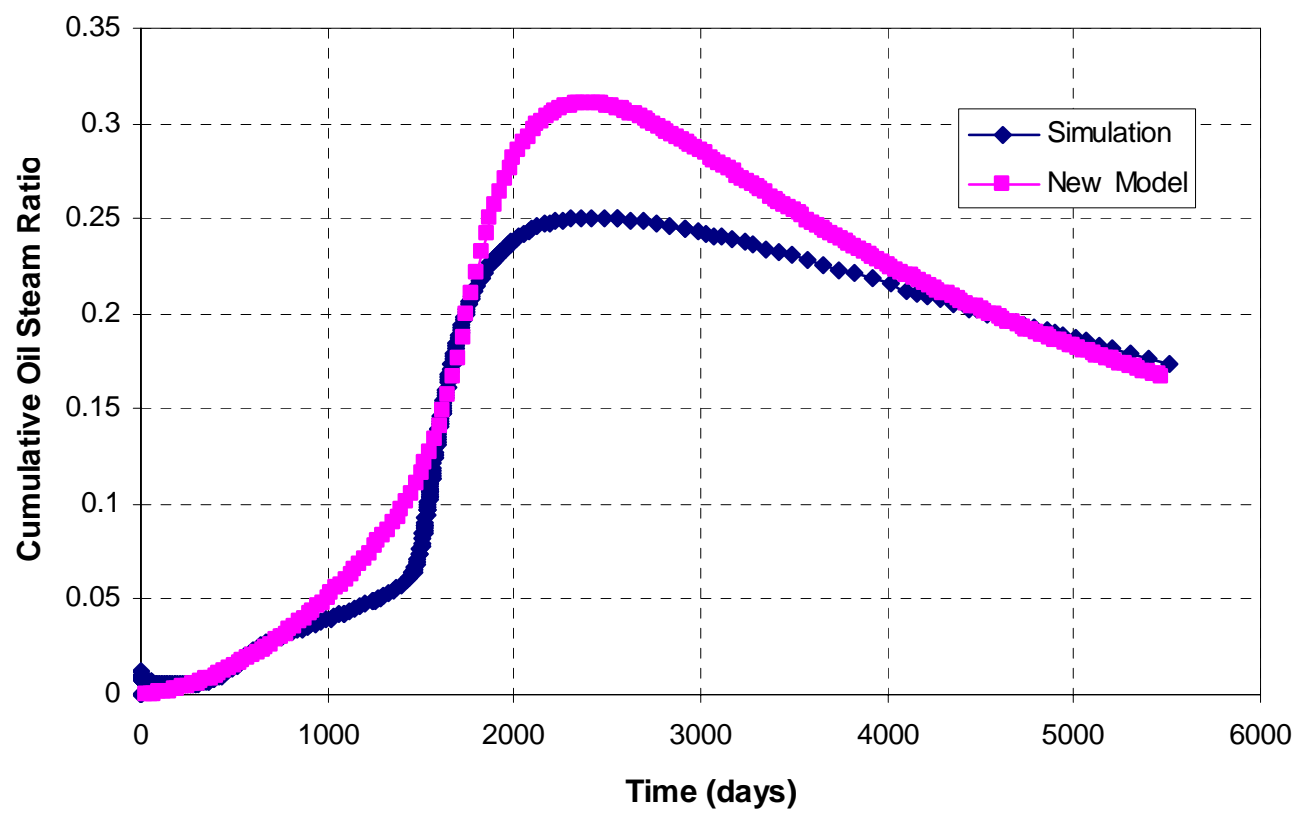

Fig. 4.25-Cumulative oil steam ratio ( $\mathrm{SPE}$ comparative model, area $=10 \mathrm{ac}$, injection rate $=1200 \mathrm{~B} / \mathrm{D}$ ). 


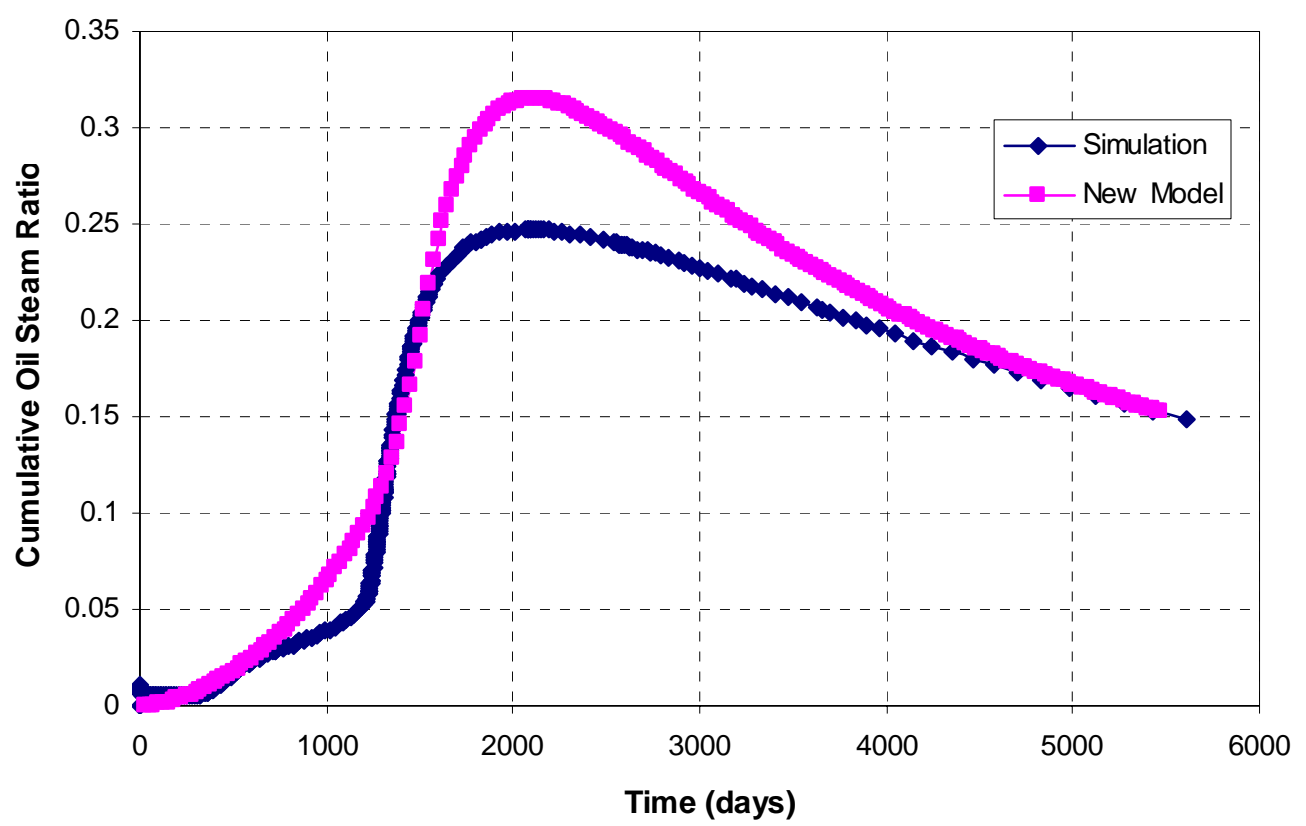

Fig. 4.26-Cumulative oil steam ratio (SPE comparative model, area $=10$ ac, injection rate $=1400 \mathrm{~B} / \mathrm{D})$.

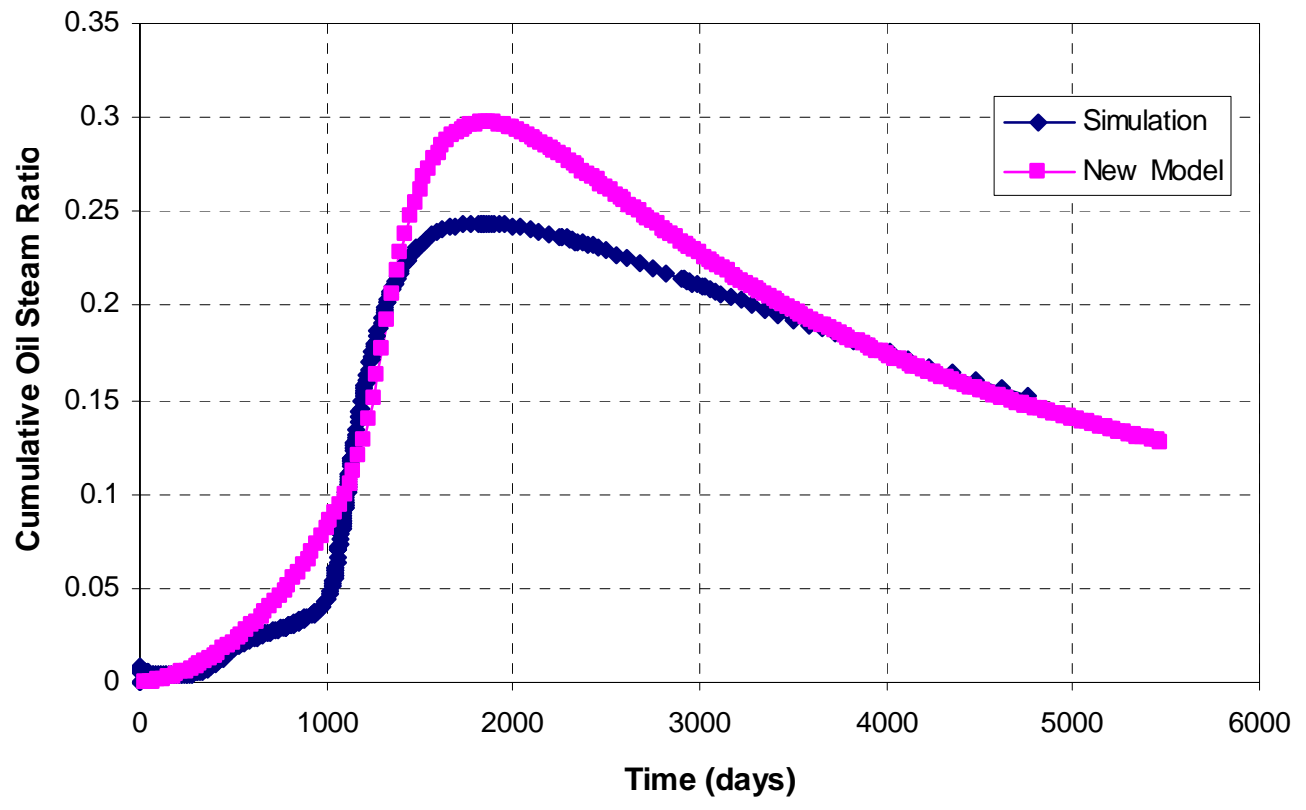

Fig. 4.27-Cumulative oil steam ratio (SPE comparative model, area $=10$ ac, injection rate $=1600 \mathrm{~B} / \mathrm{D})$. 


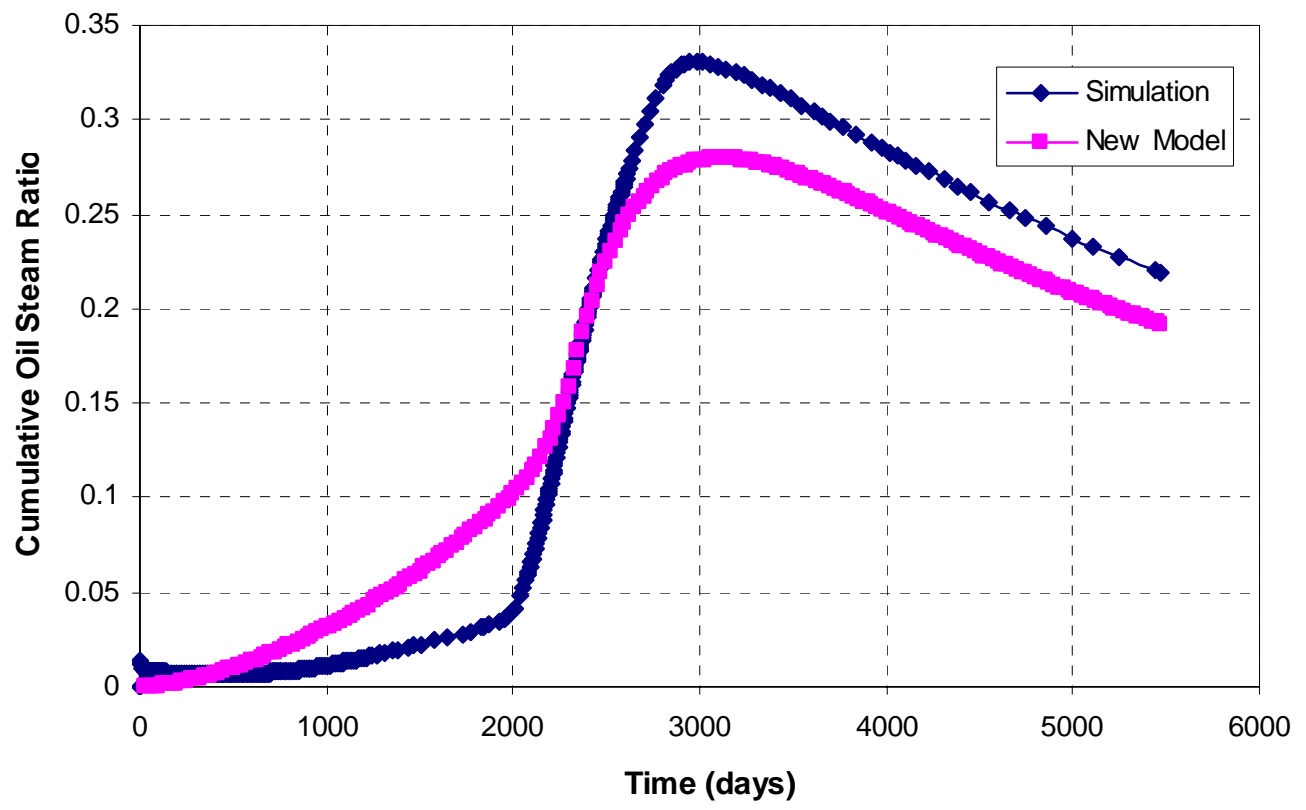

Fig. 4.28-Cumulative oil steam ratio (San Ardo model, area $=10$ ac, injection rate $=$ $1600 \mathrm{~B} / \mathrm{D})$.

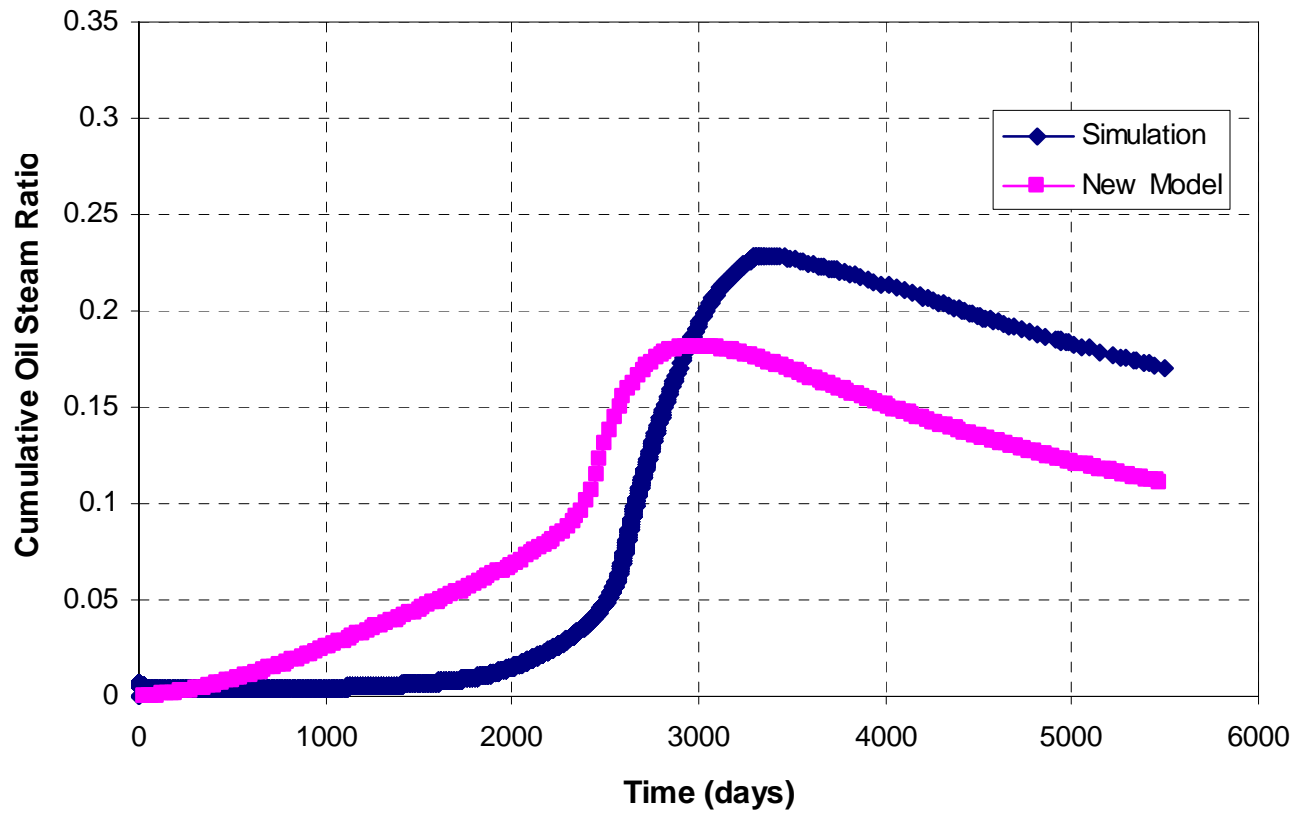

Fig. 4.29-Cumulative oil steam ratio (Hamaca model, area $=10 \mathrm{ac}$, injection rate $=$ $1600 \mathrm{~B} / \mathrm{D})$. 


\section{CHAPTER V}

\section{SUMMARY AND CONCLUSIONS}

\subsection{Summary}

The main drawback of the Jeff Jones analytical steamflood model is the unsatisfactory prediction of the oil production peak: usually significantly lower than the actual. The main objective of this study is therefore to improve this aspect of the Jeff Jones model.

As in the Jeff Jones model, oil production in the new model consists of three stages. The first production stage is related to cold oil production. The second production stage describes breakthrough of the oil bank. The third production stage is related to the production of the remaining mobile portion of original oil-in-place.

Two of the three components of the capture factor, $A_{c D}$ and $V_{o D}$, given in Jeff Jones' model were modified to obtain a satisfactory match of the oil production rate based on the new model and simulation. In the new model, $A_{c D}$ was modified to account for effect of steam injection rate on oil production in the first and second stages. In addition, the oil viscosity value for $A_{c D}$ in the second stage is taken as that at the average of the steam and initial reservoir temperature. In the third stage, the Jeff Jones $V_{o D}$ expression was modified from its square-root format to an exponential form, and took into account the effect of steam injection rate on production rate decline.

Steamflood production performances based on the new model were compared against simulation results for three cases: San Ardo field $\left(12^{\circ} \mathrm{API}\right)$, Hamaca field $\left(9^{\circ} \mathrm{API}\right)$, and that based on the SPE fourth comparative solution project ( $\left.14^{\circ} \mathrm{API}\right)$. In the first two field cases, a $45 \times 23 \times 8$ model was used that represented $1 / 8$ of a 10 -acre 5 -spot pattern 
unit, using typical rock and reservoir fluid properties. In the SPE project case, three models were used: $23 \times 12 \times 12(2.5 \mathrm{ac}), 31 \times 16 \times 12(5 \mathrm{ac})$ and $45 \times 23 \times 8(10 \mathrm{ac})$, that represented $1 / 8$ of a 5 -spot pattern unit.

Based on oil production rate and cumulative oil steam ratio performances of the 13 different cases investigated, the new model gives good agreement with simulation results, verifying the validity of the new steamflood model.

\subsection{Conclusions}

1. Although the Jeff Jones model is commonly used for analytical steamflooding performance prediction, it gives unsatisfactory prediction of the oil production peak: usually lower than actual.

2. Simulation results indicate exponential decline trends for oil rate in the third production stage. This is different from the square-root trend of the Jeff Jones model.

3. A new analytical model for steamflooding performance prediction has been developed by modifying the Jeff Jones analytical model.

4. Results based on the modified model agree well with simulation results for thirteen different cases that includes three different sets of reservoir and fluid properties: that of the SPE fourth comparative project, San Ardo field and Hamaca field.

5. Engineers will find the modified model an improved and useful tool for prediction of steamflood production performance. 


\section{NOMENCLATURE}

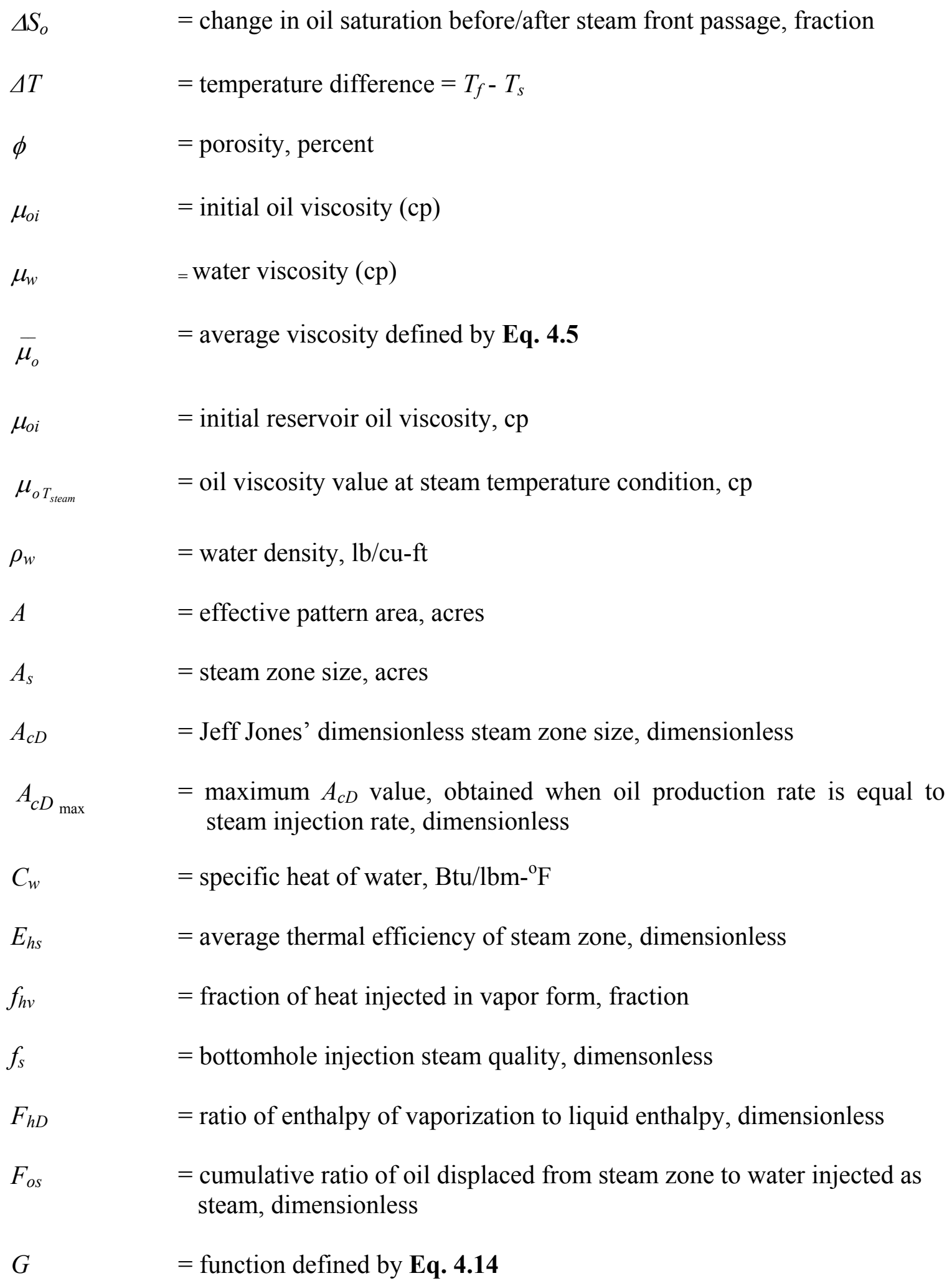




$$
\begin{aligned}
& h_{f} \quad=\text { enthalpy of saturated water at steam temperature, Btu/lbm } \\
& h_{f g} \quad=\text { latent heat of steam, BTU/lbm } \\
& h_{n} \quad=\text { net zone thickness, } \mathrm{ft} \\
& h_{s} \quad=\text { steam zone thickness, } \mathrm{ft} \\
& h_{s c} \quad=\text { enthalpy of condensate, BTU } / \mathrm{lbm} \\
& h_{s v} \quad=\text { enthalpy of vapor, BTU/lbm } \\
& h_{t} \quad=\text { gross formation thickness, } \mathrm{ft} \\
& i_{s} \quad=\text { steam injection rate, cold water equivalent, } \mathrm{B} / \mathrm{D} \\
& K=\text { constant defined in Eq. 4.16, dimensionless } \\
& k_{h}=\text { bulk thermal conductivity of cap rock and base rock, BTU/ft-hr- }{ }^{\circ} \mathrm{F} \\
& k_{o} \quad=\text { oil relative permeability, fraction } \\
& k_{r g} \quad=\text { gas relative permeability (gas/oil system), fraction } \\
& k_{\text {rgro }}=\text { gas relative permeability at residual oil saturation (gas/oil system), } \\
& \text { fraction } \\
& k_{\text {rog }}=\text { oil relative permeability (gas/oil system), fraction } \\
& k_{\text {roiw }}=\text { oil relative permeability at interstitial water saturation, fraction } \\
& k_{\text {row }}=\text { oil relative permeability (water-oil system), fraction } \\
& k_{r w} \quad=\text { water relative permeability (water-oil system), fraction } \\
& k_{r w r o} \quad=\text { water relative permeability at residual oil saturation (water/oil system), } \\
& \text { fraction } \\
& k_{w} \quad=\text { water relative permeability, fraction } \\
& M \quad=\text { mobility ratio, dimensionless } \\
& M_{1} \quad=\text { average heat capacity of steam zone, } \mathrm{BTU} / \mathrm{cu} \mathrm{ft}^{-} \mathrm{F} \\
& M_{2} \quad=\text { average heat capacity of cap rock and base rock, } \mathrm{BTU} / \mathrm{cu} \mathrm{ft}{ }^{\circ} \mathrm{F}
\end{aligned}
$$




$$
\begin{aligned}
& N \quad=\text { oil originally in place, } \mathrm{STB} \\
& N_{c} \quad=\text { ratio of the volume of moveable oil to that of steam injection up to the } \\
& \text { critical time, } t_{c} \\
& N_{D} \quad=\text { cumulative oil displacement, } \mathrm{RB} \\
& N_{D_{\max }} \quad=N_{D} \text { from Myhill-Stegemeier calculation }-N_{D} \text { up to } A_{c D \text { max }}, \mathrm{RB} \\
& p_{s} \quad=\text { steam injection pressure, } \text { psia } \\
& Q_{i n j} \quad=\text { heat injection rate, } \mathrm{BTU} / \mathrm{hr} \\
& q_{o} \quad=\text { oil production rate }(\mathrm{STB} / \mathrm{D}) \\
& q_{\text {od }} \quad=\text { oil displacement rate/ Myhill-Stegemeier's oil production rate (RB/D) } \\
& S_{g} \quad \text { = gas saturation, fraction } \\
& S_{g c} \quad=\text { critical gas saturation, fraction } \\
& S_{i w} \quad=\text { interstitial water saturation, fraction } \\
& S_{o i} \quad=\text { initial oil saturation, fraction } \\
& S_{\text {or }} \quad \text { = residual oil saturation, fraction } \\
& S_{\text {org }} \quad=\text { residual oil saturation (gas/oil system), fraction } \\
& S_{\text {orw }} \quad=\text { residual oil saturation (water/oil system), fraction } \\
& S_{w} \quad=\text { water saturation, fraction } \\
& S_{w c} \quad=\text { connate water saturation, fraction } \\
& S_{\text {wir }} \quad=\text { irreducible water saturation, fraction } \\
& t \quad=\text { time of steam injection, years } \\
& t_{c} \quad=\text { critical time, years } \\
& t_{c D}=\text { time of steam injection at onset of convective heat transport through } \\
& \text { condensation front, dimensionless } \\
& t_{D} \quad=\text { time of steam injection, dimensionless }
\end{aligned}
$$


$t_{f} \quad=$ initial formation temperature, ${ }^{\circ} \mathrm{F}$

$t_{s} \quad=$ steam temperature, ${ }^{\circ} \mathrm{F}$

$U(x)=$ unit function, equals 0 for $x<0$, equals 1 for $x>0$

$V_{O D} \quad=$ volume of displaced oil produced, fraction

$V_{p D} \quad=$ initial pore void filled with steam as water, fraction

$V_{s, i n j} \quad=$ cumulative steam injection, $\mathrm{RB}$ 


\section{REFERENCES}

1. Marx, J.W and Langenheim, R.H.: "Reservoir Heating by Hot Fluid Injection," Trans, AIME(1959) 216, 312-314.

2. Mandl, G. and Volek, C.W.: "Heat and Mass Transport in Steam Drive Processes," Soc. Pet. Eng. J. (March 1969) 59-79; Trans, AIME, 246.

3. Boberg, T.C. and Lantz, R.B.: "Calculation of the Production Rate of a Thermally Stimulated Well," J. Pet. Tech. (December 1966): 1613-23.

4. Neuman, C.H.: "A Mathematical Model of the Steam Drive Process - Applications," paper SPE 4757 presented at the 1975 SPE $50^{\text {th }}$ Annual Technical Conference and Exhibition, Dallas, 28 Sept. - 1 Oct.

5. Myhill, N.A. and Stegemeier, G.L.: "Steam-Drive Correlation and Prediction," J. Pet. Tech. (Feb. 1978), 173-182.

6. Gomaa, E.E.: “Correlations for Predicting Oil Recovery by Steamflood," J.Pet.Tech. (Feb. 1980), 325-332.

7. Jones, J.: "Steam Drive Model for Hand-Held Programmable Calculators," J. Pet. Tech. (September 1981), 1583-1598.

8. Aziz, K., Ramesh, A.B., and Woo. P.T.: "Fourth SPE Comparative Solution Project: Comparison of Steam Injection Simulators," J. Pet. Tech. (December 1987), 15761584.

9. Hong, K.C.: Steamflood Reservoir Management, PennWell Books, Tulsa, (1994).

10. Pratts, M.: Thermal Recovery Monograph Vol. 7, Society of Petroleum Engineering, Houston, (1986). 
11. Van Lookeren, J.: "Calculation methods for Linear and Radial Steam Flow in Oil Reservoirs," paper SPE 6788 presented at the 1977 SPE 52 ${ }^{\text {nd }}$ Annual Technical Conference and Exhibition, Denver, 9-12 Oct.

12. User Guide, STARS Advanced Process and Thermal Reservoir Simulator Version 2003, Computer Modeling Group Ltd., Calgary, (2003).

13. Todd, M.R., O’Dell, P.M., and Hirassaki, G.J.: "Methods for Increased Accuracy in Numerical Reservoir Simulators," Soc. Pet. Eng. J. (Dec. 1974), 573-92; Trans., AIME, 253.

14. Coats, K.H. et al.: “Three-Dimensional Simulation of Steamflooding,” Soc. Pet. Eng. J. (Dec. 1974), 573-92; Trans., AIME, 257.

15. Abou-Kassem, J.H. and Aziz, K.: "Grid Orientation During Steam Displacement," paper SPE 10497 presented at the 1982 SPE Symposium on Reservoir Simulation, New Orleans, 1-3 Feb.

16. Yanosik, J.L. and McCracken, T.A.: "A Nine-Point, Finite-Difference Reservoir Simulator for Realistic Prediction of Adverse Mobility Ratio Displacement," Soc. Pet. Eng. J. (Aug. 1979), 253-62.

17. Coats, K.H., Ramesh, A.B.: "Effects of Grid Type and Difference Scheme on Pattern Steamflood Simulation Results," J. Pet. Tech. (May 1987), 557-569.

18. Sandoval, J.E. (2004): A Simulation Study of Steam and Steam-Propane Injection Using A Novel Smart Horizontal Producer to Enhance Oil Production, MS Thesis, Texas A\&M University, College Station.

19. Venturini, G.J. (2002): Simulation Studies of Steam-Propane Injection for the Hamaca Heavy Oil Field, MS Thesis, Texas A\&M University, College Station. 
20. Effinger, A.W. and Wasson, J.A: "Applying Marx and Langenheim Calculations to the Prediction of Oil Recovery by Steamflooding in Venango Sands," USBM Information Circular 8482, U.S. Dept. of Interior (1969).

21. Ejiogu, G.C. and Fiori, M.: "High-Pressure Saturated-Steam Correlations," J. Pet. Tech. (December 1987), 1585-1590. 


\section{APPENDIX A}

\section{JEFF JONES OIL DISPLACEMENT CALCULATION}

The method used is basically that proposed by Myhill and Stegemeier. The rate of oil displacement is a function of $F_{o s}$, which is in turn a function of $E_{h s}$ or overall reservoir thermal efficiency. Formula for $E_{h s}$ calculation:

$$
E_{h s}=\frac{1}{t_{D}}\left(e^{t_{D}} \operatorname{erfc} \sqrt{t_{D}}+2 \sqrt{t_{D} / \pi}-1\right)
$$

if $t_{D} \leq t_{c D}$,

$$
\begin{aligned}
E_{h s}= & \frac{1}{t_{D}}\left[\left(e^{t_{D}} \operatorname{erfc} \sqrt{t_{D}}+2 \sqrt{t_{D} / \pi}-1\right)-\sqrt{\frac{t_{D}-t_{c D}}{\pi}}\left(\frac{1}{1+F_{h D}}+\right.\right. \\
& \left.\left.\frac{t_{D}-t_{c D}-3}{3} e^{t_{D}} \operatorname{erfc} \sqrt{t_{D}}-\frac{t_{D}-t_{c D}}{3 \sqrt{\pi t_{D}}}\right)\right]
\end{aligned}
$$

if $t_{D}>t_{c D}$

where,

$t_{D}=\frac{42,048 k_{h} t}{h_{t}^{2} M_{1}}$.

The constant in Eq. A-3 assumes that heat capacity of the base rock and caprock is 1.2 times that of the reservoir and converts time to a yearly basis. The dimensionless time is based on correlation:

$t_{c D}=0.48 F_{h D}^{1.71}$.

Dimensionless steam quality:

$$
F_{h D}=\frac{f_{s} h_{f g}}{C_{w} \Delta T} .
$$


where,

$h_{f g}=865-0.207 p_{s}$

erfc function can be estimated from Effigner and Wasson equation:

$$
\begin{aligned}
\operatorname{erfc} \sqrt{t_{D}}= & \left(0.2548292 K-0.284496736 K^{2}+1.421413741 K^{3}\right. \\
& \left.-1.453152027 K^{4}+1.061405429 K^{5}\right)
\end{aligned}
$$

where,

$$
K=\frac{1}{1+0.3275911 \sqrt{t_{D}}}
$$

Cumulative ratio of oil produced to water as steam injected:

$$
F_{o s}^{\prime}=\frac{\rho_{w} c_{w}}{M_{1}} \frac{h_{n}}{h_{t}} \Delta S_{o} \phi\left(1+F_{h D}\right) E_{h s} .
$$

With the preceding information, cumulative oil displacement is calculated as:

$$
N_{d}=F_{o s}^{\prime} V_{s, i n j}
$$

Oil displacement rate is the time derivative of $N_{d}$ function:

$$
q_{o}=\frac{N_{d n}-N_{d n-1}}{\Delta t}
$$




\section{APPENDIX B}

\section{SIMULATION INPUT DATA FOR FOURTH SPE COMPARATIVE CASE, AREA $=2.5$ ACRE, STEAM INJECTION RATE $=400$ STB/D}

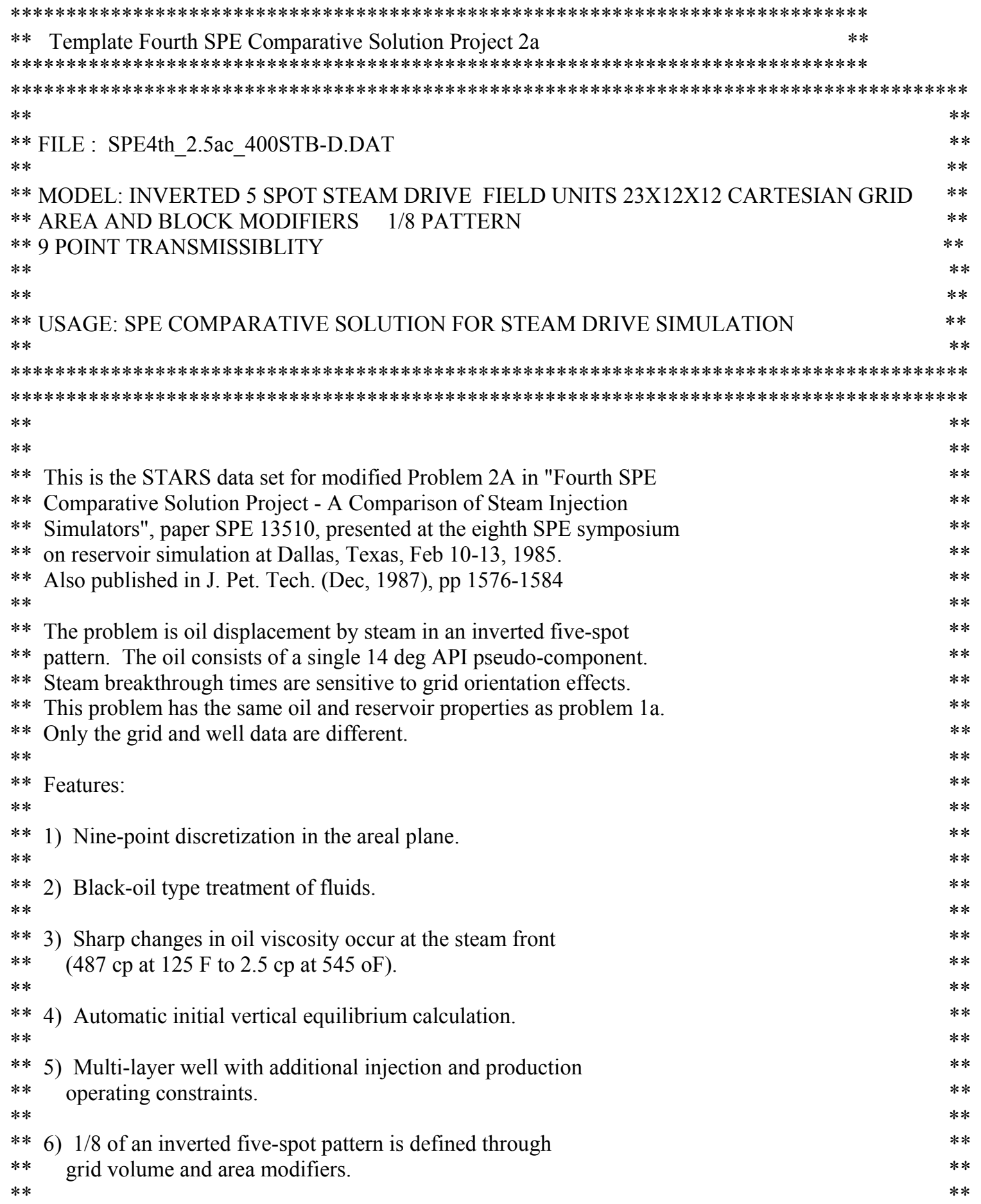




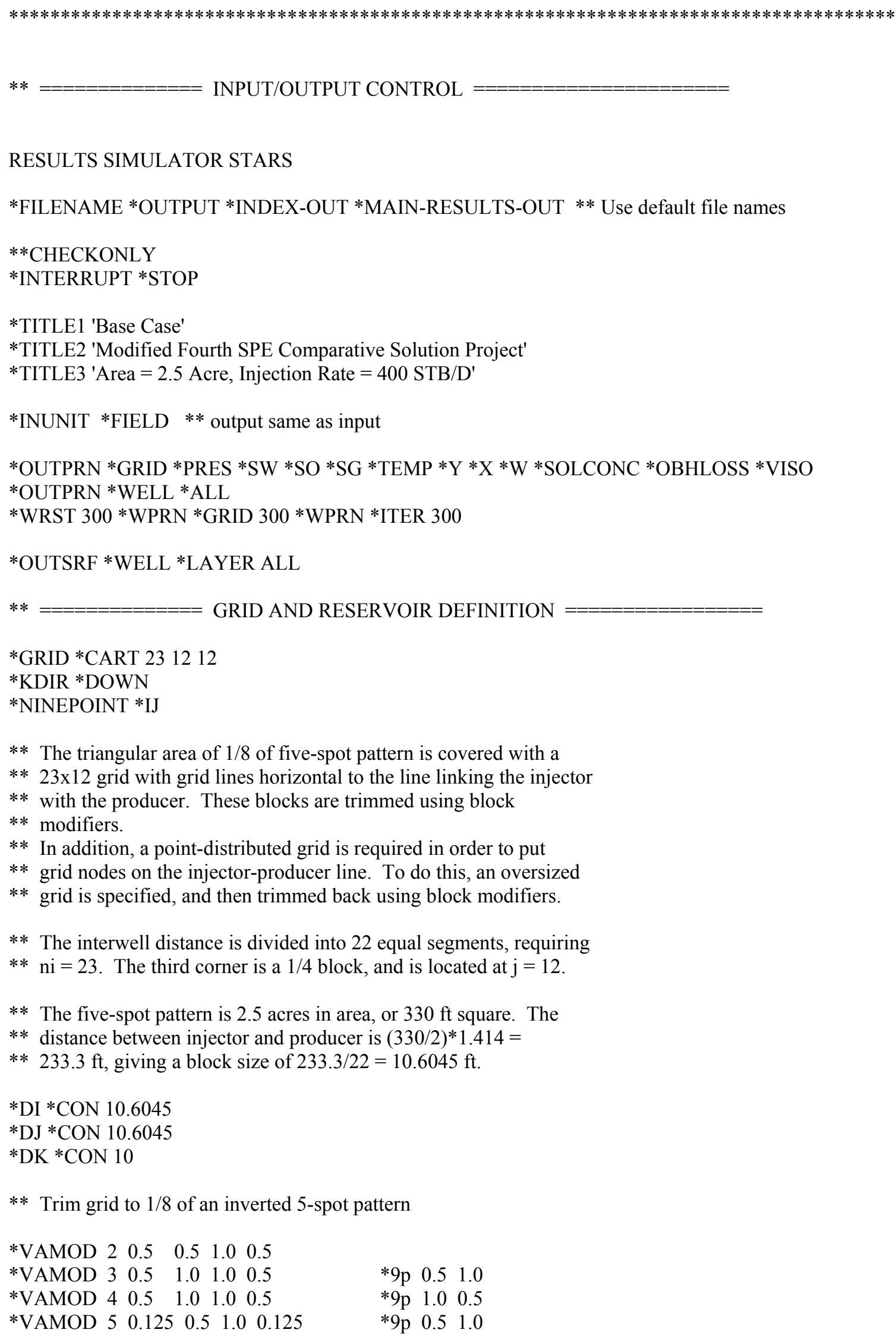




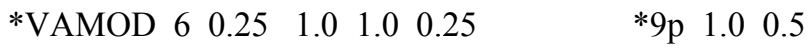 \\ *VATYPE *ALL \\ 52222222222222222222225 \\ 03111111111111111111140 \\ 00311111111111111111400 \\ 00031111111111111114000 \\ 00003111111111111140000 \\ 00000311111111111400000 \\ 00000031111111114000000 \\ 00000003111111140000000 \\ 00000000311111400000000 \\ 00000000031114000000000 \\ 00000000003140000000000 \\ 00000000000600000000000
}

52222222222222222222225 03111111111111111111140 00311111111111111111400 00031111111111111114000 00003111111111111140000 00000311111111111400000 00000031111111114000000 00000003111111140000000 00000000311111400000000 00000000031114000000000 00000000003140000000000 00000000000600000000000

52222222222222222222225 03111111111111111111140 00311111111111111111400 00031111111111111114000 00003111111111111140000 00000311111111111400000 00000031111111114000000 00000003111111140000000 00000000311111400000000 00000000031114000000000 00000000003140000000000 00000000000600000000000

52222222222222222222225 03111111111111111111140 00311111111111111111400 00031111111111111114000 00003111111111111140000 00000311111111111400000 00000031111111114000000 00000003111111140000000 00000000311111400000000 00000000031114000000000 00000000003140000000000 00000000000600000000000 
75

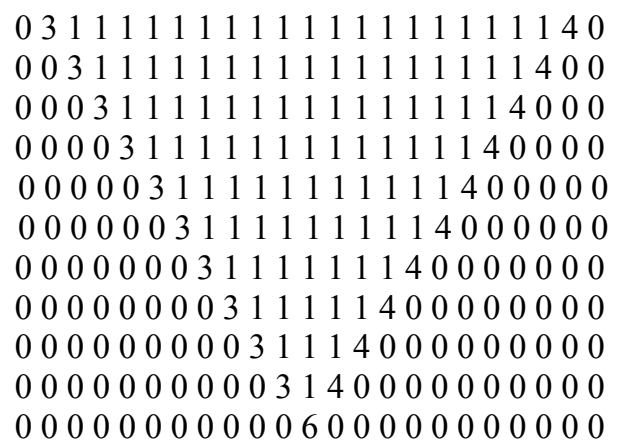

52222222222222222222225

03111111111111111111140

00311111111111111111400

00031111111111111114000

00003111111111111140000

00000311111111111400000

00000031111111114000000

00000003111111140000000

00000000311111400000000

00000000031114000000000

00000000003140000000000

00000000000600000000000

52222222222222222222225

03111111111111111111140

00311111111111111111400

00031111111111111114000

00003111111111111140000

00000311111111111400000

00000031111111114000000

00000003111111140000000

00000000311111400000000

00000000031114000000000

00000000003140000000000

00000000000600000000000

52222222222222222222225

03111111111111111111140

00311111111111111111400

00031111111111111114000

00003111111111111140000

00000311111111111400000

00000031111111114000000

00000003111111140000000

00000000311111400000000

00000000031114000000000

00000000003140000000000

00000000000600000000000

52222222222222222222225

03111111111111111111140

00311111111111111111400

00031111111111111114000

00003111111111111140000 
00000311111111111400000 00000031111111114000000 00000003111111140000000 00000000311111400000000 00000000031114000000000 00000000003140000000000 00000000000600000000000

52222222222222222222225 03111111111111111111140 00311111111111111111400 00031111111111111114000 00003111111111111140000 00000311111111111400000 00000031111111114000000 00000003111111140000000 00000000311111400000000 00000000031114000000000 00000000003140000000000 00000000000600000000000

52222222222222222222225 03111111111111111111140 00311111111111111111400 00031111111111111114000 00003111111111111140000 00000311111111111400000 00000031111111114000000 00000003111111140000000 00000000311111400000000 00000000031114000000000 00000000003140000000000 00000000000600000000000

52222222222222222222225 03111111111111111111140 00311111111111111111400 00031111111111111114000 00003111111111111140000 00000311111111111400000 00000031111111114000000 00000003111111140000000 00000000311111400000000 00000000031114000000000 00000000003140000000000 00000000000600000000000

*POR *CON 0.3

*PERMI *CON 1000

*PERMJ *EQUALSI

*PERMK *EQUALSI / 10

*END-GRID 
*CPOR 5e-4

*PRPOR 75

*ROCKCP 35

*THCONR 24

*THCONW 24

*THCONO 24

*THCONG 24

*HLOSSPROP *OVERBUR 4224 *UNDERBUR 4224

$* *=============$ FLUID DEFINITIONS $===================$

*MODEL 222 ** Components are water and dead oil. Most water $* *$ properties are defaulted $(=0)$. Dead oil $\mathrm{K}$ values

** are zero, and no gas properties are needed.

$\begin{array}{llll}\text { *COMPNAME } & \text { 'WATER' } & \text { 'OIL' } & \\ \text { ** } & ---- & - & \\ \text { *CMM } & 18.02 & 600 & \\ \text { *PCRIT } & 3206.2 & 0 & * * \text { These four properties } \\ \text { *TCRIT } & 705.4 & 0 & * * \text { are for the gas phase. } \\ \text { *AVG } & 1.13 \mathrm{e}-5 & 0 & \text { ** The dead oil component does } \\ \text { *BVG } & 1.075 & 0 & \text { ** not appear in the gas phase. } \\ \text { *MOLDEN } & 0 & 0.10113 \\ \text { *CP } & 0 & 5 . \mathrm{e}-6 \\ \text { *CT1 } & 0 & 3.8 \mathrm{e}-4 \\ \text { *CPL1 } & 0 & 300\end{array}$

*VISCTABLE

** Temp

$\begin{array}{lll}75 & 0 & 5780\end{array}$

$100 \quad 0 \quad 1380$

$\begin{array}{lll}150 & 0 & 187\end{array}$

$\begin{array}{lll}200 & 0 & 47\end{array}$

$\begin{array}{lll}250 & 0 & 17.4\end{array}$

$\begin{array}{lll}300 & 0 & 8.5\end{array}$

$\begin{array}{lll}350 & 0 & 5.2\end{array}$

$\begin{array}{lll}500 & 0 & 2.5\end{array}$

$\begin{array}{lll}800 & 0 & 2.5\end{array}$

*PRSR 14.7

*TEMR 60

*PSURF 14.7

*TSURF 60

** $============$ ROCK-FLUID PROPERTIES

*ROCKFLUID

*SWT ** Water-oil relative permeabilities 


\begin{tabular}{rrrl} 
** & $\mathrm{Sw}$ & $\mathrm{Krw}$ & \multicolumn{1}{c}{ Krow } \\
$* *$ & - & ------ & ---- \\
0.45 & 0.0 & 0.4 \\
0.47 & 0.000056 & 0.361 \\
0.50 & 0.000552 & 0.30625 \\
0.55 & 0.00312 & 0.225 \\
0.60 & 0.00861 & 0.15625 \\
0.65 & 0.01768 & 0.1 \\
0.70 & 0.03088 & 0.05625 \\
0.75 & 0.04871 & 0.025 \\
0.77 & 0.05724 & 0.016 \\
0.80 & 0.07162 & 0.00625 \\
0.82 & 0.08229 & 0.00225 \\
0.85 & 0.1 & 0.0
\end{tabular}

*SLT ** Liquid-gas relative permeabilities

\begin{tabular}{|c|c|c|}
\hline * Sl & $\mathrm{Krg}$ & Krog \\
\hline "--- & & \\
\hline 0.45 & 0.2 & 0.0 \\
\hline 0.55 & 0.14202 & 0.0 \\
\hline 0.57 & 0.13123 & 0.00079 \\
\hline 0.60 & 0.11560 & 0.00494 \\
\hline 0.62 & 0.10555 & 0.00968 \\
\hline 0.65 & 0.09106 & 0.01975 \\
\hline 0.67 & 0.08181 & 0.02844 \\
\hline 0.70 & 0.06856 & 0.04444 \\
\hline 0.72 & 0.06017 & 0.05709 \\
\hline 0.75 & 0.04829 & 0.07901 \\
\hline 0.77 & 0.04087 & 0.09560 \\
\hline 0.80 & 0.03054 & 0.12346 \\
\hline 0.83 & 0.02 & 0.15486 \\
\hline 0.85 & 0.01574 & 0.17778 \\
\hline 0.87 & 0.01080 & 0.20227 \\
\hline 0.90 & 0.00467 & 0.24198 \\
\hline 0.92 & 0.00165 & 0.27042 \\
\hline 0.94 & 0.0 & 0.30044 \\
\hline & 0.0 & 0.4 \\
\hline
\end{tabular}

** $=============$ INITIAL CONDITIONS

*INITIAL

** Automatic static vertical equilibrium

*VERTICAL *DEPTH_AVE

*REFPRES 75

*REFBLOCK 111

*TEMP *CON 125 


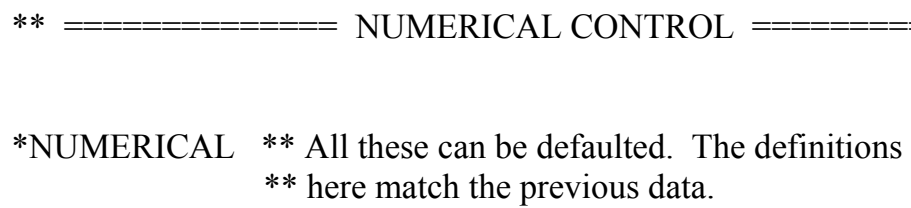

*NORM *PRESS 200 *SATUR $0.2 *$ TEMP 50

*RUN

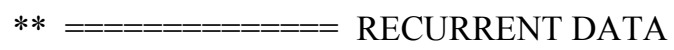

** Project starts on January 01, 2004

*DATE 20040101

*DTWELL 1

*WELL 1 'INJECTOR' *VERT 11 *FRAC .125

*WELL 2 'PRODUCER' *VERT 231 *FRAC .125

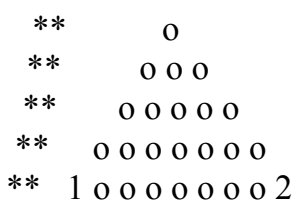

*INJECTOR *MOBWEIGHT 'INJECTOR'

*INCOMP WATER $1.0 \quad 0.0$

*TINJW 545

QUAL .7

*OPERATE *BHP 1000

*OPERATE *MAX *STW 400

*PERFV 'INJECTOR' $* * \mathrm{k}$ wi

$\begin{array}{ll}6 & 32235.39\end{array}$

32235.39

32235.39

32235.39

32235.39

32235.39

$12 \quad 32235.39$

$$
\begin{aligned}
& * * \text { Inject only in the bottom layer } \\
& * * 2 * \mathrm{pi}^{*} \mathrm{k} * \mathrm{~h} / \ln (\mathrm{cc} * \operatorname{sqrt}((\mathrm{dx} * * 2+\mathrm{dy} * * 2) / \mathrm{pi}) / \mathrm{rw}) \\
& * * \mathrm{k}=1000 \mathrm{md}, \mathrm{h}=10 \mathrm{ft}, \mathrm{dx}=\mathrm{dy}=10.6045 \mathrm{ft}, \\
& * * \mathrm{cc}=0.249, \mathrm{rw}=0.3 \mathrm{ft}
\end{aligned}
$$

*PRODUCER 'PRODUCER'

*OPERATE *BHP 17

*PERFV 'PRODUCER' **

$\begin{array}{lc}\mathrm{k} & \text { wi } \\ 1 & 32235.39 \\ 2 & 32235.39 \\ 3 & 32235.39 \\ 4 & 32235.39 \\ 5 & 32235.39 \\ 6 & 32235.39 \\ 7 & 32235.39 \\ 8 & 32235.39 \\ 9 & 32235.39 \\ 10 & 32235.39 \\ 11 & 32235.39\end{array}$


$12 \quad 32235.39$

OPEN 'PRODUCER'

OPEN 'INJECTOR'

*TIME 365

*TIME 730

*TIME 1095

*TIME 1460

*TIME 1825

*TIME 2190

*TIME 2555

*TIME 2920

*TIME 3285

*TIME 3650

*STOP 


\section{APPENDIX C \\ SIMULATION INPUT DATA FOR SAN ARDO CASE AREA $=10$ ACRE, STEAM INJECTION RATE $=1600$ STB/D}

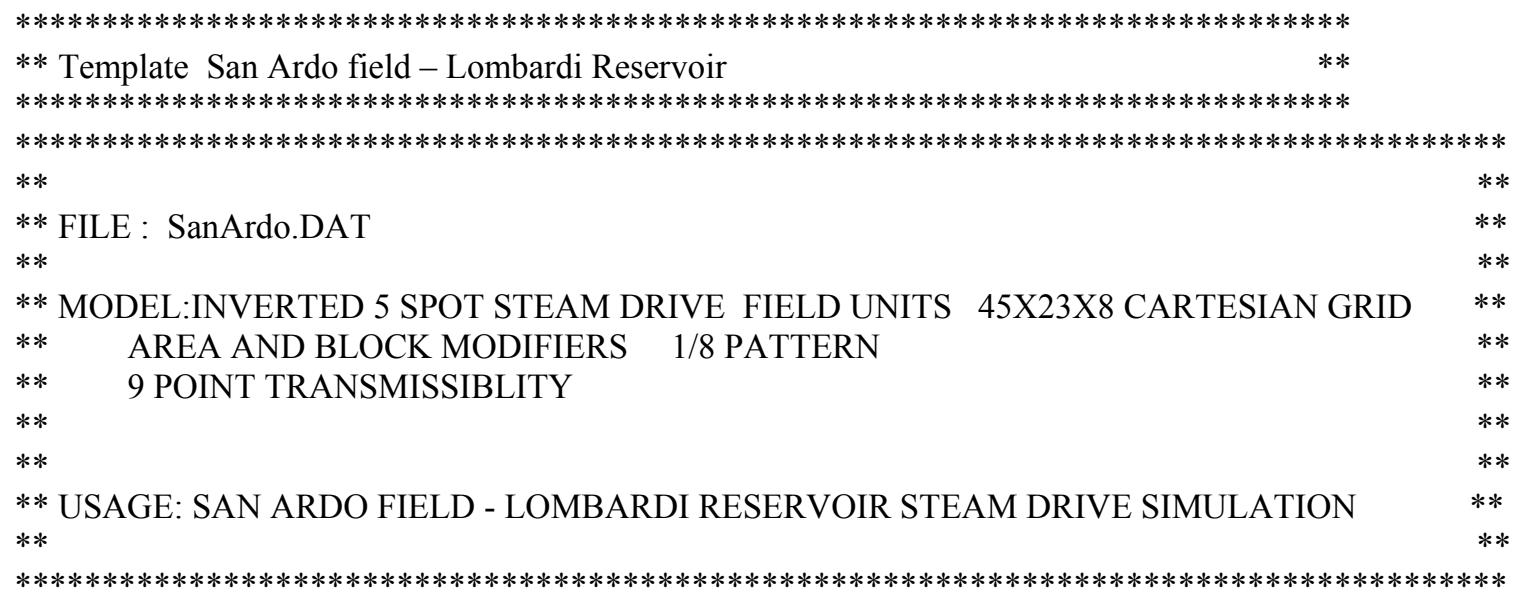

** $=============$ INPUT/OUTPUT CONTROL

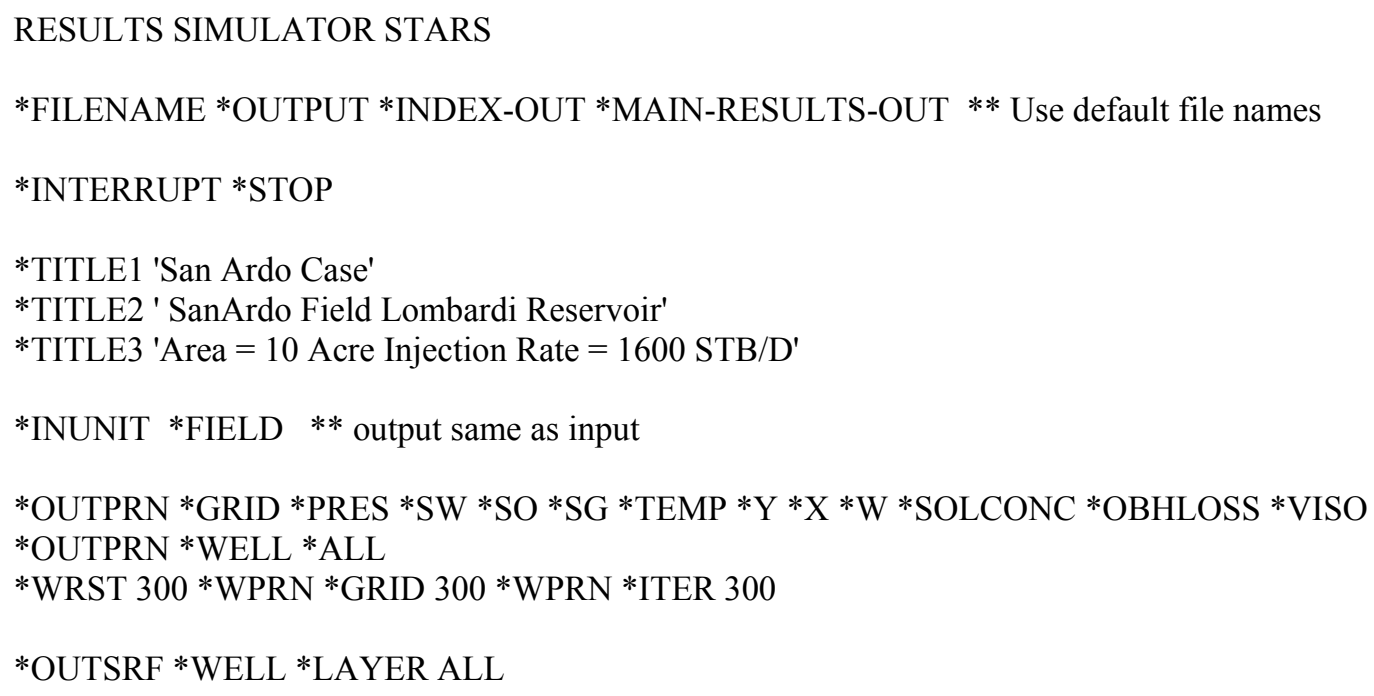


** In addition, a point-distributed grid is required in order to put

** grid nodes on the injector-producer line. To do this, an oversized

** grid is specified, and then trimmed back using block modifiers.

** The interwell distance is divided into 44 equal segments, requiring

** $n i=45$. The third corner is a $1 / 4$ block, and is located at $j=23$.

** The five-spot pattern is 10 acres in area, or $660 \mathrm{ft}$ square. The

** distance between injector and producer is $(660 / 2) * 1.414=$

** $466.69 \mathrm{ft}$, giving a block size of 233.3/44 = $10.6045 \mathrm{ft}$.

*DI *CON 10.607

*DJ *CON 10.607

*DK *CON 14.375

DTOP $1035 * 1900$

** Trim grid to $1 / 8$ of an inverted 9 -spot pattern

*VAMOD $2 \quad 0.5 \quad 0.5 \quad 1.0 \quad 0.5$

$\begin{array}{lllllllll}* \text { VAMOD } 3 & 0.5 & 1.0 & 1.0 & 0.5 & * 9 \mathrm{p} & 0.5 & 1.0\end{array}$

$\begin{array}{lllllllll}* V A M O D & & 0.5 & 1.0 & 1.0 & 0.5 & * 9 p & 1.0 & 0.5\end{array}$

$\begin{array}{llllllllll}* \text { *VAMOD } 5 & 0.125 & 0.5 & 1.0 & 0.125 & * 9 \mathrm{p} & 0.5 & 1.0\end{array}$

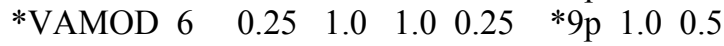

*VATYPE *ALL

522222222222222222222222222222222222222222225

031111111111111111111111111111111111111111140

003111111111111111111111111111111111111111400 000311111111111111111111111111111111111114000 000031111111111111111111111111111111111140000 000003111111111111111111111111111111111400000 000000311111111111111111111111111111114000000 000000031111111111111111111111111111140000000 000000003111111111111111111111111111400000000 000000000311111111111111111111111114000000000 000000000031111111111111111111111140000000000 000000000003111111111111111111111400000000000 000000000000311111111111111111114000000000000 000000000000031111111111111111140000000000000 000000000000003111111111111111400000000000000 000000000000000311111111111114000000000000000 000000000000000031111111111140000000000000000 000000000000000003111111111400000000000000000 000000000000000000311111114000000000000000000 000000000000000000031111140000000000000000000 000000000000000000003111400000000000000000000 000000000000000000000314000000000000000000000 0000000000000000000000600000000000000000000000

522222222222222222222222222222222222222222225 031111111111111111111111111111111111111111140 003111111111111111111111111111111111111111400 000311111111111111111111111111111111111114000 000031111111111111111111111111111111111140000 000003111111111111111111111111111111111400000 000000311111111111111111111111111111114000000 
000000031111111111111111111111111111140000000 000000003111111111111111111111111111400000000 000000000311111111111111111111111114000000000 000000000031111111111111111111111140000000000 000000000003111111111111111111111400000000000 000000000000311111111111111111114000000000000 000000000000031111111111111111140000000000000 000000000000003111111111111111400000000000000 000000000000000311111111111114000000000000000 000000000000000031111111111140000000000000000 000000000000000003111111111400000000000000000 000000000000000000311111114000000000000000000 0000000000000000000311111400000000000000000000000 0000000000000000000031114000000000000000000000 000000000000000000000314000000000000000000000 000000000000000000000000600000000000000000000000000

522222222222222222222222222222222222222222225 031111111111111111111111111111111111111111140 003111111111111111111111111111111111111111400 000311111111111111111111111111111111111114000 000031111111111111111111111111111111111140000 000003111111111111111111111111111111111400000 000000311111111111111111111111111111114000000 000000031111111111111111111111111111140000000 000000003111111111111111111111111111400000000 000000000311111111111111111111111114000000000 000000000031111111111111111111111140000000000 000000000003111111111111111111111400000000000 000000000000311111111111111111114000000000000 000000000000031111111111111111140000000000000 000000000000003111111111111111400000000000000 000000000000000311111111111114000000000000000 000000000000000031111111111140000000000000000 000000000000000003111111111400000000000000000 000000000000000000311111114000000000000000000 000000000000000000031111140000000000000000000 000000000000000000003111400000000000000000000 0000000000000000000003140000000000000000000000 000000000000000000000060000000000000000000000

522222222222222222222222222222222222222222225 031111111111111111111111111111111111111111140 003111111111111111111111111111111111111111400 000311111111111111111111111111111111111114000 000031111111111111111111111111111111111140000 000003111111111111111111111111111111111400000 000000311111111111111111111111111111114000000 000000031111111111111111111111111111140000000 000000003111111111111111111111111111400000000 000000000311111111111111111111111114000000000 000000000031111111111111111111111140000000000 000000000003111111111111111111111400000000000 000000000000311111111111111111114000000000000 000000000000031111111111111111140000000000000 000000000000003111111111111111400000000000000 
000000000000000311111111111114000000000000000 000000000000000031111111111140000000000000000 000000000000000003111111111400000000000000000 000000000000000000311111114000000000000000000 0000000000000000000311111400000000000000000000 00000000000000000000311140000000000000000000000 000000000000000000000314000000000000000000000 000000000000000000000060000000000000000000000

522222222222222222222222222222222222222222225 031111111111111111111111111111111111111111140 003111111111111111111111111111111111111111400 000311111111111111111111111111111111111114000 000031111111111111111111111111111111111140000 000003111111111111111111111111111111111400000 000000311111111111111111111111111111114000000 000000031111111111111111111111111111140000000 000000003111111111111111111111111111400000000 000000000311111111111111111111111114000000000 000000000031111111111111111111111140000000000 000000000003111111111111111111111400000000000 000000000000311111111111111111114000000000000 000000000000031111111111111111140000000000000 000000000000003111111111111111400000000000000 000000000000000311111111111114000000000000000 000000000000000031111111111140000000000000000 000000000000000003111111111400000000000000000 000000000000000000311111114000000000000000000 0000000000000000000311111400000000000000000000 000000000000000000003111400000000000000000000 00000000000000000000031400000000000000000000000 0000000000000000000000600000000000000000000000

522222222222222222222222222222222222222222225 031111111111111111111111111111111111111111140 003111111111111111111111111111111111111111400 000311111111111111111111111111111111111114000 000031111111111111111111111111111111111140000 000003111111111111111111111111111111111400000 000000311111111111111111111111111111114000000 000000031111111111111111111111111111140000000 000000003111111111111111111111111111400000000 000000000311111111111111111111111114000000000 000000000031111111111111111111111140000000000 000000000003111111111111111111111400000000000 000000000000311111111111111111114000000000000 000000000000031111111111111111140000000000000 000000000000003111111111111111400000000000000 000000000000000311111111111114000000000000000 000000000000000031111111111140000000000000000 000000000000000003111111111400000000000000000 000000000000000000311111114000000000000000000 000000000000000000031111140000000000000000000 000000000000000000003111400000000000000000000 000000000000000000000314000000000000000000000 000000000000000000000060000000000000000000000 
522222222222222222222222222222222222222222225 031111111111111111111111111111111111111111140 003111111111111111111111111111111111111111400 000311111111111111111111111111111111111114000 000031111111111111111111111111111111111140000 000003111111111111111111111111111111111400000 000000311111111111111111111111111111114000000 000000031111111111111111111111111111140000000 000000003111111111111111111111111111400000000 000000000311111111111111111111111114000000000 000000000031111111111111111111111140000000000 000000000003111111111111111111111400000000000 000000000000311111111111111111114000000000000 000000000000031111111111111111140000000000000 000000000000003111111111111111400000000000000 000000000000000311111111111114000000000000000 000000000000000031111111111140000000000000000 000000000000000003111111111400000000000000000 0000000000000000003111111140000000000000000000 00000000000000000003111114000000000000000000000 000000000000000000003111400000000000000000000 00000000000000000000003140000000000000000000000000 000000000000000000000060000000000000000000000000

522222222222222222222222222222222222222222225 031111111111111111111111111111111111111111140 003111111111111111111111111111111111111111400 000311111111111111111111111111111111111114000 000031111111111111111111111111111111111140000 000003111111111111111111111111111111111400000 000000311111111111111111111111111111114000000 000000031111111111111111111111111111140000000 000000003111111111111111111111111111400000000 000000000311111111111111111111111114000000000 000000000031111111111111111111111140000000000 000000000003111111111111111111111400000000000 000000000000311111111111111111114000000000000 000000000000031111111111111111140000000000000 000000000000003111111111111111400000000000000 000000000000000311111111111114000000000000000 000000000000000031111111111140000000000000000 000000000000000003111111111400000000000000000 000000000000000000311111114000000000000000000 000000000000000000031111140000000000000000000 000000000000000000003111400000000000000000000 0000000000000000000003140000000000000000000000000 000000000000000000000060000000000000000000000

\footnotetext{
*POR *CON 0.345

*PERMI *CON 6922

*PERMJ *EQUALSI

*PERMK *EQUALSI / 10
} 
*END-GRID

*CPOR 8E-04

*PRPOR 275

*ROCKCP 35.02

*THCONR 24

*THCONW 24

*THCONO 24

*THCONG 24

*HLOSSPROP *OVERBUR 6024 *UNDERBUR 6024

\begin{tabular}{|c|c|c|c|}
\hline *MODEL 333 & \multicolumn{3}{|c|}{ ** Components are water and live oil (consists of 'GAS' and 'OIL') } \\
\hline $\begin{array}{l}\text { COMPNAME } \\
* *\end{array}$ & 'WATER' & 'OIL' & $\begin{array}{l}\text { 'GAS' } \\
------\end{array}$ \\
\hline CMM & 0.0000 & 456.015 & 16.7278 \\
\hline PCRIT & 0.00 & 179.02 & 670.46 \\
\hline TCRIT & 0.00 & 1036.21 & -107.35 \\
\hline KV1 & $0.000 \mathrm{E}+0$ & $5.165 \mathrm{E}+6$ & $1.534 \mathrm{E}+5$ \\
\hline KV2 & $0.000 \mathrm{E}+0$ & $0.000 \mathrm{E}+0$ & $0.000 \mathrm{E}+0$ \\
\hline KV3 & $0.000 \mathrm{E}+0$ & $0.000 \mathrm{E}+0$ & $0.000 \mathrm{E}+0$ \\
\hline KV4 & 0.0 & -15362.5 & -1914.1 \\
\hline KV5 & 0.00 & -459.67 & -459.67 \\
\hline MOLDEN & $0.000 \mathrm{E}+00$ & $1.356 \mathrm{E}-01$ & $4.515 \mathrm{E}-02$ \\
\hline $\mathrm{CP}$ & $0.000 \mathrm{E}+00$ & $3.805 \mathrm{E}-06$ & $3.754 \mathrm{E}-03$ \\
\hline CT1 & $0.000 \mathrm{E}+00$ & $1.660 \mathrm{E}-04$ & 1.910E-03 \\
\hline
\end{tabular}

\begin{tabular}{|c|c|c|c|}
\hline $\begin{array}{l}\text { VISCTABL } \\
* * \mathrm{~T}, \operatorname{deg} \mathrm{F} \\
* *\end{array}$ & 'WATER' & 'OIL' 'G & \\
\hline 50.000 & $0.0000 \mathrm{E}+00$ & 500000 & $1.1018 \mathrm{E}-02$ \\
\hline 100.000 & $0.0000 \mathrm{E}+00$ & 20000 & $1.1882 \mathrm{E}-02$ \\
\hline 150.000 & $0.0000 \mathrm{E}+00$ & 1500 & $1.2721 \mathrm{E}-02$ \\
\hline 200.000 & $0.0000 \mathrm{E}+00$ & 240 & $1.3536 \mathrm{E}-02$ \\
\hline 250.000 & $0.0000 \mathrm{E}+00$ & 60 & $1.4326 \mathrm{E}-02$ \\
\hline 300.000 & $0.0000 \mathrm{E}+00$ & 20 & $1.5094 \mathrm{E}-02$ \\
\hline 350.000 & $0.0000 \mathrm{E}+00$ & 8 & $1.5840 \mathrm{E}-02$ \\
\hline 400.000 & $0.0000 \mathrm{E}+00$ & 3.5 & $1.6566 \mathrm{E}-02$ \\
\hline 450.000 & $0.0000 \mathrm{E}+00$ & 1.8 & $1.7273 \mathrm{E}-02$ \\
\hline 500.000 & $0.0000 \mathrm{E}+00$ & 1 & $1.7962 \mathrm{E}-02$ \\
\hline 550.000 & $0.0000 \mathrm{E}+00$ & 0.6 & $1.8635 \mathrm{E}-02$ \\
\hline 600.000 & $0.0000 \mathrm{E}+00$ & 0.35 & $1.9293 \mathrm{E}-02$ \\
\hline 650.000 & $0.0000 \mathrm{E}+00$ & 0.2 & $1.9937 \mathrm{E}-02$ \\
\hline 700.000 & $0.0000 \mathrm{E}+00$ & 0.13 & $2.0568 \mathrm{E}-02$ \\
\hline
\end{tabular}

PRSR $275.000 * *$ reference pressure, corresponding to the density TEMR $127.000 * *$ reference temperature, corresponding to the density PSURF $14.696^{* *}$ pressure at surface, for reporting well rates, etc.

TSURF $60.000 * *$ temperature at surface, for reporting well rates, etc. 
$* *$ ROCK-FLUID PROPERTIES

*ROCKFLUID

\begin{tabular}{llllll} 
*RPT 1 *WATWET *STONE2 & $* *$ \\
*SWT & \multicolumn{4}{c}{$* *$ WATER-OIL } \\
** & Sw & Krw & Krow \\
$* *$ & --- & ----- & ----- & \\
& 0.500000 & 0.000000 & 0.550000 & 0.000000 \\
& 0.525000 & 0.010000 & 0.275000 & 0.000000 \\
& 0.550000 & 0.020000 & 0.120000 & 0.000000 \\
& 0.575000 & 0.030000 & 0.020000 & 0.000000 \\
& 0.600000 & 0.050000 & 0.000000 & 0.000000 \\
& 0.625000 & 0.080000 & 0.000000 & 0.000000 \\
& 0.650000 & 0.115000 & 0.000000 & 0.000000 \\
0.675000 & 0.150000 & 0.000000 & 0.000000 \\
& 0.700000 & 0.195000 & 0.000000 & 0.000000 \\
0.725000 & 0.245000 & 0.000000 & 0.000000 \\
& 0.750000 & 0.295000 & 0.000000 & 0.000000 \\
0.775000 & 0.360000 & 0.000000 & 0.000000 \\
0.800000 & 0.420000 & 0.000000 & 0.000000 \\
0.825000 & 0.495000 & 0.000000 & 0.000000 \\
0.850000 & 0.570000 & 0.000000 & 0.000000 \\
0.875000 & 0.650000 & 0.000000 & 0.000000 \\
0.900000 & 0.740000 & 0.000000 & 0.000000 \\
1.000000 & 1.000000 & 0.000000 & 0.000000
\end{tabular}

*SLT *NOSWC

** $\quad$ SL $\quad$ KRG $\quad$ KROG

$\begin{array}{lllll}0.850000 & 0.460000 & 0.000000 & 0.000000\end{array}$ $\begin{array}{lllll}0.875000 & 0.290000 & 0.065000 & 0.000000\end{array}$ $\begin{array}{lllll}0.900000 & 0.160000 & 0.150000 & 0.000000\end{array}$ $\begin{array}{lllll}0.925000 & 0.080000 & 0.240000 & 0.000000\end{array}$ $\begin{array}{lllll}0.950000 & 0.030000 & 0.340000 & 0.000000\end{array}$ $\begin{array}{lllll}0.975000 & 0.005000 & 0.435000 & 0.000000\end{array}$ $\begin{array}{llll}1.000000 & 0.000000 & 0.550000 & 0.000000\end{array}$

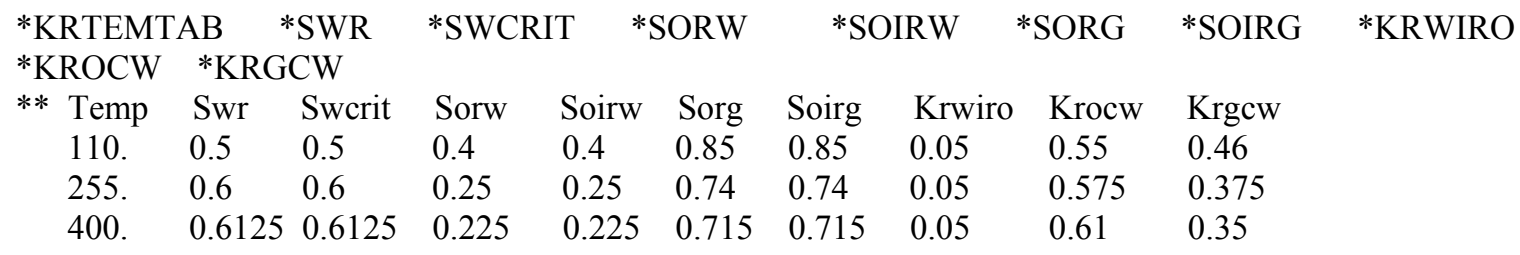

\footnotetext{
$* *=============$ INITIAL CONDITIONS $====================$
}

\footnotetext{
*INITIAL

** Automatic static vertical equilibrium

*VERTICAL *DEPTH_AVE
} 
*REFPRES 275

*REFDEPTH 1957.5

SW CON 0.267

SO CON 0.733

*TEMP *CON 127

MFRAC OIL 'OIL' CON 0.78904

MFRAC_GAS 'GAS' CON 0.21096

** $==============$ NUMERICAL CONTROL

*NUMERICAL

*NORM *PRESS $200 *$ SATUR $0.2 *$ TEMP 50

*RUN

$* *==============$ RECURRENT DATA

** Project starts on January 01,2004

*DATE 20040101

*DTWELL 1

*WELL 1 'INJECTOR' *VERT 11 *FRAC .125

*WELL 2 'PRODUCER' *VERT 451 *FRAC .125

$$
\begin{aligned}
& \text { ** } \quad 0 \\
& \text { ** } \quad \text { o o o } \\
& \text { ** oо оо } \\
& \text { ** o о о о о о } \\
& \text { ** } 1 \text { o o o o o o o } 2
\end{aligned}
$$

*INJECTOR *MOBWEIGHT 'INJECTOR'

*INCOMP WATER $1.0 \quad 0.0 \quad 0.0$

*TINJW 582.3

QUAL .8

*OPERATE *BHP 1350

*OPERATE *MAX *STW 1600

*PERFV 'INJECTOR' ** $\mathrm{k}$ wi

** Inject only in the bottom layer

** $2 * \mathrm{pi}^{*} \mathrm{k} * \mathrm{~h} / \ln \left(\mathrm{cc}^{*} \operatorname{sqrt}((\mathrm{dx} * * 2+\mathrm{dy} * * 2) / \mathrm{pi}) / \mathrm{rw}\right)$

$5 \quad 320715.436$

$6 \quad 320715.436$

$7 \quad 320715.436$

$8 \quad 320715.436$

$* * \mathrm{k}=6922 \mathrm{md}, \mathrm{h}=14.375 \mathrm{ft}, \mathrm{dx}=\mathrm{dy}=10.607 \mathrm{ft}$, $* * \mathrm{cc}=0.249, \mathrm{rw}=0.3 \mathrm{ft}$

*PRODUCER 'PRODUCER'

*OPERATE *BHP 15

*OPERATE *MAX *STL 5000

**OPERATE *MAX *STEAM $10 * *$ Steam CWE in bbl/day

*PERFV 'PRODUCER' $\quad * * \quad \mathrm{k}$ wi 


$\begin{array}{ll}5 & 320715.436 \\ 6 & 320715.436 \\ 7 & 320715.436 \\ 8 & 320715.436\end{array}$

\section{OPEN 'PRODUCER'}

OPEN 'INJECTOR'

*TIME 365

*TIME 730

*TIME 1095

*TIME 1460

*TIME 1825

*TIME 2190

*TIME 2555

*TIME 2920

*TIME 3285

*TIME 3650

*TIME 4015

*TIME 4380

*TIME 4745

*TIME 5110

*TIME 5475

*TIME 5840

*TIME 6205

*TIME 6570

*TIME 6935

*TIME 7300

*STOP 


\section{APPENDIX D \\ SIMULATION INPUT DATA FOR HAMACA CASE AREA = 10 ACRE, STEAM INJECTION RATE = 1600 STB/D}

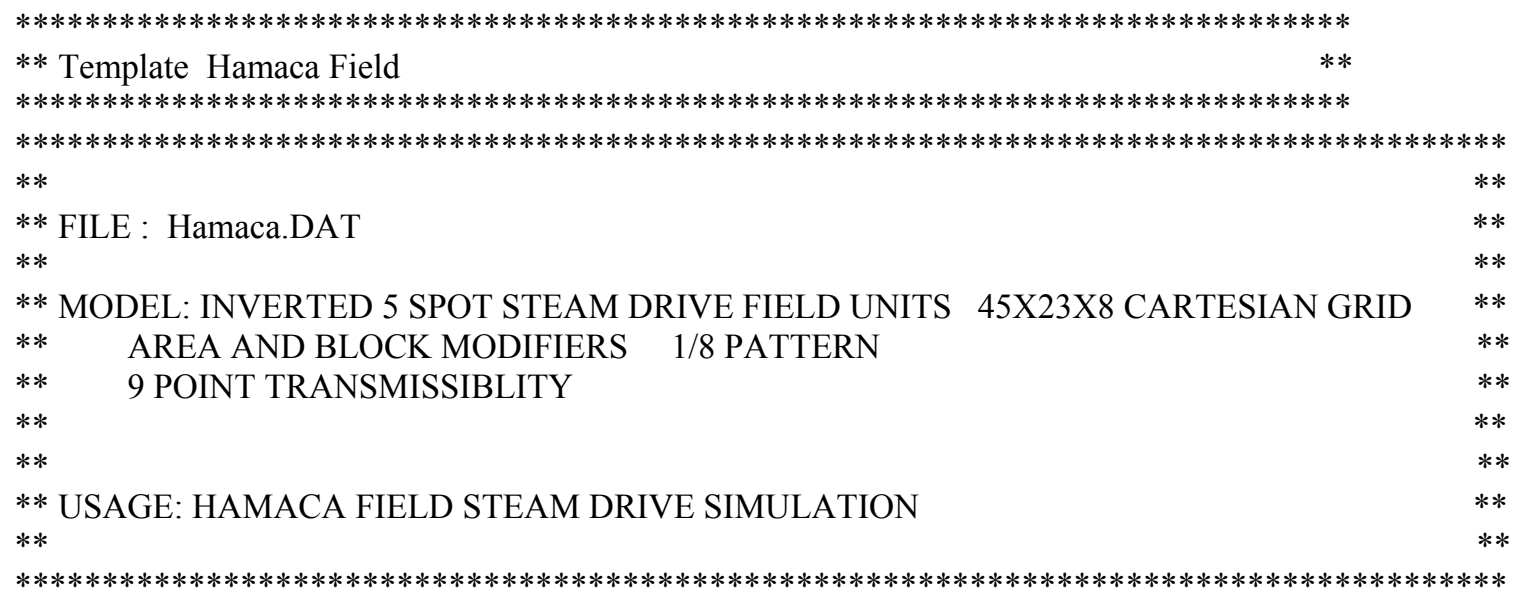

$* *===========$ INPUT/OUTPUT CONTROL

\section{RESULTS SIMULATOR STARS}

*FILENAME *OUTPUT *INDEX-OUT *MAIN-RESULTS-OUT ** Use default file names

\section{**CHECKONLY}

*INTERRUPT *STOP

*TITLE1 'Hamaca Case'

*TITLE2 'Hamaca Field'

$*$ TITLE3 'Area $=10$ Acre Injection Rate $=1600$ STB/D'

*INUNIT *FIELD ** output same as input

*OUTPRN *GRID *PRES *SW *SO *SG *TEMP *Y *X*W *SOLCONC *OBHLOSS *VISO

*OUTPRN *WELL *ALL

*WRST $300 *$ WPRN *GRID $300 *$ WPRN *ITER 300

*OUTSRF *WELL *LAYER ALL

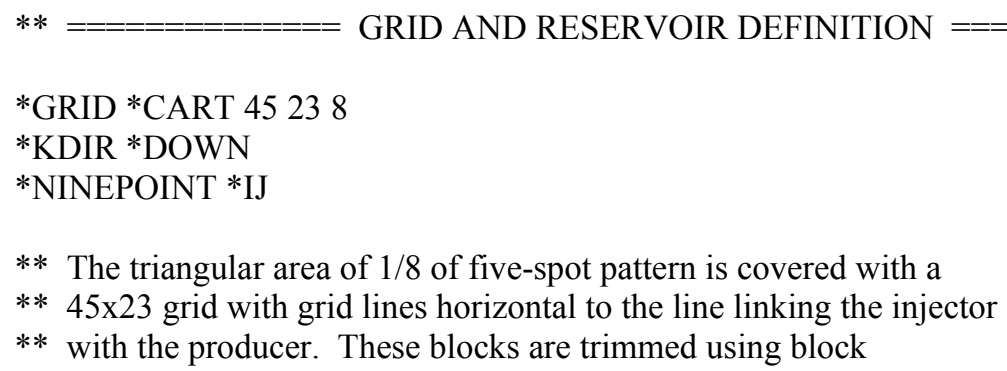




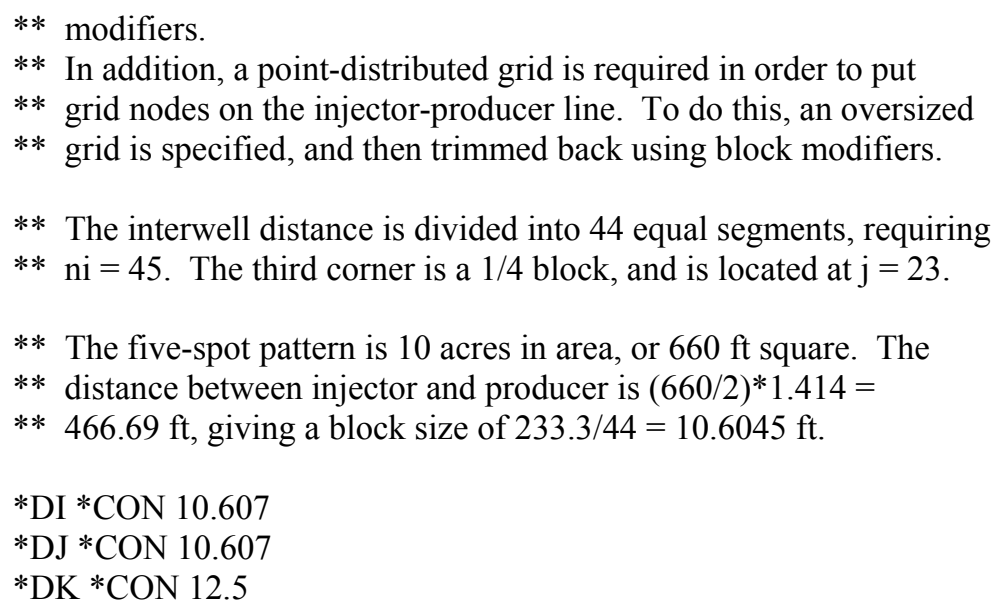

522222222222222222222222222222222222222222225 031111111111111111111111111111111111111111140 003111111111111111111111111111111111111111111400 000311111111111111111111111111111111111114000 000031111111111111111111111111111111111140000 000003111111111111111111111111111111111400000 
000000311111111111111111111111111111114000000 000000031111111111111111111111111111140000000 000000003111111111111111111111111111111440000000000 0000000003111111111111111111111111114000000000 0000000000311111111111111111111111400000000000 000000000003111111111111111111111400000000000 000000000000311111111111111111114000000000000 000000000000031111111111111111140000000000000 000000000000003111111111111111400000000000000 000000000000000311111111111114000000000000000 000000000000000031111111111140000000000000000 000000000000000000311111111114000000000000000000000 000000000000000000311111114000000000000000000 000000000000000000031111140000000000000000000 000000000000000000003111400000000000000000000 000000000000000000000314000000000000000000000 0000000000000000000000600000000000000000000000

522222222222222222222222222222222222222222225 031111111111111111111111111111111111111111140 003111111111111111111111111111111111111111400 000311111111111111111111111111111111111114000 000031111111111111111111111111111111111111111400000 0000031111111111111111111111111111111114000000 0000003111111111111111111111111111111140000000 000000031111111111111111111111111111140000000 0000000031111111111111111111111111114000000000 000000000311111111111111111111111114000000000 000000000031111111111111111111111140000000000 0000000000031111111111111111111114000000000000 000000000000311111111111111111111400000000000000 000000000000031111111111111111140000000000000 000000000000003111111111111111400000000000000 000000000000000311111111111114000000000000000 0000000000000000311111111111140000000000000000 000000000000000003111111111400000000000000000 000000000000000000311111114000000000000000000 00000000000000000003111114000000000000000000000 000000000000000000003111400000000000000000000 000000000000000000000331400000000000000000000000 000000000000000000000060000000000000000000000

522222222222222222222222222222222222222222225 031111111111111111111111111111111111111111140 003111111111111111111111111111111111111111400 000311111111111111111111111111111111111114000 000031111111111111111111111111111111111140000 0000031111111111111111111111111111111114000000 000000311111111111111111111111111111114000000 0000000311111111111111111111111111111400000000 000000003111111111111111111111111111400000000 0000000003111111111111111111111111140000000000 0000000000311111111111111111111111400000000000 000000000003111111111111111111111400000000000 000000000000311111111111111111114000000000000 0000000000000311111111111111111400000000000000 
000000000000003111111111111111400000000000000 000000000000000311111111111114000000000000000 000000000000000031111111111140000000000000000 000000000000000003111111111400000000000000000 000000000000000000311111114000000000000000000 000000000000000000031111140000000000000000000 0000000000000000000031114000000000000000000000 000000000000000000000314000000000000000000000 000000000000000000000060000000000000000000000

522222222222222222222222222222222222222222225 031111111111111111111111111111111111111111140 003111111111111111111111111111111111111111400 000311111111111111111111111111111111111114000 000031111111111111111111111111111111111140000 000003111111111111111111111111111111111400000 000000311111111111111111111111111111114000000 000000031111111111111111111111111111140000000 000000003111111111111111111111111111400000000 000000000311111111111111111111111114000000000 000000000031111111111111111111111140000000000 000000000003111111111111111111111400000000000 000000000000311111111111111111114000000000000 000000000000031111111111111111140000000000000 000000000000003111111111111111400000000000000 000000000000000311111111111114000000000000000 000000000000000031111111111140000000000000000 000000000000000003111111111400000000000000000 000000000000000000311111114000000000000000000 0000000000000000000311111400000000000000000000 000000000000000000003111400000000000000000000 0000000000000000000003140000000000000000000000 000000000000000000000060000000000000000000000

522222222222222222222222222222222222222222225 031111111111111111111111111111111111111111140 003111111111111111111111111111111111111111400 000311111111111111111111111111111111111114000 000031111111111111111111111111111111111140000 000003111111111111111111111111111111111400000 000000311111111111111111111111111111114000000 000000031111111111111111111111111111140000000 000000003111111111111111111111111111400000000 000000000311111111111111111111111114000000000 000000000031111111111111111111111140000000000 000000000003111111111111111111111400000000000 000000000000311111111111111111114000000000000 000000000000031111111111111111140000000000000 000000000000003111111111111111400000000000000 000000000000000311111111111114000000000000000 000000000000000031111111111140000000000000000 000000000000000003111111111400000000000000000 0000000000000000003111111140000000000000000000 0000000000000000000311111400000000000000000000 0000000000000000000031114000000000000000000000 
000000000000000000000314000000000000000000000 000000000000000000000060000000000000000000000

522222222222222222222222222222222222222222225 031111111111111111111111111111111111111111140 003111111111111111111111111111111111111111400 000311111111111111111111111111111111111114000 000031111111111111111111111111111111111140000 000003111111111111111111111111111111111400000 000000311111111111111111111111111111114000000 000000031111111111111111111111111111140000000 000000003111111111111111111111111111400000000 000000000311111111111111111111111114000000000 000000000031111111111111111111111140000000000 000000000003111111111111111111111400000000000 000000000000311111111111111111114000000000000 000000000000031111111111111111140000000000000 000000000000003111111111111111400000000000000 0000000000000003111111111111140000000000000000 000000000000000031111111111140000000000000000 000000000000000003111111111400000000000000000 000000000000000000311111114000000000000000000 0000000000000000000311111400000000000000000000 00000000000000000000311140000000000000000000000 0000000000000000000003140000000000000000000000 000000000000000000000060000000000000000000000

522222222222222222222222222222222222222222225 031111111111111111111111111111111111111111140 003111111111111111111111111111111111111111400 000311111111111111111111111111111111111114000 000031111111111111111111111111111111111140000 000003111111111111111111111111111111111400000 000000311111111111111111111111111111114000000 000000031111111111111111111111111111140000000 000000003111111111111111111111111111400000000 000000000311111111111111111111111114000000000 000000000031111111111111111111111140000000000 000000000003111111111111111111111400000000000 000000000000311111111111111111114000000000000 000000000000031111111111111111140000000000000 000000000000003111111111111111400000000000000 000000000000000311111111111114000000000000000 000000000000000031111111111140000000000000000 000000000000000003111111111400000000000000000 000000000000000000311111114000000000000000000 000000000000000000031111140000000000000000000 00000000000000000000031114000000000000000000000000 0000000000000000000003140000000000000000000000 0000000000000000000000600000000000000000000000

\footnotetext{
*POR * CON 0.3

*PERMI *CON 12000

*PERMJ *EQUALSI

*PERMK *EQUALSI / 10
} 
*END-GRID

${ }^{*}$ CPOR $4 \mathrm{e}-4$

*PRPOR 275

*ROCKCP 35

*THCONR 24

*THCONW 24

*THCONO 24

*THCONG 24

*HLOSSPROP *OVERBUR 6024 *UNDERBUR 6024

** $==============$ FLUID DEFINITIONS $======================$

*MODEL 222 ** Components are water and dead oil. Most water

** properties are defaulted $(=0)$. Dead oil K values

** are zero, and no gas properties are needed.

$\begin{array}{lll}\text { *COMPNAME } & \text { 'WATER' } & \text { 'OIL' } \\ \text { ** } & ---- & ----- \\ \text { *CMM } & 18 & 511.78 \\ \text { *PCRIT } & 635 & 2415.7 \\ \text { *TCRIT } & 323 & 2280 \\ \text { *CPG1 } & 0 & 0 \\ \text { *CPG2 } & 0 & 0 \\ \text { *CPG3 } & 0 & 0 \\ \text { *CPG4 } & 0 & 0 \\ & & \\ \text { *MASSDEN } & 62.7401 & 63.18664 \\ \text { *CP } & 0 & 5 . \mathrm{e}-6 \\ \text { *CT1 } & 0 & 5.005 \mathrm{E}-4 \\ \text { *CT2 } & 0 & 0\end{array}$

*VISCTABLE

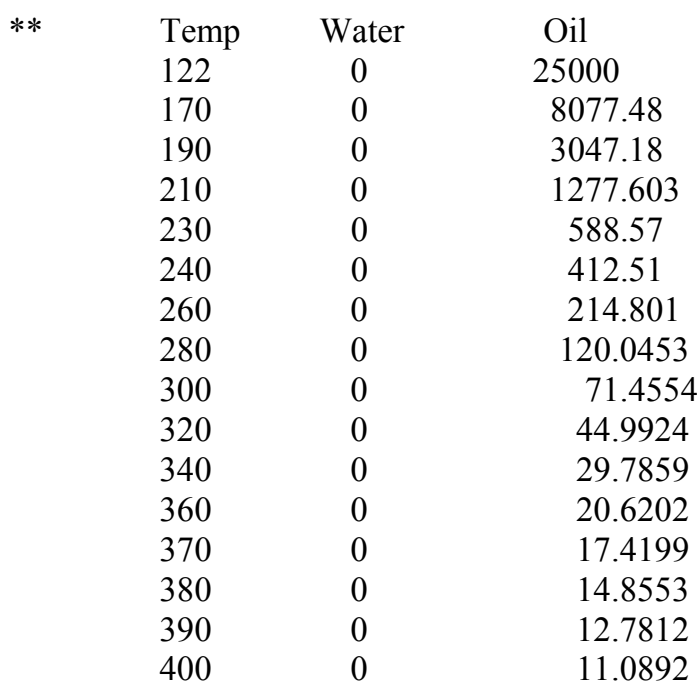




$\begin{array}{rll}410 & 0 & 9.697 \\ 420 & 0 & 8.5443 \\ 430 & 0 & 7.5815 \\ 440 & 0 & 6.7721 \\ 450 & 0 & 6.0873 \\ 460 & 0 & 5.5044 \\ 470 & 0 & 5.0053 \\ 480 & 0 & 4.5756 \\ 490 & 0 & 4.2038 \\ 500 & 0 & 3.8805 \\ 1000 & 0 & 3.8805\end{array}$

*PRSR 14.7

*TEMR 60

*PSURF 14.7

*TSURF 60

$* *=============$ ROCK-FLUID PROPERTIES

*ROCKFLUID

*SWT ** Water-oil relative permeabilities

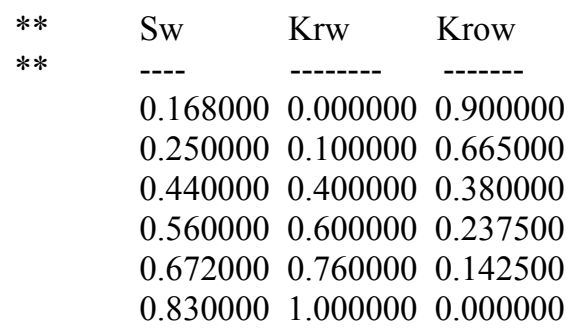

*SLT ** Liquid-gas relative permeabilities

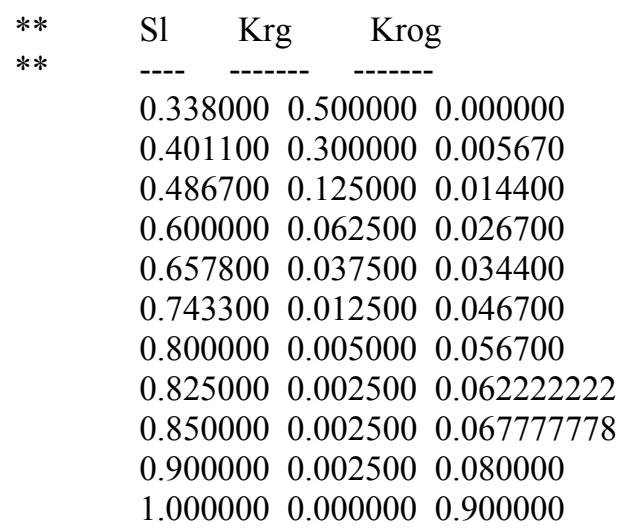

** $=============$ INITIAL CONDITIONS $====================$ 
*INITIAL

** Automatic static vertical equilibrium

*VERTICAL *DEPTH_AVE

*REFPRES 275

*REFBLOCK 111

*TEMP *CON 125

$* *=============$ NUMERICAL CONTROL

*NUMERICAL ** All these can be defaulted. The definitions

** here match the previous data.

*NORM *PRESS 30 *SATUR $0.09 *$ TEMP 15

* RUN

$* *============$ RECURRENT DATA

** Project starts on January 01, 2004

*DATE 20040101

*DTWELL 1

*WELL 1 'INJECTOR' *VERT 11 *FRAC .125

*WELL 2 'PRODUCER' *VERT 451 *FRAC .125

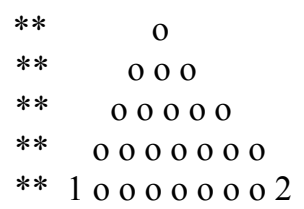

*INJECTOR *MOBWEIGHT 'INJECTOR'

*INCOMP WATER $1.0 \quad 0.0$

*TINJW 600

QUAL .8

*OPERATE *BHP 1600

*OPERATE *MAX *STW 1600

*PERFV 'INJECTOR' **

wi

483472.39

483472.39

483472.39

483472.39
** Inject only in the bottom layer

$* * 2 * \mathrm{pi}^{*} \mathrm{k} * \mathrm{~h} / \ln (\mathrm{cc} * \operatorname{sqrt}((\mathrm{dx} * * 2+\mathrm{dy} * * 2) / \mathrm{pi}) / \mathrm{rw})$

$* * \mathrm{k}=12000 \mathrm{md}, \mathrm{h}=12.5 \mathrm{ft}, \mathrm{dx}=\mathrm{dy}=10.607 \mathrm{ft}$,

$* * \mathrm{cc}=0.249, \mathrm{rw}=0.3 \mathrm{ft}$

*PRODUCER 'PRODUCER'

*OPERATE *BHP 90

*OPERATE *MAX *STL 3500 


$\begin{array}{llll}\text { *PERFV 'PRODUCER' } & * * & \mathrm{k} & \text { wi } \\ & & \\ 5 & 483472.39 \\ 6 & 483472.39 \\ 7 & 483472.39 \\ & 8 & 483472.39\end{array}$

\section{OPEN 'PRODUCER'}

OPEN 'INJECTOR'

*TIME 365

*TIME 730

*TIME 1095

*TIME 1460

*TIME 1825

*TIME 2190

*TIME 3650

*TIME 5475

*STOP 


\section{APPENDIX E}

\section{VBA PROGRAM OF NEW MODEL}

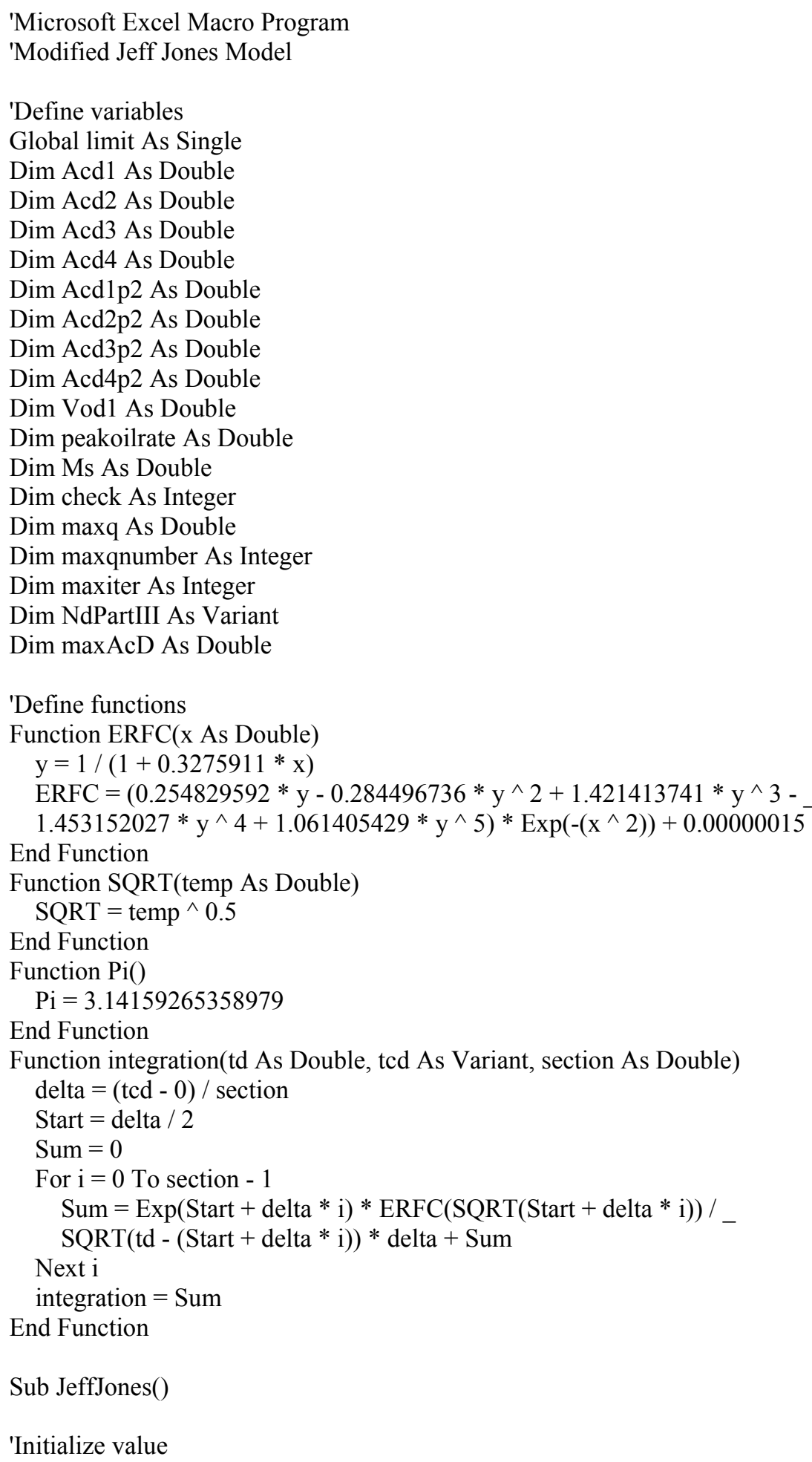


check $=0$
maxq $=0$
NdPartIII $=0$
StartIterVoD $=0$

With Sheets("JJ Formula")

'Get data entry

$\mathrm{a}=$ Worksheets("JJ Formula").Range("A").Value 'Area

por = Worksheets("JJ Formula").Range("por").Value 'Porosity

Soi $=$ Worksheets("JJ Formula").Range("Soi").Value 'Initial oil saturation

Sor = Worksheets("JJ Formula").Range("Sor").Value 'Residual oil saturation

$\mathrm{Sgi}=$ Worksheets("JJ Formula").Range("Sgi").Value 'Initial gas saturation

Oil_viscosity = Worksheets("JJ Formula").

Range("oil_viscosity").Value 'Initial Oil viscosity

Tres = Worksheets("JJ Formula").Range("Tres").Value 'Reservoir temperature

Bo = Worksheets("JJ Formula").Range("Bo").Value 'Oil formation volume factor

$\mathrm{kh}=$ Worksheets("JJ Formula").Range("kh").Value 'Thermal conductivity of formation

Rock_Density = Worksheets("JJ Formula").Range("Rock_Density").Value 'Rock Density

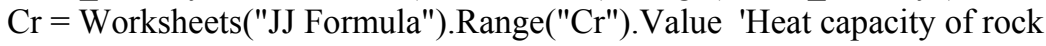

Water_Density = Worksheets("JJ Formula").

Range("Water_Density").Value 'Water density

Oil_Density = Worksheets("JJ Formula").Range("Oil_Density").Value 'Oil density

$\mathrm{Cw}=$ Worksheets("JJ Formula").Range("Cw").Value 'Heat capacity of water

$\mathrm{Co}=$ Worksheets("JJ Formula").Range("Co").Value 'Heat capacity of oil

ht $=$ Worksheets("JJ Formula").Range("ht").Value 'Total thickness

$\mathrm{hn}=$ Worksheets("JJ Formula").Range("hn").Value 'Net thickness

M_1Temp = Worksheets("JJ Formula").

Range("M_1Temp").Value 'Volumetric heat capacity of rock

Irate $=$ Worksheets("JJ Formula").Range("Irate").Value 'Injection rate

Ps = Worksheets("JJ Formula").Range("Ps").Value 'Saturated steam pressure

fs = Worksheets("JJ Formula").Range("fs").Value 'Steam quality

Tinj = Worksheets("JJ Formula").Range("Tinj").Value 'Injection temperature

viscosity = Worksheets("JJ Formula").

Range("viscosity").Value 'Oil viscosity@ steam temperature

Ms = Worksheets("JJ Formula").

Range("Ms").Value 'Volumetric heat capacity of overburden and underburden

TotalDay = Worksheets("JJ Formula").

Range("TotalDay").Value 'Total day of calculations

DeltaDay = Worksheets("JJ Formula").

Range("DeltaDay").Value 'Delta day of calculations

peakoilrate $=$ Irate 'Maximum oil production rate

'Calculate volumetric heat capacity of formation

If M_1 Temp $=0$ Then

M_1 $=(1-$ por $) *$ Rock_Density $* \mathrm{Cr}+$ por $*$ Sor * Oil_Density $*$ Co

Else + por $*(1-\mathrm{fs}) \wedge 0.5 *(1-$ Sor $) *$ Water_Density $* \overline{\mathrm{C}} \mathrm{W}$

M_1 = M_1Temp

End If

'Calculate enthalpy of condensate

If Ps $>=500$ And Ps $<=1500$ Then

$\mathrm{Hsc}=77.036 * \mathrm{Ps}^{\wedge} 0.28302$

ElseIf Ps $>1500$ And Ps $<=2500$ Then 


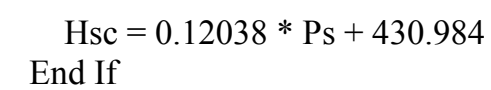

'Calculate enthalpy of vapor

$\mathrm{Hsv}=1204.8-0.000197697 *(\mathrm{Ps}-453.23)^{\wedge} 1.73808$

'Calculate latent heat of steam

hfg $=\mathrm{Hsv}-\mathrm{Hsc}$

'Calculate fraction of heat injected in vapor form

$\mathrm{fhv}=1 /(1+\mathrm{Cw} *($ Tinj - Tres $) /(\mathrm{fs} * \mathrm{hfg}))$

'Determine critical dimensionless time

Worksheets("JJ Formula").Range("goal").GoalSeek Goal:=fhv, ChangingCell:=Worksheets("JJ Formula").Range("ChangingCell") tcd = Worksheets("JJ Formula").Range("ChangingCell")

'Calculate ratio of enthalpy of vaporization to liquid enthalpy $\mathrm{fhD}=\mathrm{fs} * \mathrm{hfg} /(\mathrm{Cw} *($ Tinj - Tres $))$

'Calculate dimensionless time constant

'Dimensionless time $=\mathrm{tD}$ multiplier multiply by time

tD_multiplier $=35040 * \mathrm{Ms} * \mathrm{kh} /\left(\mathrm{ht}^{\wedge}{ }^{\wedge} 2 * \mathrm{M}_{-}{ }^{\wedge}{ }^{\wedge} 2\right)$

'Calculate cumulative oil steam ratio constant

'Cumulative oil steam ratio $=$ Fos_multiplier multiply by Ehs

Fos_multiplier $=$ Water_Density $* \mathrm{CW} / \mathrm{M} \_1 * \mathrm{hn} / \mathrm{ht} *$

(Soi - Sor $) *$ por $*(1+\mathrm{fhD})$

'Calculate heat injection rate

Qinj $=14.6 *$ Irate * $(\mathrm{Hsc}+\mathrm{fs} * \mathrm{hfg}-\mathrm{Cw} *($ Tres -32$))$

'Calculate oil originally in place

$\mathrm{N}=43560 * \mathrm{a} * \mathrm{hn} *$ por $*$ Soi / $(5.62 *$ Bo $)$

'Calculate alpha

alpha $=0.00015 *$ Irate +0.05

'Calculate betha

$\mathrm{tc}=\mathrm{tcd} * \mathrm{ht}^{\wedge} 2 * \mathrm{M} 1 \wedge 2 /(35040 * \mathrm{kh} * \mathrm{Ms})$

$\mathrm{Nc}=7758 * \mathrm{a} * \mathrm{hn} * \overline{\text { por }} *($ Soi - Sor $) /(365 *$ Irate $* \mathrm{tc})$

betha $=17.93 * \mathrm{Nc}+1.3401$

'Coefficient for AcD Stage I

Acd $1=$ alpha

$\operatorname{Acd} 2=100$

$\operatorname{Acd} 3=0.5$

Acd $4=2$

'Coefficient for AcD Stage II

Acd1p2 $=0.11$

$\operatorname{Acd} 2 \mathrm{p} 2=100$

Acd $3 \mathrm{p} 2=0.5$

$\operatorname{Acd} 4 \mathrm{p} 2=4$ 
'Coefficient for VoD

Vod1 $=$ betha

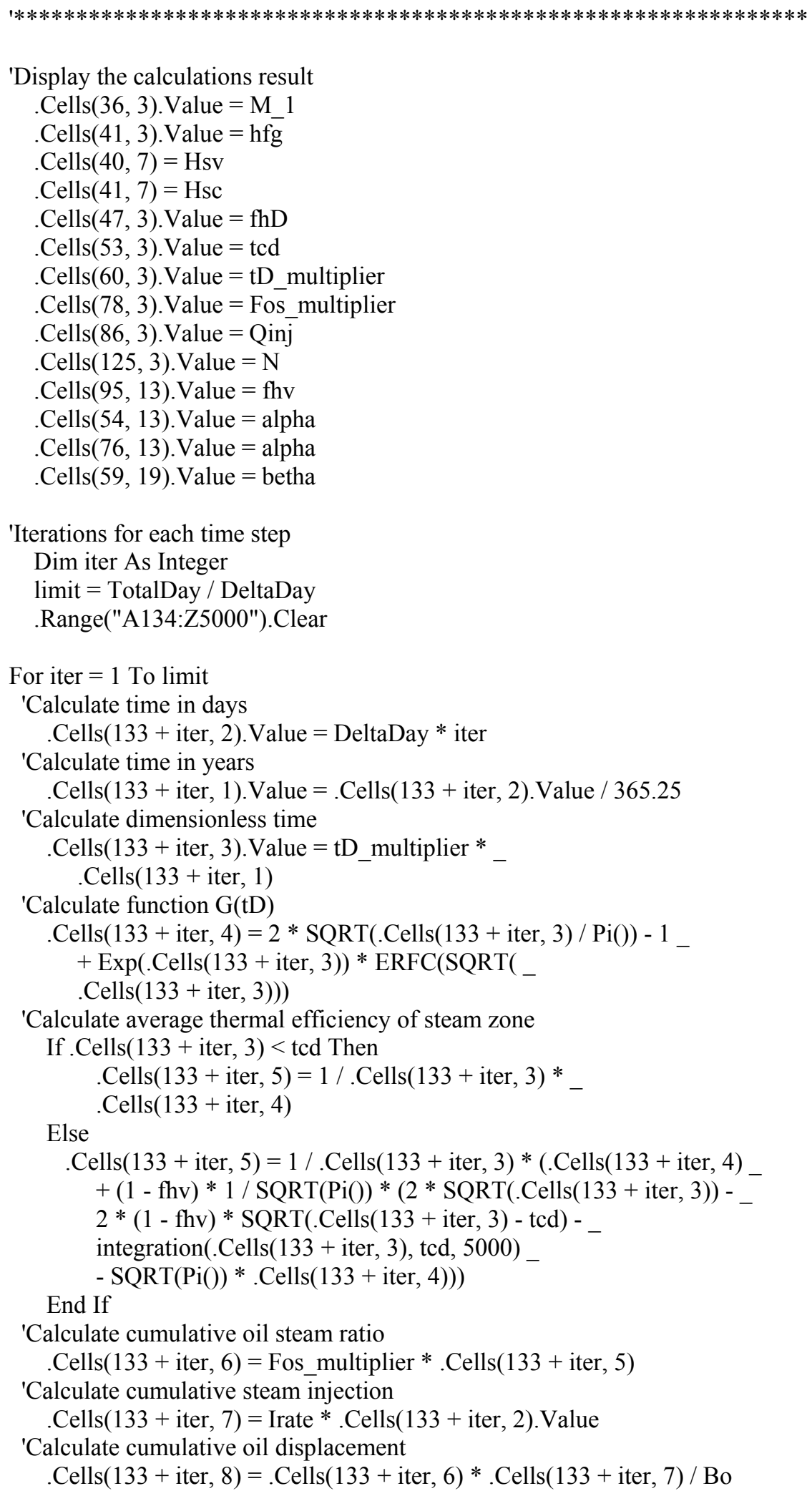

For iter $=1$ To limit

'Calculate time in days .Cells $(133+$ iter, 2$)$. Value $=$ DeltaDay $*$ iter

'Calculate time in years . Cells $(133+$ iter, 1$)$. Value $=$. Cells $(133+$ iter, 2$)$. Value $/ 365.25$

'Calculate dimensionless time

.Cells $(133+$ iter, 3$)$.Value $=$ tD_multiplier * .Cells $(133+$ iter, 1$)$

'Calculate function $\mathrm{G}(\mathrm{tD})$

'Calculate average thermal efficiency of steam zone

If .Cells $(133+$ iter, 3$)<$ tcd Then .Cells $(133+$ iter, 5$)=1 / . \operatorname{Cells}(133+$ iter, 3$) *$ .Cells $(133+$ iter, 4$)$

Else

$$
\begin{aligned}
& . \text { Cells }(133+\text { iter, } 5)=1 / . \text { Cells }(133+\text { iter, } 3) *(. \text { Cells }(133+\text { iter, } 4) \\
& +(1-\text { fhv }) * 1 / \operatorname{SQRT}(\operatorname{Pi}()) *\left(2 * \operatorname{SQRT}(. C e l l s(133+\text { iter, } 3))-{ }_{-}\right. \\
& 2 *(1-\text { fhv }) * \text { SQRT }(. C e l l s(133+\text { iter, } 3)-\text { tcd })- \\
& \text { integration }(. \text { Cells }(133+\text { iter, 3), tcd, 5000) } \\
& \text { - SQRT }(\operatorname{Pi}()) * \text {.Cells }(133+\text { iter, } 4)))
\end{aligned}
$$

'Calculate cumulative oil steam ratio .Cells $(133+$ iter, 6$)=$ Fos_multiplier * .Cells(133 + iter, 5)

'Calculate cumulative steam injection .Cells(133 + iter, 7) $=$ Irate * .Cells(133 + iter, 2).Value

'Calculate cumulative oil displacement .Cells $(133+$ iter, 8$)=$. Cells $(133+$ iter, 6$) *$.Cells $(133+$ iter, 7$) /$ Bo 


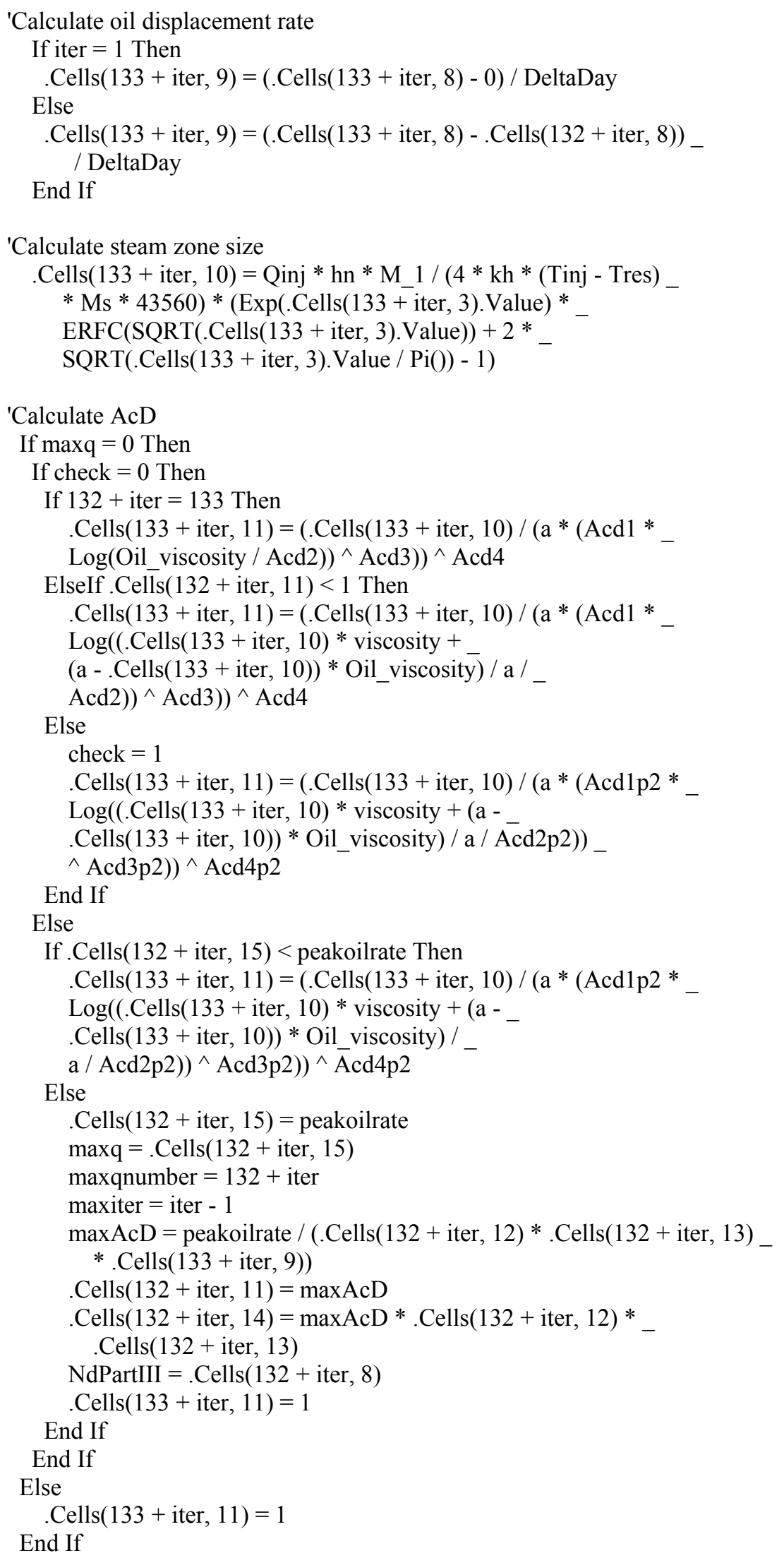




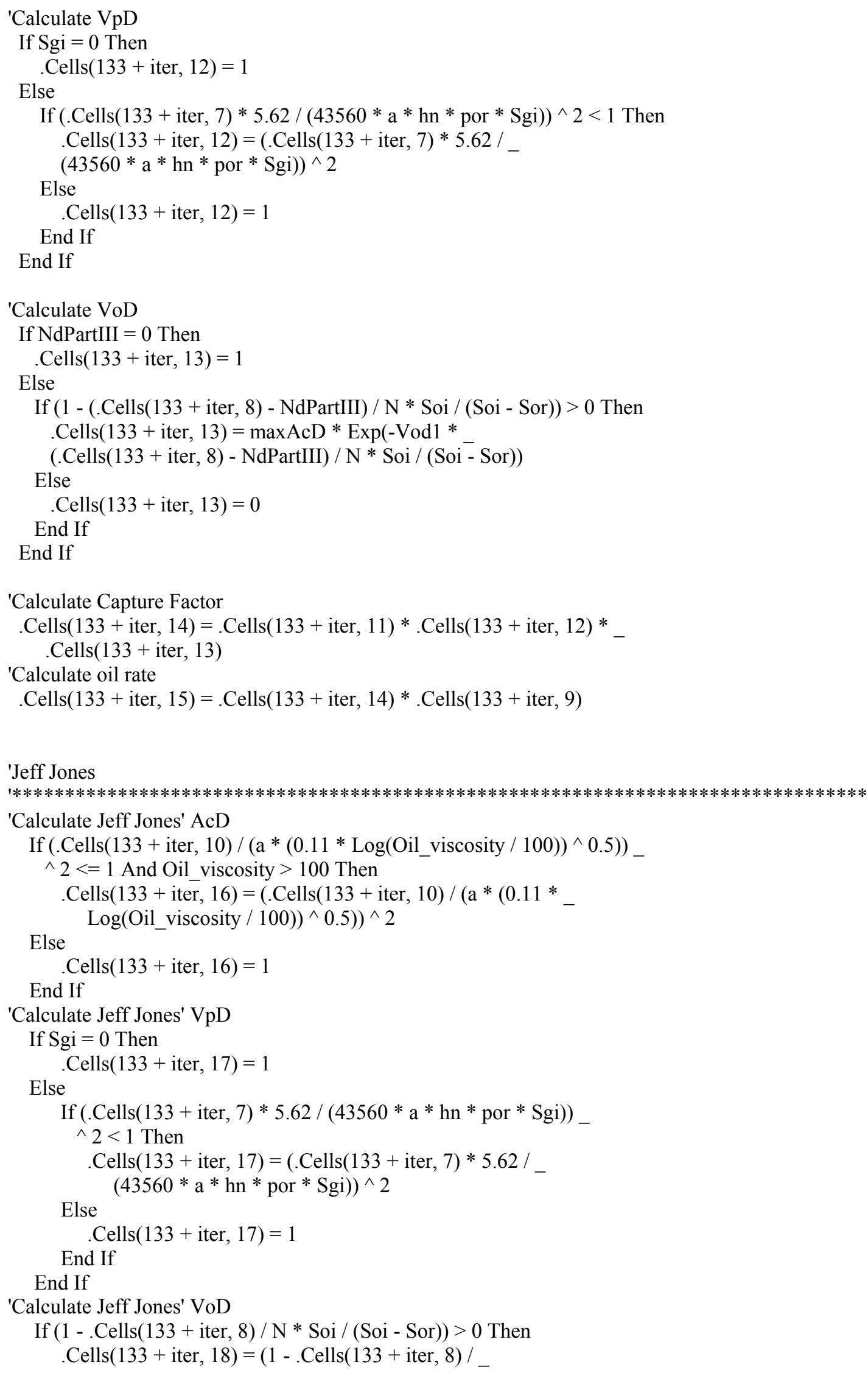




$$
\begin{aligned}
& \text { Else } \left.\left.\mathrm{N}^{*} \text { Soi / (Soi - Sor }\right)\right)^{\wedge} 0.5 \\
& . \text { Cells }(133+\text { iter, } 18)=0
\end{aligned}
$$

End If

'Calculate Jeff Jones' Capture Factor

. Cells $(133+$ iter, 19) $=$. Cells $(133+$ iter, 16) * .Cells $(133+$ iter, 17) *

.Cells(133 + iter, 18)

'Calculate Jeff Jones' oil production rate

. Cells $(133+$ iter, 20) $=$. Cells $(133+$ iter, 19) *.Cells(133 + iter, 9)

1*************************************************************************************

Next

'Cell borders

Sheets("JJ Formula").Range(Sheets("JJ Formula").Cells(134, 1),

Sheets("JJ Formula").Cells(133 + limit, 20)).Select

Selection.Borders(xlDiagonalDown).LineStyle $=x 1$ None

Selection.Borders(xlDiagonalUp).LineStyle $=$ xlNone

With Selection.Borders(xlEdgeLeft)

.LineStyle $=\mathrm{xlContinuous}$

.Weight $=\mathrm{xlThin}$

.ColorIndex $=$ xlAutomatic

End With

With Selection.Borders(xlEdgeTop)

. LineStyle $=\mathrm{xlContinuous}$

. Weight $=\mathrm{xlThin}$

. ColorIndex $=\mathrm{xlAutomatic}$

End With

With Selection.Borders(xlEdgeBottom)

. LineStyle $=\mathrm{xlContinuous}$

. Weight $=\mathrm{xlThin}$

.ColorIndex $=$ xlAutomatic

End With

With Selection.Borders(xlEdgeRight)

.LineStyle $=\mathrm{xlContinuous}$

. Weight $=\mathrm{xlThin}$

.ColorIndex $=\mathrm{xlAutomatic}$

End With

With Selection.Borders(xlInsideVertical)

. LineStyle $=\mathrm{xlContinuous}$

.Weight $=\mathrm{xlThin}$

.ColorIndex $=$ xlAutomatic

End With

With Selection.Borders(xlInsideHorizontal)

. LineStyle $=\mathrm{xlContinuous}$

. Weight $=$ xlThin

. ColorIndex $=\mathrm{xlAutomatic}$

End With

Sheets("JJ Formula").Cells(20, 11).Select

End With

End Sub 


\section{VITA}

Name:

Permanent Address:

Email:

Education:
Suandy Chandra

Jln. Samudera No. 6

Medan - 20214

Sumatera Utara, Indonesia

suandych@yahoo.com

M.S., Petroleum Engineering

Texas A\&M University

College Station, TX 77843-3116, U.S.A.

August 2005

B.S., Petroleum Engineering,

Institut Teknologi Bandung

Bandung, Indonesia

March 2003 